\title{
The Electrical Conductivity of Sodium Polysulfide Melts
}

\author{
Mei-Hui Wang \\ (M.S. Thesis) \\ Deparment of Chemical Engineering \\ University of California \\ and \\ Materials Sciences Division \\ Lawrence Berkeley Laboratory \\ University of California \\ Berkeley, CA 94720
}

June 1992

This work was supported by the Assistant Secretary for Conserwation and Renewable Energy', Office of Transportation Technologies, Electric and Hybrid Propulsion Division of the U.S. Department of Energy under Contract No. DE-AC03-76SF00098. 


\title{
The Electrical Conductivity of Sodium Polysulfide Meits
}

\author{
Mei-Hui Wang
}

\begin{abstract}
Austract
The sodium polysulfide mell has been described by a macroscopic motel. This model considers the melt to be composed of sodium cations, monosulfide anions, and neutral sulfur solvent. The transport equations of concentrated solution theory are used to derived the goveming equations for this binaryelectrolyte melt model. These equations relate measurable transport properties to fundamental transport parameters. The focus of this research is to measure the electrical conductivity of sodium polysulfide melts and calculate one of fundamental transport paraneters from the experimental data.

The conductance cells used in the conductivity measurements are axisymmetric cylindrical cells with a microelectrode. The electrode effects, including double-layer capacity, charge uransfer resistance, and concentration overpotential, were minimized by the use of the alternating current at an adequately high frequency. The high cell constants of the conductance cells not only enhanced the experimental accuracy but also made the electrode effects negligible.

The electrical conductivities of sodium polysulfide $\mathrm{Na}_{2} \mathrm{~S}_{4}$ and $\mathrm{Na}_{2} \mathrm{~S}_{5}$ were measured as a function of temperature (range: 300 to $360^{\circ} \mathrm{C}$ ). Variations between experiments were only up $102 \%$. The values of the Arthenius activation energy derived from the experimental data are about $33 \mathrm{~kJ} / \mathrm{mol}$.

The fundamental transport parameter which quantifies the interaction within sodium cations and monosulfide anions are of interest and expected to be positive. Values of it were calculated from the experimental conductivity data and most of them are positive. Some negative values were obtained probably due to the experimental errors of transference number, diffusion coefficient, density or conductivity data.
\end{abstract}


To My Parents 
Table of Contents

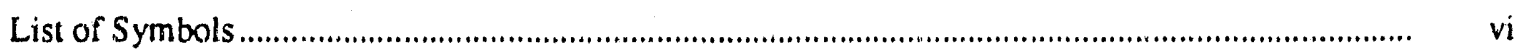

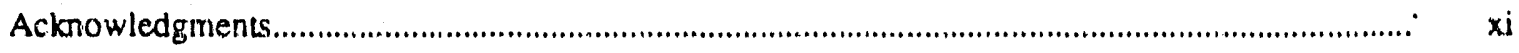

Chapter 1. The Sodium/Sulfur System .........................................................................

1.1 Introduction ..........................................................................................

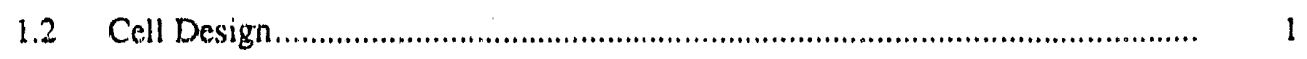

1.3 Operation of the Sodium/Sulfur Cell _.............................................................. 2

1.4 Open-Circuit Cell Potential ........................................................................... 3

Chapter 2. Transport P'henomena of Sodium Polysulfide Meits................................................ 6

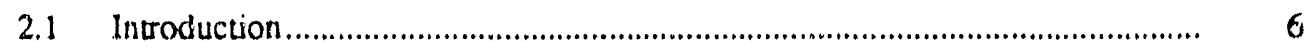

2.2 The Macroscopic Model of Sodium Polysulfide Melts ................................... 6

2.3 Experimentally Determined Transport Properties and Activation Energy ......... 9

2.4 Transpon Parameters ............................................................................ 23

Chapter 3. The Measurement of Electrolytic Conductivity .................................................. 30

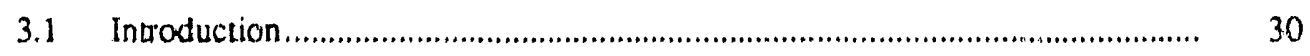

$3.2 \quad$ Electrode Effects............................................................................... 31

3.3 Electrochemical Impedance ................................................................... 37

3.4 The Primary Resistance of Axisymmetric Cylindrical Cells with Disk

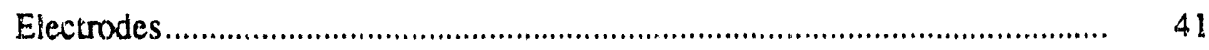

chapter 4. Experimental Determination of Electrical Conductivity .......................................... 49

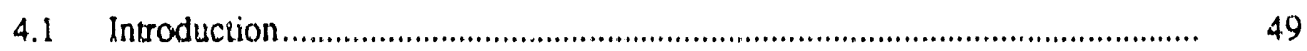

4.2. Experimental Equipment ..................................................................... 50

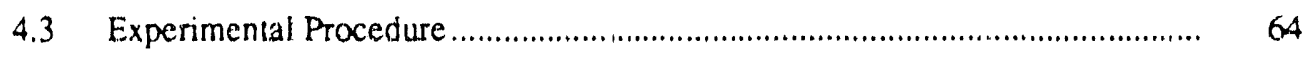

chapter 5. Experimental Results and Discussion ........................................................ 70

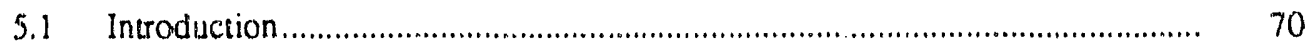


5.2 The Experimental Results of Disk Cells ............................................................ 70

5.3 Determination of the Altermating Current's Amplitude and Frequency ............. 70

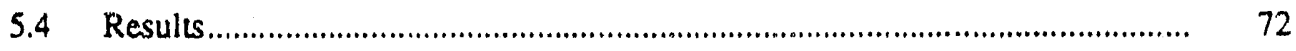

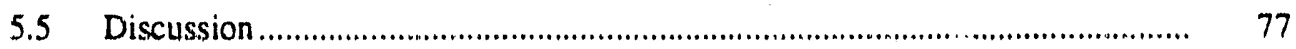

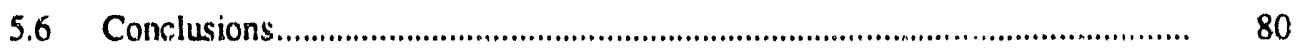

References 


\section{List of symbols}

\section{Roman Characters:}

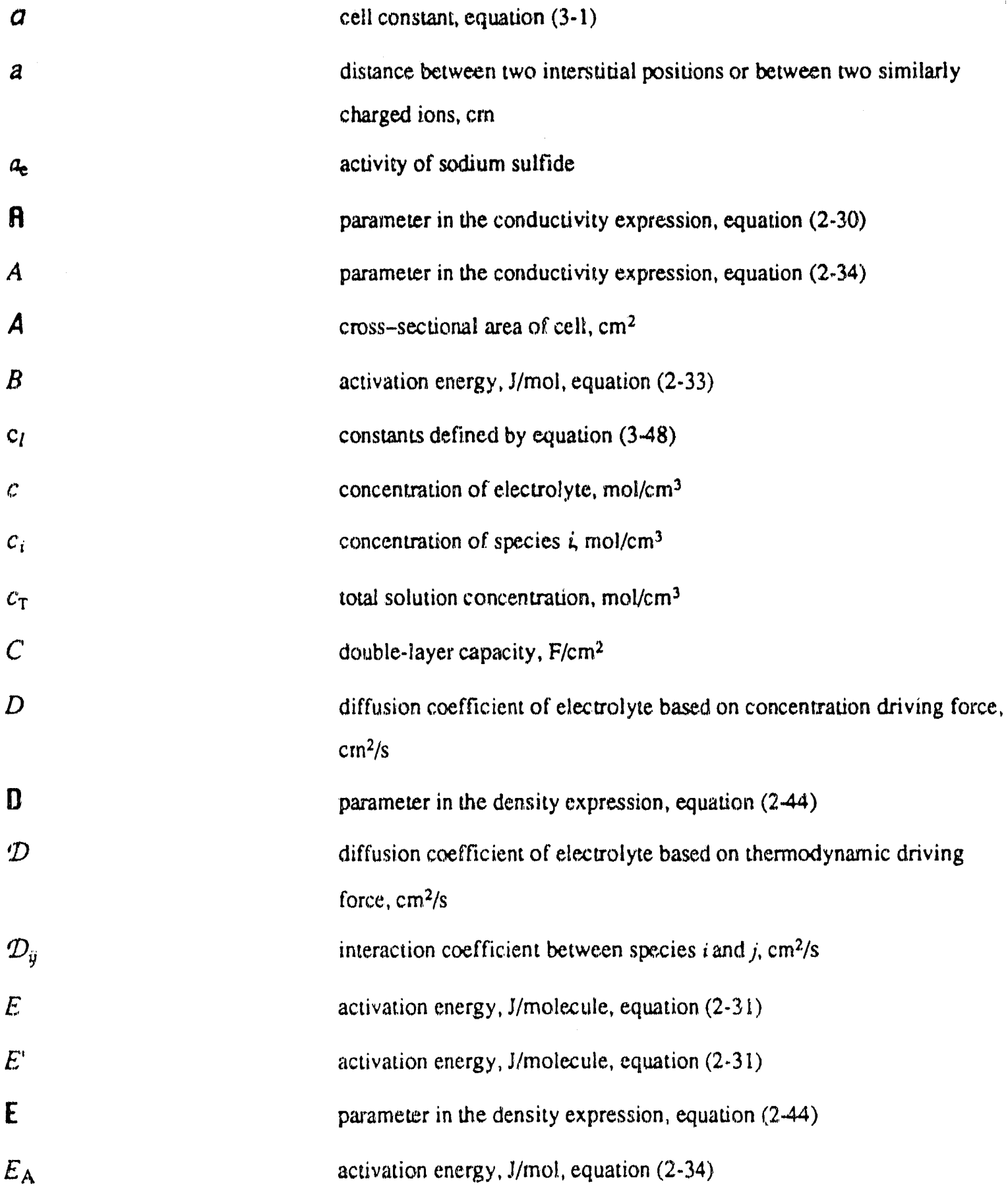




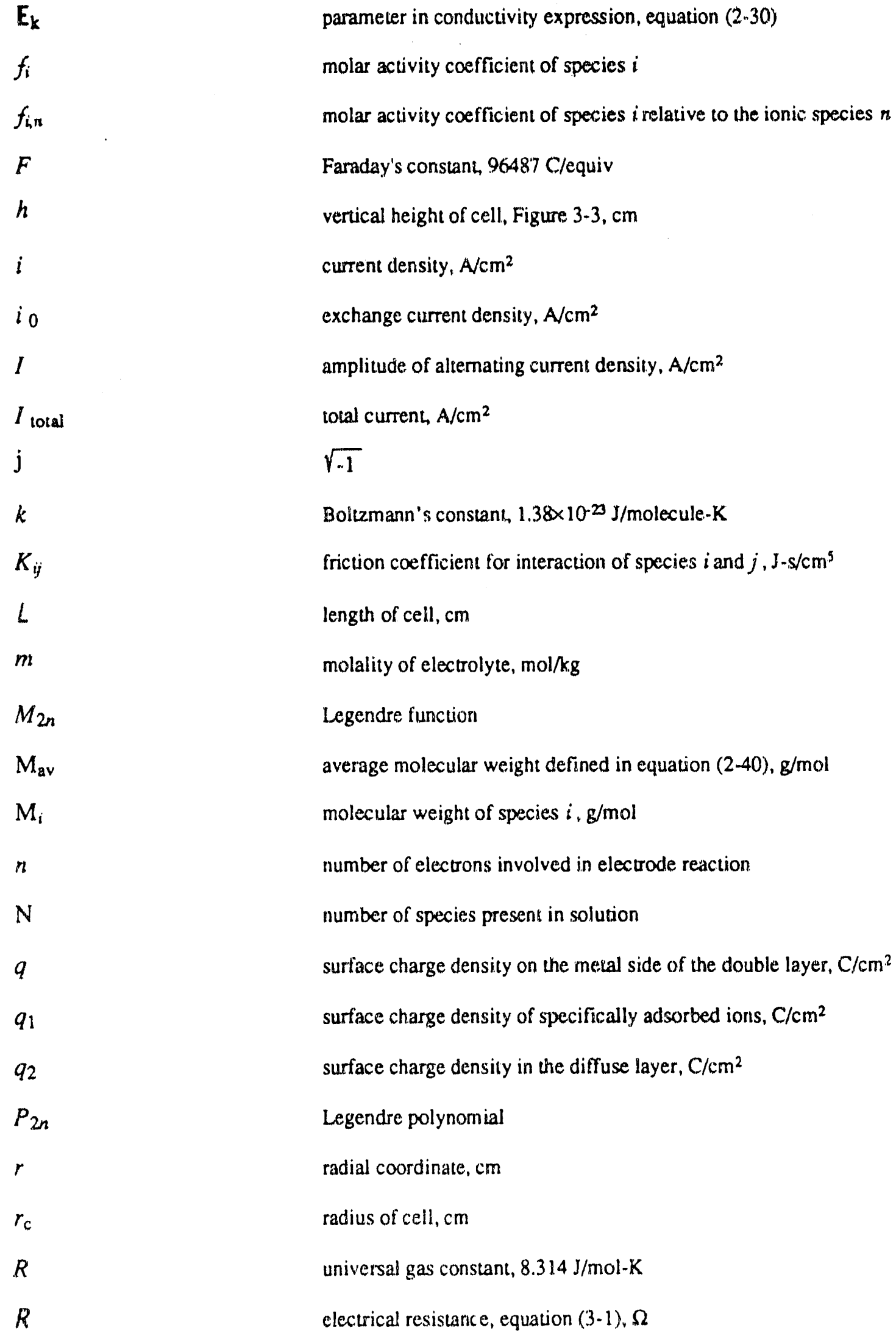




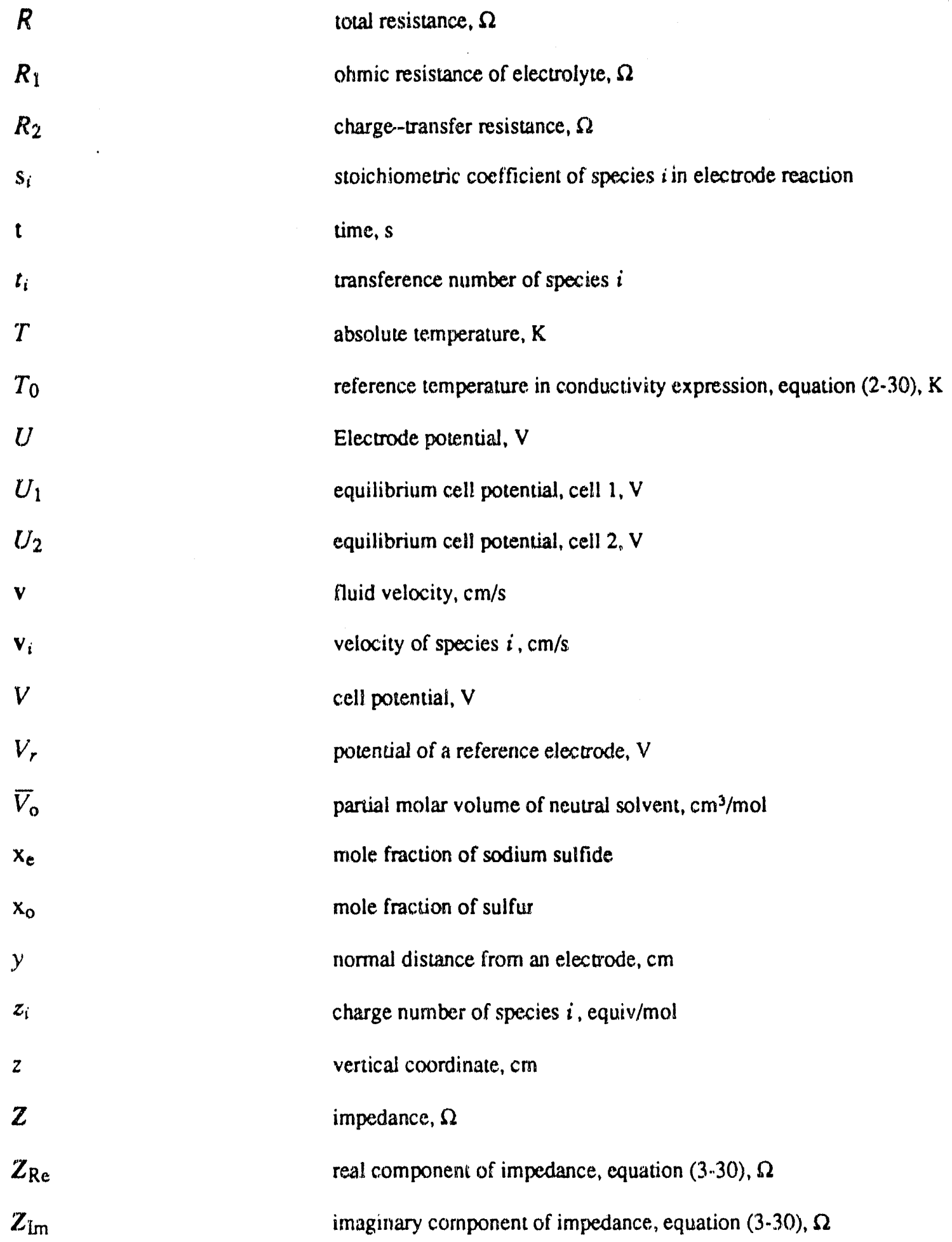


Greek symbols:

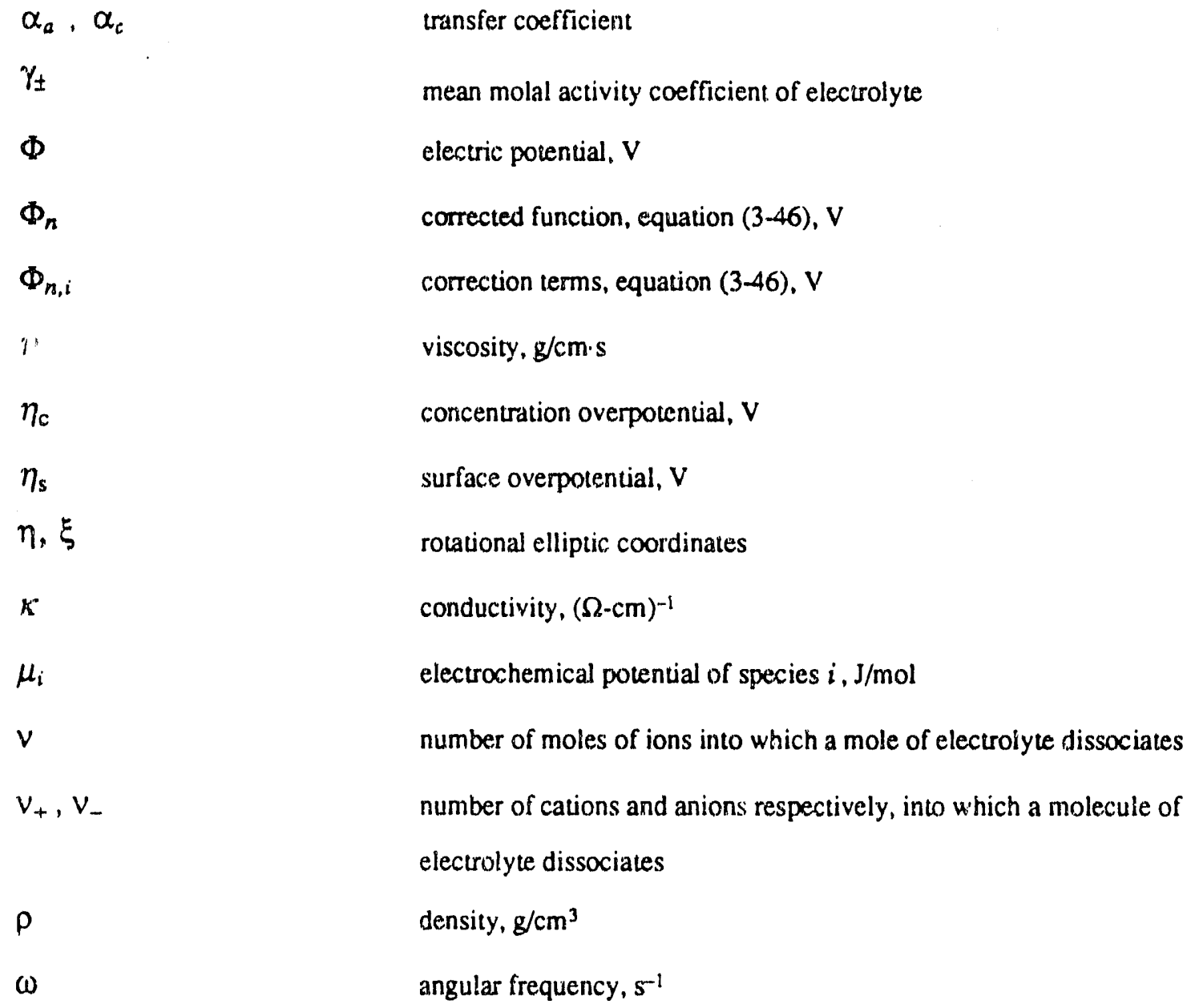

transfer coefficient

mean molal activity coefficient of electrolyte

electric potential, $\mathrm{V}$

corrected function, equation (3-46), V

correction terms, equation (3-46), V

viscosity, $\mathrm{g} / \mathrm{cm} \cdot \mathrm{s}$

concentration overpotencial, $\mathrm{V}$

surface overpotential, $\mathrm{V}$

rotational elliptic coordinates

conductivity, $(\Omega-\mathrm{cm})^{-1}$

electrochemical potential of species $i, \mathrm{~J} / \mathrm{mol}$

number of moles of ions into which a mole of electrolyte dissociates number of cations and anions respectively, into which a molecule of electrolyte dissociates

density, $\mathrm{g} / \mathrm{cm}^{3}$

angular frequency, $\mathrm{s}^{-1}$

neutral sulfur soivent

electrolyte

species number $i$

species number $j$

cation

anion

in the bulk solution 
Superscripts:

0

0

$n$ with respect to solvent velocity

at the electrode surface

initial value

selected ionic species 
Acknowledgments

I would like to thank Professor Jokn Newman for giving me the opportunity to do this work. His patience and guidance have guided me through this work.

Many thanks are due to Paul Ridgway who assisted with the experiment in this thesis. I am also very grateful to Professor Caims for the use of his laboratory space and equipment.

I would like to thank my committee members, Professor Scott Lynn and Professor Lutgard De Jonghe for the time they spent reviewing this manuscript and for their suggestions.

The assistance of my research colleagues, Vincent Battaglia, Marc Doyle, Doug Eames, Tom Fuller, Anthony Grabowski, Bava Pillay, Ben Rush, Paul Shain, and Shigeru Umino and the friendships will always be remembered.

I would like to thank my parents, my two brothers, and my fiancé, Tsuan-Chung Chang, for their encouragement and support.

Finally, I thank the machine shop personnel for fabricating the experimental apparatus.

This work was supported by the Assistant Secretary for Conservation and Renewable Energy, Office of Transportation Technologies, Electric and Hybrid Propulsion Division of the U. S. Department of Energy under Contract DE-AC03-76SF00098. 


\section{Chapter 1. The Sodium/Sulfur System}

\subsection{Introduction}

The sodium/sulfur cell at an operating temperature of $300^{\circ} \mathrm{C}$ is composed of two liquid electrodes: sodium and sulfur; and a solid electrolyte, $\beta$ "-alumina or glass. The characteristics of very high current densities achieved on both charge and discharge, the high charge acceptance, and the low cell resistance, combined with the abundant availability and the low price of sulfur, make the sodium/sulfur cell attractive for both electric-vehicle and load-leveling applications.

Corrosion of the container materials, electrolyte fracture, and leaking seals are some of the major technical problems in the sodium/sulfur battery. ${ }^{2}$ Many corporations have made efforts on these problems in order to commercialize the sodium/sulfur cull. On the other hand, in order to predict the behavior of this system and minimize cosly and time, consuming experiments, mathernatical modeling of the sodium/sulfur system and knowledge of the transport paramerers of sodium polysulfides are necessary.

The sodium/sulfur battery is perhaps the closest to commercial viability of all the molten-sait, high-temperature batteries. The design of the sodium/sulfur cell and the operation of the sulfur electrode presented in this chapter will offer background information on the transport process in the sodium/sulfur system.

\subsection{Cell Design}

Two designs of the sodium sulfur battery are being developed. One uses $\beta$ "-alumina disks or tubes as electrolyte ${ }^{2}$ and the other uses glass fibers as electrolytes. ${ }^{3}$

$\beta^{\prime \prime}$-alumina, the electrolyte of ceramic cells, is a good sodium conductor at $300{ }^{\circ} \mathrm{C}$. Flat-plate cells, central-sodium-tube cells, central-sulfur-tube cells, and multitubular cells (central sodium and central suifur) are ceramic cells of different types. Among them, central-sodium-tube ceramic cells are the most well developed because of having been constructed and tested by several companies, such as Yuasa Battery Co., General Electric Company USA, British Rai!, etc. The ceramic electrolyte of the central-sodium-tube cell is in the form of a thin-walled tube, sealed at one end, with a diameter of 1 to $5 \mathrm{~cm}$. Sodium fills the 
tube and a reservair above the tube. This tube is immersed into a sulfur- filled tube in which porous graphite is in contact with the ceramic electrolyte and a backing electrode and acts as a current collector.

The Dow chemical company used borate glasses as the electrolyte to develop glass-fiber cells. Due to the high resistivity of glass, very thin walled and high-surface-area hollow glass fibers are required. The fibers, typically $70 \mu \mathrm{m}$ id by $90 \mu \mathrm{m}$ od, $10 \mathrm{~cm}$ long, are sealed at one end and open at the other end. The open ends communicate through a "tubesheet" into a common mclten sodium reservoir. These sodium. filled fibers are immersed into the sulfur reservoir. Layers of aluminum foil, placed between fibers and attached al the bottom to the sulfur reservoir, act as the current collector of the sulfur electrode.

The following discussion will be mainly based on the central-sodium-tube cells since they are the most common sodium/sulfur cells.

\subsection{Operation of the Sodium/? ulfur Cell}

During discharge of the sodium/sulfur cell, the oxidation of sodiurn occurs in the sodium electrode on the surface of the solid electrolyte,

$$
\mathrm{Na} \rightarrow \mathrm{Na}^{+}+\mathrm{C}^{-}
$$

Sodium ions pass through the solid electrolyte and arrive at the carbonmelectrolyte-sulfur boundary in the sulfur electrode where the reduction of sulfur nccurs. Because the resistence of pure sulfur is as high as $10^{8}$ $\Omega-\mathrm{cm}$ at $350^{\circ} \mathrm{C}$, the initial reduction of sulfur can occur only where the carbon natrix is in contacl with the solid electrolyte. The phase diagram for sodium and sulfur is shown in Figure 1-1. The discharge of the sulfur electrodte proceents from $100 \%$ of sulfur to $60 \%$ of sulfur in the Figure. At the very beginning of the discharge, sodium and sulfur combine to form a single phase, which contains over $99 \%$ sulfur. Since the range of this single phase is so small, a second phase, $\mathrm{Na}_{2} \mathrm{~S}_{5,2}$, appears very soon. Consequently, the initial reduction of sulfur is

$$
5 S+2 e^{-} \rightarrow S s^{2-}
$$




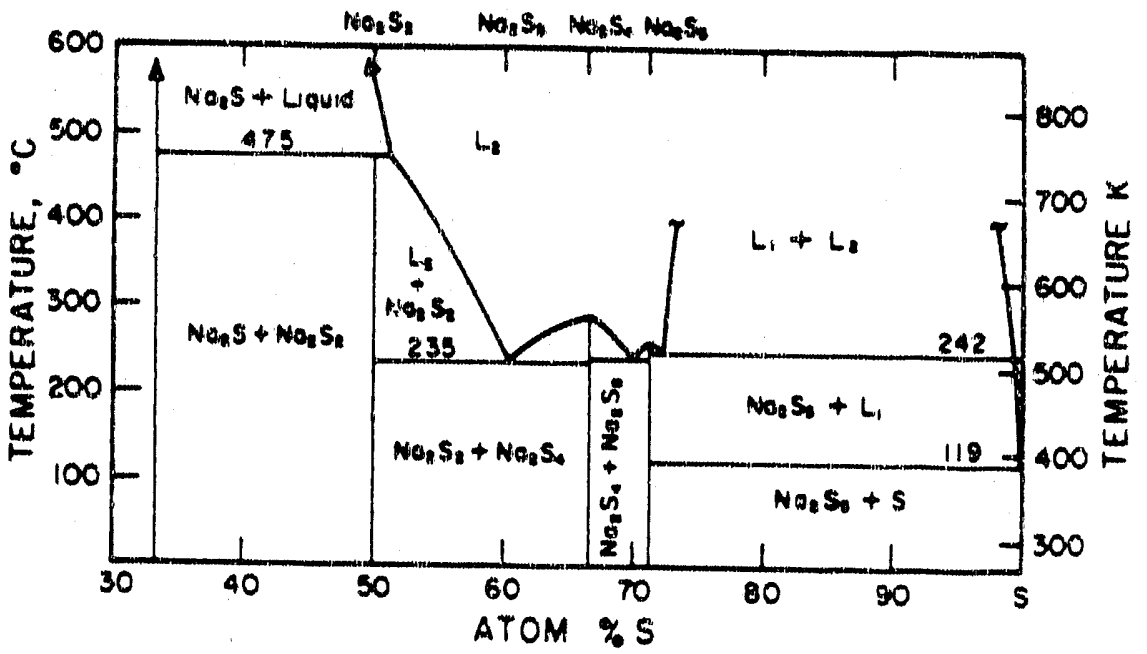

INW Wi.sW

Figure 1-1. Sodium-sulfur phase diagram according to Gupta and Tischer. ${ }^{4}$ 
Sodium pentasulfide is a molten electrolyte; hence its formation shifts reaction (1-2) from the carbon-solid electrolyte-sulfur boundary to the carbon- $\mathrm{Na}_{2} \mathrm{~S}_{5.2}$ melt-sulfur boundary. The diffusion rate of sodium ions through $\mathrm{Na}_{2} \mathrm{~S}_{5.2}$ melt limits the reaction rate. As the reaction front moves away from the solid electrolyte, the resistance of the melt to the diffusion of sodium ions becomes important, and the following reaction becomes possible.

$$
x S_{5}^{2-}+(10-2 x) e^{--} \rightarrow 5 S_{2}^{2-}
$$

$x$ is smaller than 5 and greater than 3, which corresponds to the single-phase region located between $60 \%$ of sulfur to $70 \%$ of sulfur above $300^{\circ} \mathrm{C}$ on the phase diagram. As the discharge proceeds, reaction (1-3) accounts for an increasing fraction of the current.

\section{1 ; Open-Circuil Cell Potential}

The open-circuit potential of the sodium/sulfur cell is plotled versus the polysulfide composition in the sulfur electrode at $360^{\circ} \mathrm{C}$ in Figure 1-2.5 The melt composition, $x_{e}$, is the mole fraction of sodium sulfide in the sulfur electrode when the sodium polysulfides in the electrode are considered to be composed only of sodium sulfide and sulfur. In Figure 1-2, the potential versus composition shows four distinct regions. These four potential regions in Figure 1.2 from the left margin to the right correspond to the four phase regions at $360^{\circ} \mathrm{C}$ in Figure $1-1$ from the right margin 20 the left respectively. At the beginning of the discharge, the potential drops rapidly, where the composition is in the single-phase region of nearly pure sulfur. As the discharge proceeds further, the second phase, $\mathrm{Na}_{2} \mathrm{~S}_{5.2}$. starts to form. In this two-phase region, the potential is independent of the discharge state of the cell and varies only slightly with temperature. When the overall melt composition reaches approximately $\mathrm{Na}_{2} \mathrm{~S}_{5.2}$, the melt becomes a single phase again, and the potential decreases nearly linearly with the mole fraction of sodium sulfide. If the discharge is continued far enough, another phase. $\mathrm{Na}_{2} \mathrm{~S}_{2}$, begirs to form, and again the potential should be constant in the lwo-phase region. However sodium sulfur cells are not designed to be discharged into this phase region. 


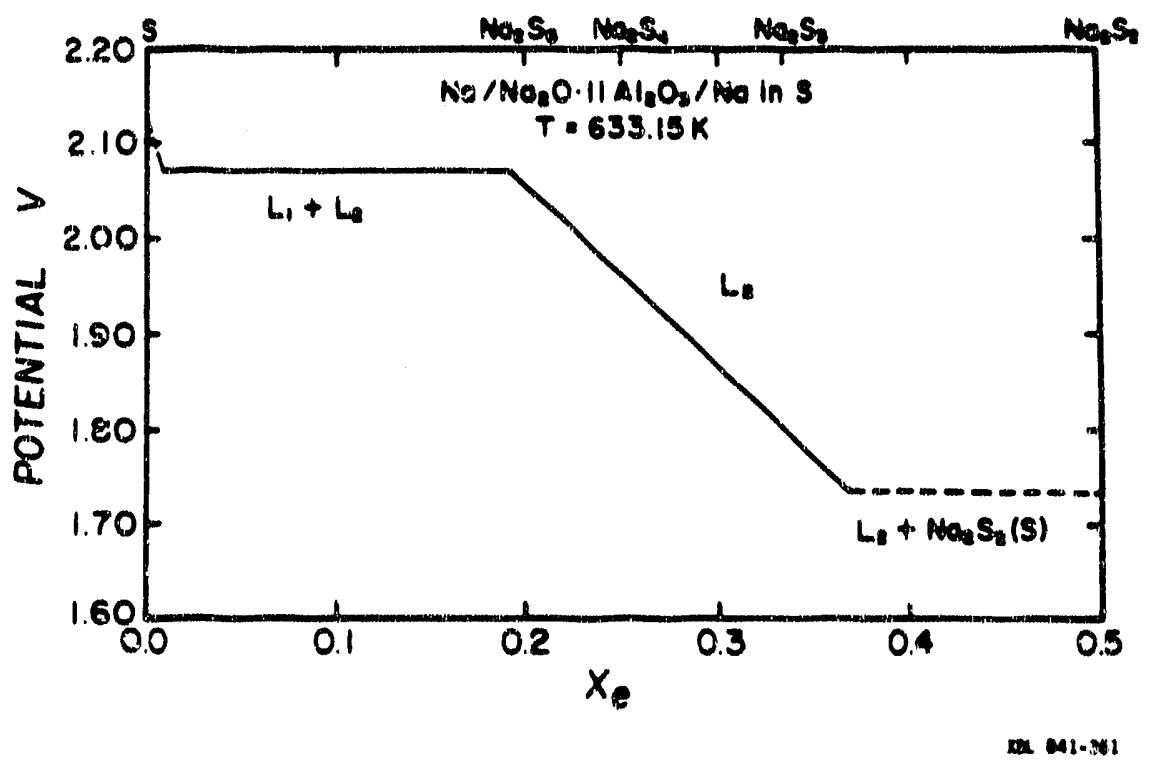

Figure 1-2. Cell potential versus sulfur electrode melt composition for an equilibrium cell discharge. Melt composition is defined by the mole fraction of sodium sulfide, $x_{e}{ }^{5}$ 


\section{Chapter 2. Transport Phenomens of Sodium Polysulfide Melts}

\subsection{Introduction}

The transport process of sodium polysulfide melts on the basis of the macroscopic model will be described and formulated in this chapter. The macroscopic model considers sodium polysulfide melts as sodium cations and monosulfide anions, in neutral sulfur solvent.

From a microscopic view, the actual composition of these melts involves various polysulfide anions and sodium cations. The determination of the actual species present in polysulfide melts has been attempted in several past works. However, none of these works determined the microscopic melt cornposition directly and conciusively. Tegman's model ${ }^{6}$ is perhaps the most comprehensive. In addition to using Tegman's model, Risch' related the transport parameters $\mathcal{D}_{i j}$ in the transport equations to the inverse of the iunic radii to a given power to predict the transport properties of sodium polysulfide melts, which were compared to recent transport-property data. More details are given in reference seven. In this chapter, we will not consider the microscopic model.

The experimental methods to determine the transport properties will be reviewed, and the activation energy of various transport-property data will be presented in section 2.3. Besides, we will present the procedure to calculate elementary transport parameters $\mathcal{D}_{i j}$ from transport-property data. The results of $\mathcal{D}_{i j}$ and activation energy were basically calculated by Thompson. ${ }^{8}$ Some negative values of the transport parameter $\mathcal{D}_{+}$shown in the results are not physically reasonable. Additionally, the activationenergy values of conductivity data from Cleaver and Davies ${ }^{9}$ are different from those of other transportproperty data. These confusing results are the motivations to re-measure the electrical conductivity of sodium polysulfide melts.

\subsection{The Macroscopic Model of Sodium Polysulfide Melts}

The model presented here is based on concentrated-solution theory developed by Newman, Bennion, and Tobias. ${ }^{10}$ Some additional information bas been discussed by Newman. 11 


\section{Concentrated-Solution Theory}

The multicomponent diffusion equation,

$$
c_{i} \nabla \mu_{i}=\sum_{j} K_{i j}\left(\mathbf{v}_{j}-\mathbf{v}_{i}\right)=R T \sum_{j} \frac{c_{i} c_{j}}{c_{\mathrm{T}} \mathcal{D}_{i j}}\left(\mathbf{v}_{j}-\mathbf{v}_{i}\right),
$$

is the macroscopic description of multicomponent diffusion in either dilute or concentrated solutions. $\mu_{i}$ is the electrochemical potential of species $i$, and $\mathbf{v}_{i}$ is the velocity of species $i$. The total concentration is

$$
c_{\mathrm{T}}=\sum_{i} c_{i}
$$

$K_{i j}$ 's are friction coefficients or interaction coefficients, which can be simply related to diffusion coefficients, $\mathcal{D}_{i j}$ s, by

$$
K_{i j}=R T \frac{c_{i} c_{j}}{c_{T} \mathcal{D}_{i j}}
$$

The term - $c_{i} \nabla \mu_{i}$ in equation (2-1) can be regarded as a driving force per unit volume acting on species $i$ and $\sum_{j} K_{i j}\left(v_{-}-v_{i}\right)$ is the drag force as a result of the relative motion of the species. Newton's third's law requires that

$$
K_{i j}=K_{j i} \text { or } \mathcal{D}_{i j}=\mathcal{D}_{j i}
$$

$\mathcal{D}_{i i}$ is not defined. Therefore, the number of transport parameters $\mathcal{D}_{i i}$ 's , defined by equation $(2-1)$, is $N(N-$ 1) 2 , where $N$ is the number of species.

Summation of equation (2-1) over $i$ yields

$$
\sum_{i} c_{i} \nabla \mu_{i}=\sum_{i} \sum_{j} K_{i j}\left(\mathbf{v}_{j}-\mathbf{v}_{i}\right)
$$

The lefrt side is zero by the Gibbs-Duhem relation, and the right side is zero since $K_{i j}=K_{j i}$. Consequently, the number of independent equations (2-1) is one less than the number of species. 


\section{Flux Equations for a Binary Electrolyte:}

\section{The Macroscopic Model of Sodium Polysulfide Melts}

Sodium polysulfide melts in the macroscopic model are binary electrolytes. For a binary electrolyte, there are two independent diffusion equations,

$$
c_{+} \nabla \mu_{+}=K_{0+}\left(\mathbf{v}_{0}-\mathbf{v}_{+}\right)+K_{+}\left(\mathbf{v}_{-}-\mathbf{v}_{+}\right)
$$

and

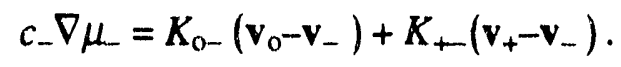

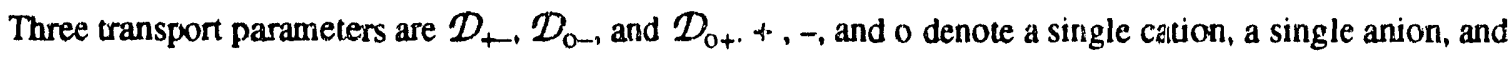
a neutral solvent. However, equations (2-6) and (2-7) are not direct expressions for the fluxes. The expressions of the species velocities in terms of the driving forces are preferred. By using the definition of the current density,

$$
i=F \sum_{i} c_{i} z_{i} \mathbf{v}_{i}
$$

we rewrite equations $(2-6)$ and $(2-7)$ as

$$
\begin{aligned}
\mathbf{N}_{+} & =c_{+} \mathbf{v}_{+}=-\frac{v_{+} \mathcal{D}}{V R T} \frac{c_{T}}{c_{0}} c \nabla \mu_{\mathrm{e}}+\frac{i t_{+}^{0}}{z_{+} F}+c_{+} \mathbf{v}_{0}, \\
\text { and } & \mathbf{N}_{+}=c_{-} \mathbf{v}_{-}=-\frac{v_{-} \mathcal{D}}{V R T} \frac{c_{T}}{c_{0}} c \nabla \mu_{\mathrm{e}}+\frac{i t_{-}^{\mathrm{o}}}{z F}+c_{+} \mathbf{v}_{0} .
\end{aligned}
$$

$V_{+}$and $V_{-}$are the numbers of cations and anions produced by the dissociation of one molecule of electrolyte.

$$
\begin{gathered}
v=v_{+}+v_{-} \\
\mu_{\mathrm{e}}=v_{+} \mu_{+}+v_{-} \mu .
\end{gathered}
$$

The parameter $\mathcal{D}$ is the diffusion coefficient of the electrolyte based on a thermodynamic driving force and is related to elementary parameters $\mathcal{D}_{i j}$ 's by 


$$
\mathcal{D}=\frac{\mathcal{D}_{0+} \mathcal{D}_{0-}\left(z_{+}-z_{-}\right)}{z_{+} \mathcal{D}_{0++}-z_{-} \mathcal{D}_{0-}}
$$

The transference numbers with respect to the solvent veiocity are

$$
t_{+}^{0}=1-t_{-}^{0}=\frac{z_{+} \mathcal{D}_{0+}}{z_{+} \mathcal{D}_{0+}-2 \mathcal{D}_{0-}}
$$

In a solution of uniform composition,

$$
\nabla \mu_{i}=z_{i} F \nabla \Phi
$$

On the other hand, the electrical conductivity is defined by $\mathrm{Ohm}$ 's law as

$$
i=-\times \nabla \Phi,
$$

where $\nabla \Phi$ is the gradient of the electric potential and $K$ is the electrical conductivity. To relate $K$ to transport parameters, the definition of the current density in equation (2-8) is rewritten as

$$
i=F \sum_{i} c_{i} z_{i} \mathbf{v}_{i}=F \sum_{i} c_{i} z_{i}\left(\mathbf{v}_{i}-\mathbf{v}_{0}\right)
$$

By using equations (2-15), (2-6), and (2-7), one can transform equation (2-17) into equation (2-16) when

$$
\frac{1}{\kappa}=-\frac{R T}{c_{\mathrm{T}} z_{+} z_{-} F^{2}}\left[\frac{1}{\mathcal{D}_{+-}}+\frac{c_{0} t_{-}^{\mathrm{o}}}{c_{+} \mathcal{D}_{0_{-}}}\right]
$$

As a result, when the values of $\kappa, \mathcal{D}$, and $t_{+}^{\circ}$ are available, equations (2-13), (2-14), and (2-18) are three independent equations for the calculation of three transport parameters, $\mathcal{D}_{+}, \mathcal{D}_{0-}$, and $\mathcal{D}_{0+}$

\subsection{Experimentally Determined Transport Properties and Activation Energy}

Although many techniques have been well developed for measuring the transport properties of binary aqueous electrolytes, most of them become unusable when one has to deal with electrolyte melts at high temperatures, such as corrosive sodium polysulfide melts at $300{ }^{\circ} \mathrm{C}$. The difficulties of using these techniques for measuring diffusion coefficients and transference numbers of polysulfide melts have been 
discussed by Risch ${ }^{12}$ and Thompson. ${ }^{1 /}$ Therefore, the experimental transport property data of melts are often not as precise as those of aqueous electrolytes.

The electrical conductivity can be measured by experiment. However, thermodynamic diffusion coefficients, $\mathcal{D}$, and transference numbers, $t_{+}^{\circ}$, can not be measured experimentally directly. In this section, we will $\mathrm{b}$ iefly present the procedure to determine values of $\mathcal{D}$ and $t_{+}^{\circ}$ from thr experimental data of open. circuit cell potential and diffusion-coefficient data and review previous transport-property data. Furthernore, the activation-energy values of different transport-property data will be discussed on the basis of the significance of activation energy in transport processes.

\section{Transference Number}

Risch and Newman ${ }^{14}$ have calculated transference numbers from open-circuit potential data presented by Cleaver and Davies. ${ }^{15}$ In this section, we will only explain how the transferenrs number can be determined from the potential data very briefly. The complete discussion is given in the original work.

The open-circuit-potential measurements have been performed on the following cell, Cell 2.

\section{Cell 2}

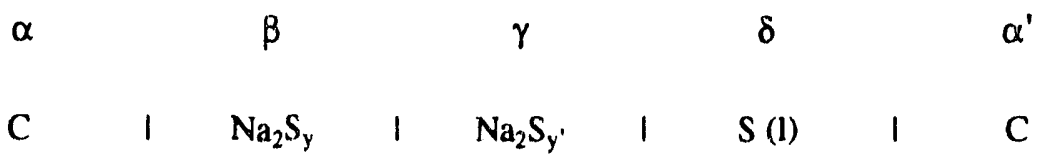

The differential of the potential, $U_{2}$, is given by

$$
d U_{2}=-\frac{R T}{2 F}\left[t_{+}^{\mathrm{o}} \frac{1-\mathrm{x}_{\mathrm{e}}}{\mathrm{X}_{\mathrm{e}}}+1\right] d \ln a_{\mathrm{b}} .
$$

$a_{0}$ denotes the activity of sulfur in the melth and $x_{e}$ denotes the mole fraction of sodium sulfide in phase $\beta$. The differential of the activity of sulfur can be determined from the potential of cell 1 :

\section{Cell 1}

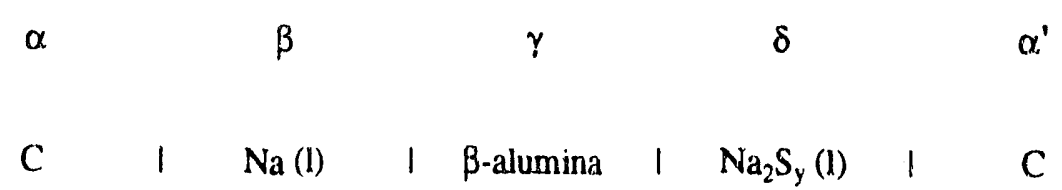




$$
d \ln a_{0}=\frac{2 F}{R T} \mathrm{x}_{\mathrm{e}} d U_{1}
$$

By substituting equation (2-20) into equation (2-19) and rearranging equation (2-19), one can get the expression of the transference number in terms of the cell potentials of two cells and composition as

$$
t_{+}^{\mathrm{o}}=\frac{-\frac{d U_{2}}{d \mathrm{x}_{\mathrm{e}}} \frac{d \mathrm{x}_{\mathrm{e}}}{d U_{1}}-\mathrm{x}_{\mathrm{e}}}{1-\mathrm{x}_{\mathrm{e}}}
$$

Cleaver and Davies ${ }^{15}$ present cell potentials, $U_{1}$ and $U_{2}$, versus melt composition, $\mathrm{x}_{\mathrm{e}}$, for two temperatures, 300 and $360^{\circ} \mathrm{C}$. The transference number bas been calculated based on their potential data. Figure 2-1 plots the transference number for sulfide ion as a function of composition for the two temperatures. The transference number is nearly constant over the range of compositions encountered.

\section{Thermodynamic Diffusion Coefficient}

Normally, diffusion-coefficient data determined experimentally are based on the concentration driving force. For a binary electrolyte, these data are related to thermodynamic diffusion coefficients through ${ }^{10}$

$$
D=\mathcal{D} \frac{c_{T}}{c_{0}}\left[1+\frac{d \ln \gamma_{ \pm}}{d \ln m}\right]
$$

$m$ is the molality of the electrolyte, and $\gamma_{ \pm}$is the mean molal activity coefficient, where the definition of the chemical potential, ${ }^{11}$

$$
\mu_{\mathrm{e}}=\mu_{\mathrm{e}}^{\mathrm{o}}+v R T \ln m \gamma_{ \pm}
$$

has been used. Another expression of the chemical potential used by Cleaver and Davies ${ }^{15}$ is

$$
\mu_{\mathrm{e}}=\mu_{\mathrm{e}}^{\mathrm{o}}+v R T \ln a_{\mathrm{e}}
$$




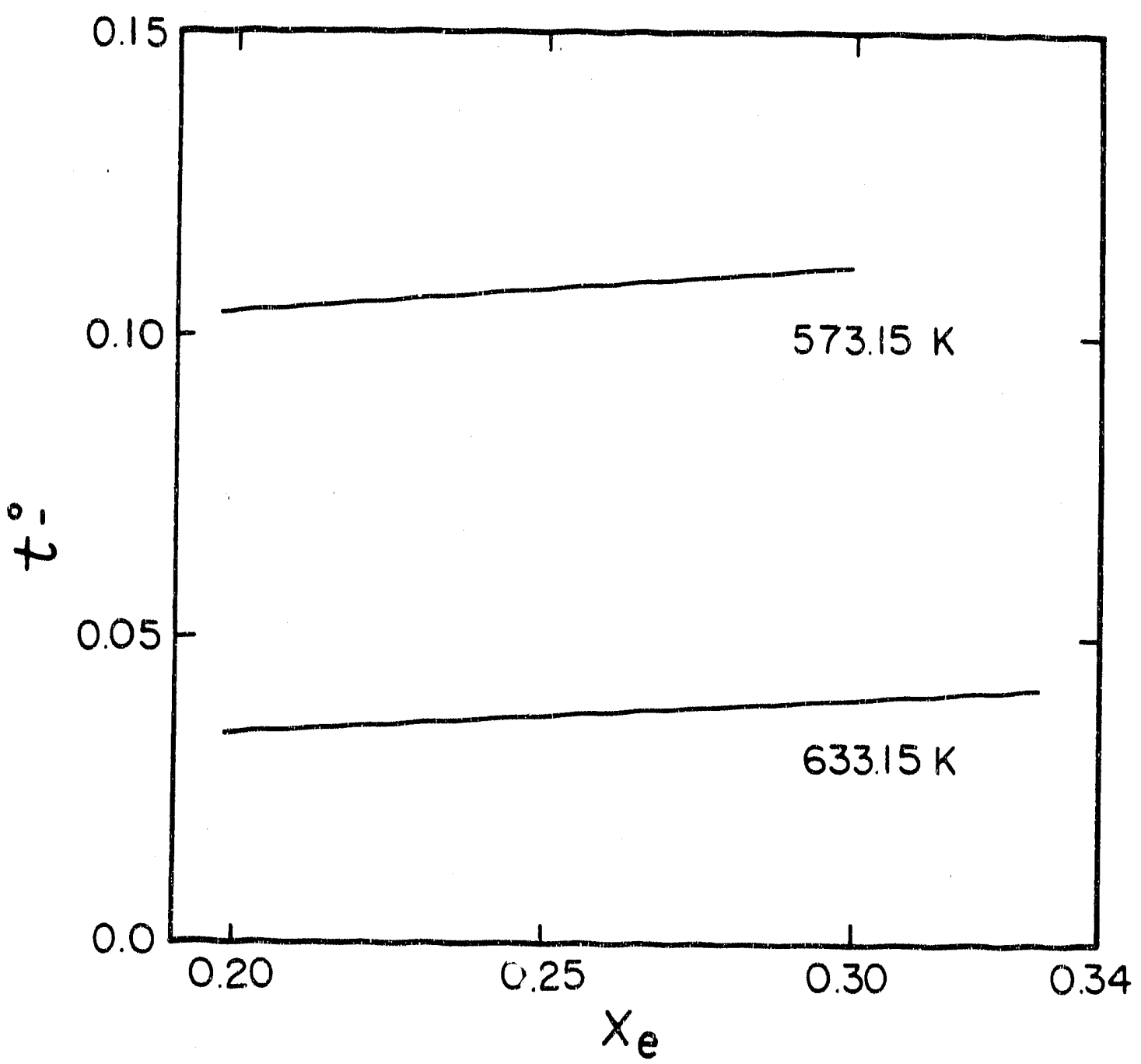

XBL $841-362$

Figure 2-1. Calculated sulfide ion transference numbers relative to neutral sulfur solvent plotted as a function of sodium polysulfide melt composition. ${ }^{14}$ 
By differentiating equations (2-23) and (2-24) with respect to $\ln m$, the desired quantity, $\left(1+\frac{d \ln \gamma_{ \pm}}{d \ln m}\right)$, in equation (2-22) is related to the activity of sodium sulfide in polysulfide melts, $a_{e}$, as

$$
1+\frac{d \ln \gamma_{ \pm}}{d \ln m}=\frac{1}{v} \frac{d \ln a_{e}}{d \ln m}
$$

Because of the Gibbs-Duhem equation,

$$
\mathrm{x}_{\mathrm{e}} d \ln a_{\mathrm{e}}+\mathrm{x}_{0} d \ln a_{0}=0 .
$$

and equation (2-20), the term of $\ln a_{\mathrm{e}}$ in equation (2-25) can be expressed in terms of $d U_{1}$. On the other hand, let us apply the definition of the electrolyte rúviality,

$$
m=\frac{1}{\mathrm{M}_{\mathrm{o}}} \frac{\mathrm{x}_{e}}{\left(1-\mathrm{x}_{\mathrm{e}}\right)} \text {. }
$$

and the chain rule to the term of $d \ln m$ on the right side of equation (2-25). Consequently, equation (2-25) can be rewritten as

$$
1+\frac{d \ln \gamma_{ \pm}}{d \ln m}=-\frac{\mathrm{x}_{\mathrm{e}}\left(1-\mathrm{x}_{\mathrm{e}}\right)^{2}}{\mathrm{~V}} \frac{2 F}{R T} \frac{d U_{1}}{d \mathrm{x}_{\mathrm{e}}} .
$$

In addition to Cleaver and Davies, Gupta and Tischer have also measured the potential of cell 1 versus composition for several temperatures. Both data were applied in equation (2-28), and the calculated thermodynamic factor is plotted versus melt composition in Figure 2-2. Moreover, the concentration term $c_{T} / c_{0}$ in equation (2-22) is related to $x_{e}$ by equation (2-43) in section 2.4 . Therefore, to obtain thermodynamic diffusion coefficients of sodium polysulfide melts using equation (2-22), one now only needs diffusion-coefficient data based on the concentration gradient.

The diffusion coefficients available for sodium polysulfides from experimental results were reviewed by Thompson. ${ }^{8}$ Many of the experimental methods which have been used to obtain diffusion coefficients are difficult to apply accurately to sodium polysulfides. Therefore, the published data measured by the various methods differ by as much as two orders of magnitude. It should be mentioned that all of these methods, except Thompson's, assumed that the polysulfide melt is a dilute solution and Fick's law can 


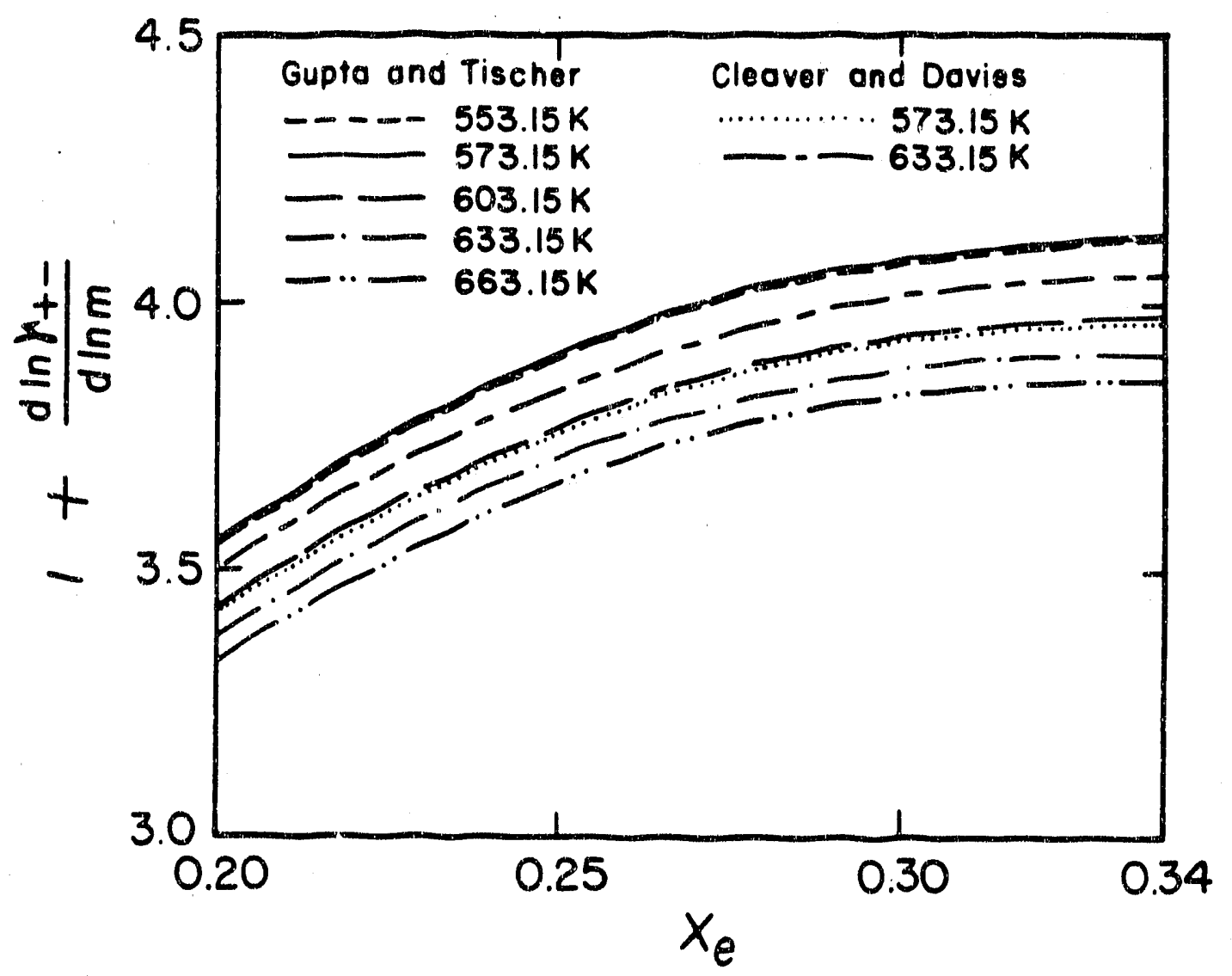

XBL $841-359$

Figure 2-2. Calculated thermodynamic factor for sodium polysulfide melts, ${ }^{12}$ determined from the data of Gupta and Tischer and Cleaver and Davies. ${ }^{15}$ 
be used to govern the diffusion process.

Thompson and Newman ${ }^{13}$ used the method of restricted diffusion to measure the diffusion coefficient as a function of sodium polysulfide melt composition and temperature. ${ }^{8}$ Restricted diffusion refers to diffusion in a vertical cell closed at both ends. Accurate diffusion coefficients of binary mixtures can be measured by observing isothermal diffusion in such a cell. The theory of restricted diffusion for dilute solutions was developed by French and Harned. ${ }^{17}$ Newman and Chapman ${ }^{18}$ extended the theory for concentrated solutions. Consequently, the method of restricted diffusion is inherently more accurate than other methods for sodium polysulfide melts and other such concentrated solutions.

In Figure 2-3, one can see thai the results of Thompson fall between the two groups of experimental data obtained by other researchers and that the repeatability of Thompson's data is excellent. Thompson summarized the experimental data as the following expression, ${ }^{24}$

$$
D=0.0153 \exp \left(-5.89 \times 10^{3} / T\right) \exp \left(5.30 \mathrm{x}_{e}\right) \mathrm{cm}^{2} / \mathrm{s}
$$

The activation energy of the diffusion coefficient is $48 \mathrm{~kJ} / \mathrm{mol}$. A comparison of the experimental data to the derived correlation is shown in Figure 2-4.

To determine D values versus temperature and composition using equation (2-22), Thompson used Cleaver and Davies's open-circuit-potential data to calculate the thermodynamic factor versus temperature and composition. Since Cleaver and Davies's data are for 300 and $360^{\circ} \mathrm{C}$ only, the derivative of the opencircuit cell potential with respect to the melt composition, $d U_{1} / d \mathrm{x}_{\mathrm{e}}$, in equation (2-28) was assumed to vary linearly with temperature between 300 and $360^{\circ} \mathrm{C}$. Figure 2.5 plots the thermodynamic diffusion coefficients calculated from both Thompson's diffusion coefficient data and the correlation given in equation (2-29) using equation (2-22).

\section{Electrical Conductivity}

The electrical conductivity of an electrolytic solution can be measured by alternating current. The experimental method will be described in detail in Chapter 4. Cleaver and Davies ${ }^{9}$ have presented conductivity data at different compositions and temperatures and correlated the data as a function of temperature for discrete melt compositions. The empirical equation is 


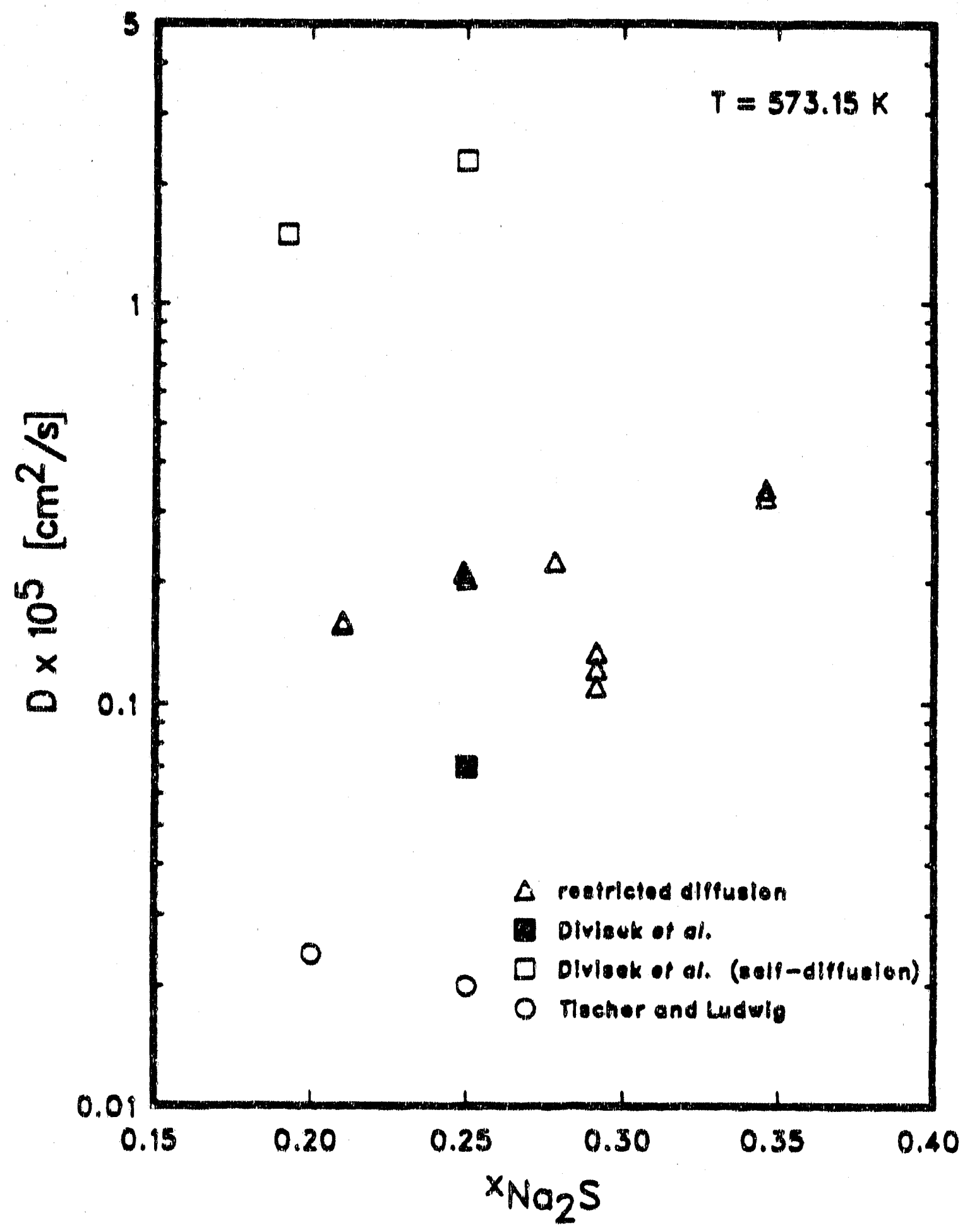

XBL 859-3961

Figure 2-3. Comparison of Thompson's experimental diffusion coefficients to the results of other researchers, ${ }^{13}$ 


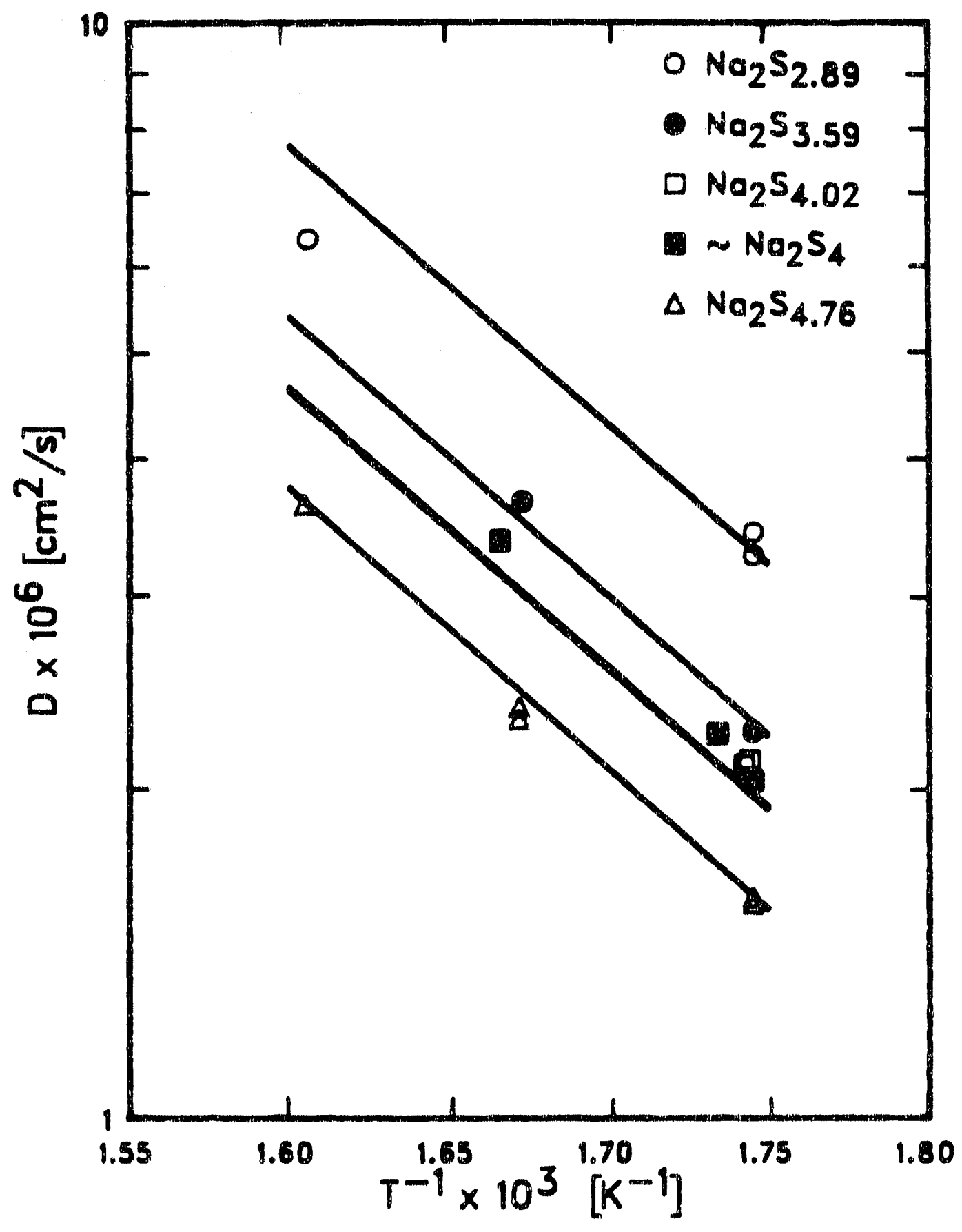

XBL $858-3733$

Figure 2-4. Comparison of Thompson's experimental diffusion coefficients to the derived correlation. ${ }^{13}$ Solid line presents the correlation given in equation (2-29). 


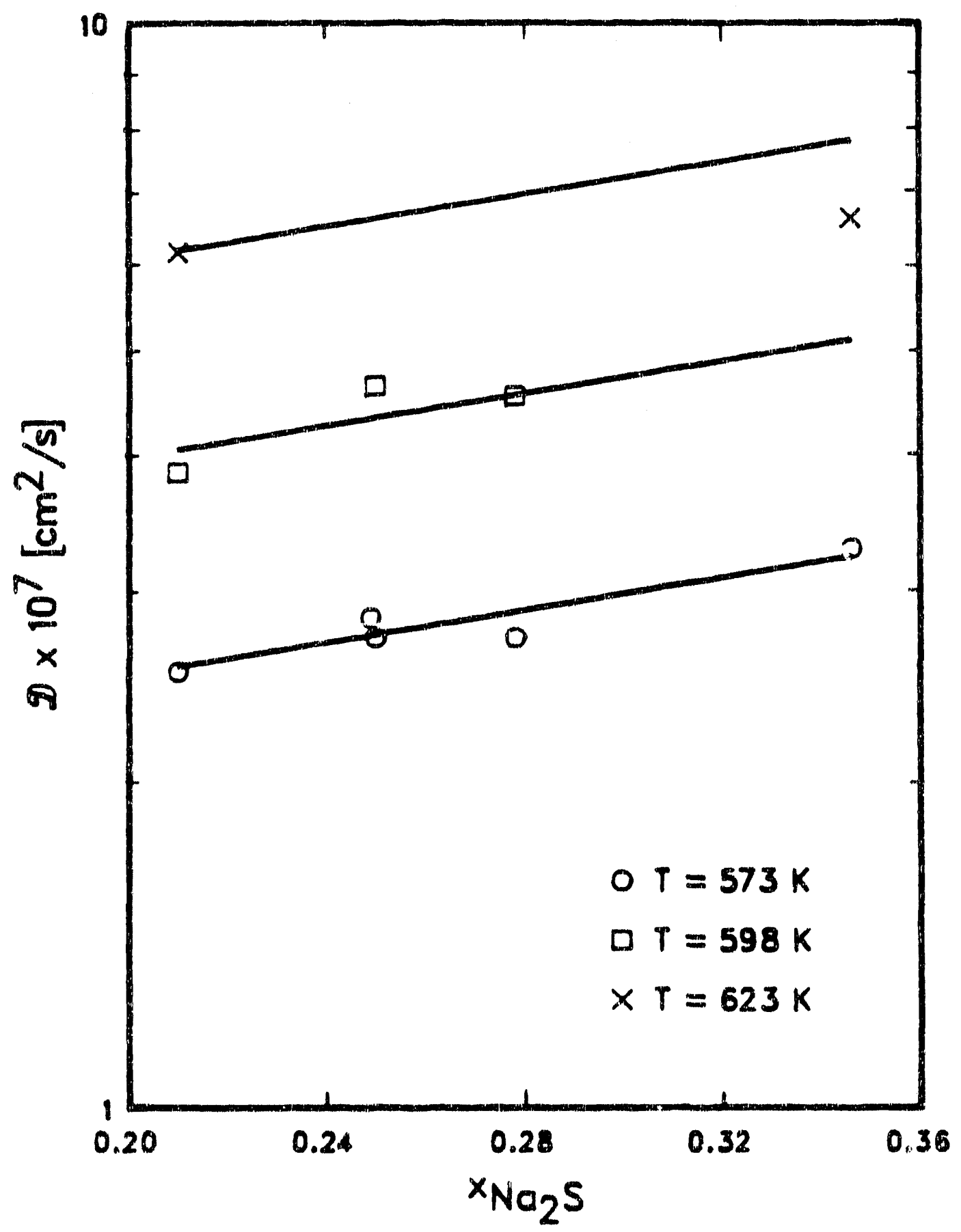

XBL $859-3850$

Figure 2-5. Values of thermodynamic diffusion coefficient versus melt composition calculated from Thompson's diffusion-coefficient data and Cleaver and Davies's open circuit potential data. ${ }^{15}$ Solid lines calculated using the diffusion coefficient correlation given in equation $(2-29){ }^{8}$ 


$$
\kappa=\boldsymbol{A} \exp \left[-\frac{\mathbf{E}_{\mathrm{k}}}{R\left(T-T_{\mathrm{o}}\right)}\right]
$$

$\boldsymbol{A}, \mathbf{E}_{\mathbf{k}}$, and $T_{0}$ depend on the melt composition. Table 2-1 gives the values of these three parameters.

This equation is based on the free-volume model for transport. $T_{0}$ is the glass transition temperature and represents the temperature for zero free volume in the liquid. The glass transition is indicated by a change in the slope of the thermogram or, in other words, an abrupt change in heat capacity. However, in the following section, the significance of the activation energy for transport will be discussed based on the conductance mechanism for a pure ionic lattice and the activation energy of the conductivity data in reference 9 will be re-calculated using the Arrhenius equation.

Table 2-1. Values of the Parameters in Equation (2-30).

\begin{tabular}{cccccc}
\hline Melt & $\mathrm{X}_{\mathrm{e}}$ & $\begin{array}{c}\text { Temp Range } \\
(\mathrm{K})\end{array}$ & $\begin{array}{c}\mathbf{A} \\
(\Omega-\mathrm{cm})^{-1}\end{array}$ & $\begin{array}{c}\mathbf{E}_{\mathrm{K}} \\
(\mathrm{kJ} / \mathrm{mol})\end{array}$ & $\begin{array}{c}T_{\mathrm{o}} \\
(\mathrm{K})\end{array}$ \\
\hline $\mathrm{Na}_{2} \mathrm{~S}_{2.1}$ & 0.476 & $728-840$ & 5.478 & 3.079 & 499 \\
$\mathrm{Na}_{2} \mathrm{~S}_{2.9}$ & 0.345 & $642-698$ & 3.863 & 2.478 & 458 \\
$\mathrm{Na}_{2} \mathrm{~S}_{3.0}$ & 0.333 & $582-693$ & 7.033 & 5.693 & 329 \\
$\mathrm{Na}_{2} \mathrm{~S}_{3.2}$ & 0.313 & $458-694$ & 7.048 & 5.854 & 330 \\
$\mathrm{Na}_{2} \mathrm{~S}_{3.8}$ & 0.263 & $428-694$ & 7.056 & 6.436 & 325 \\
$\mathrm{Na}_{2} \mathrm{~S}_{4.2}$ & 0.238 & $456-671$ & 6.279 & 6.163 & 341 \\
$\mathrm{Na}_{2} \mathrm{~S}_{5.1}$ & 0.196 & $477-681$ & 5.815 & 6.329 & 344 \\
\hline
\end{tabular}

Figure 2-6 shows the electrical-conductivity data versus the melt composition from Cleaver and Davies for several temperatures. The melt compositions in the Figure are within or very close to the operating range of the sodium/sulfur cell. The conductivity data are linear functions of melt composition for several temperatures. 


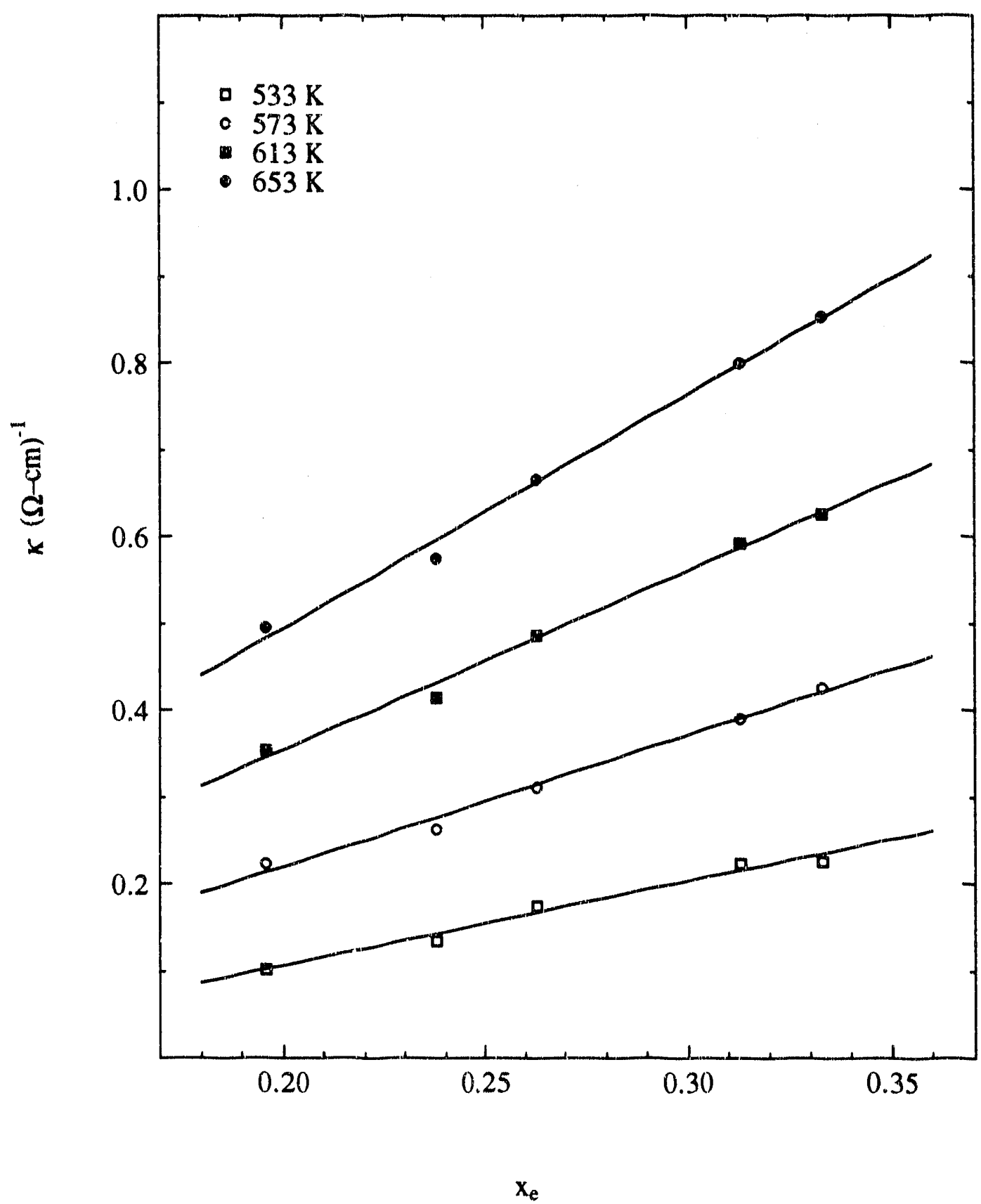

.

Figure 2-6. Sodium polysulfide conductivity versus melt composition. Data from Cleaver and Davies. ${ }^{9}$ 


\section{Activation Energy ${ }^{19}$}

A molten salt may be regarded as a highly disordered lattice with a large temperature-independent number of defects. The mechanism of conductance for a pure, stochiometric, ionic lattice is presented in reference 19. As a result, at higher temperatures, the conduction is almost entirely due to ionic diffusion, and the conductivity $\kappa$ of the crystals with lattice defects can be expressed as

$$
\kappa=\text { const } \exp \left[-\left(\frac{E^{\prime}}{a}+E\right) / k T\right]
$$

assuming that only one ionic species is migrating. $E^{\prime}$ is the energy of activation required for the formation of an interstitial ion and a vacant lattice site, or for the removal of two oppositely charged ions from the bulk crystal. In other words, $E$ ' is the energy required to create defects, and the number of defects depends on its magnitude. a corresponds to the distance between two interstitial positions or between two similarlv charged ions. $E$ is the activation energy required to overcome the intervening potential barrier. Consequently, the probability of migration of defects depends on the magnitude of $E$.

For a molten salt with a constant number of defects, assuming the transport number of one ionic species is much greater than that of the other, the conductivity $K$ is

$$
\kappa=\text { const } \exp [-E / k T]
$$

Thus, a linear relationship is to be expected between $\ln \kappa$ and $1 / T$ for a molten salt. The temperature variation of the viscosity of liquids is given by a similar law:

$$
\eta=\text { const } \exp [B / k T]
$$

where $B$ is the activation energy of the flow. $B$ is considerably greater than $E$ because the resistance of flow is governed by the large anions while the current is largely carried by the small cations. Let us plot the conductivity data shown in Figure 2-6 as $\ln \kappa v s .1 / T$ in Figure 2-7. Linear regression fits on the Figure show the Arrhenius-type temperature dependence of the conductivity. 


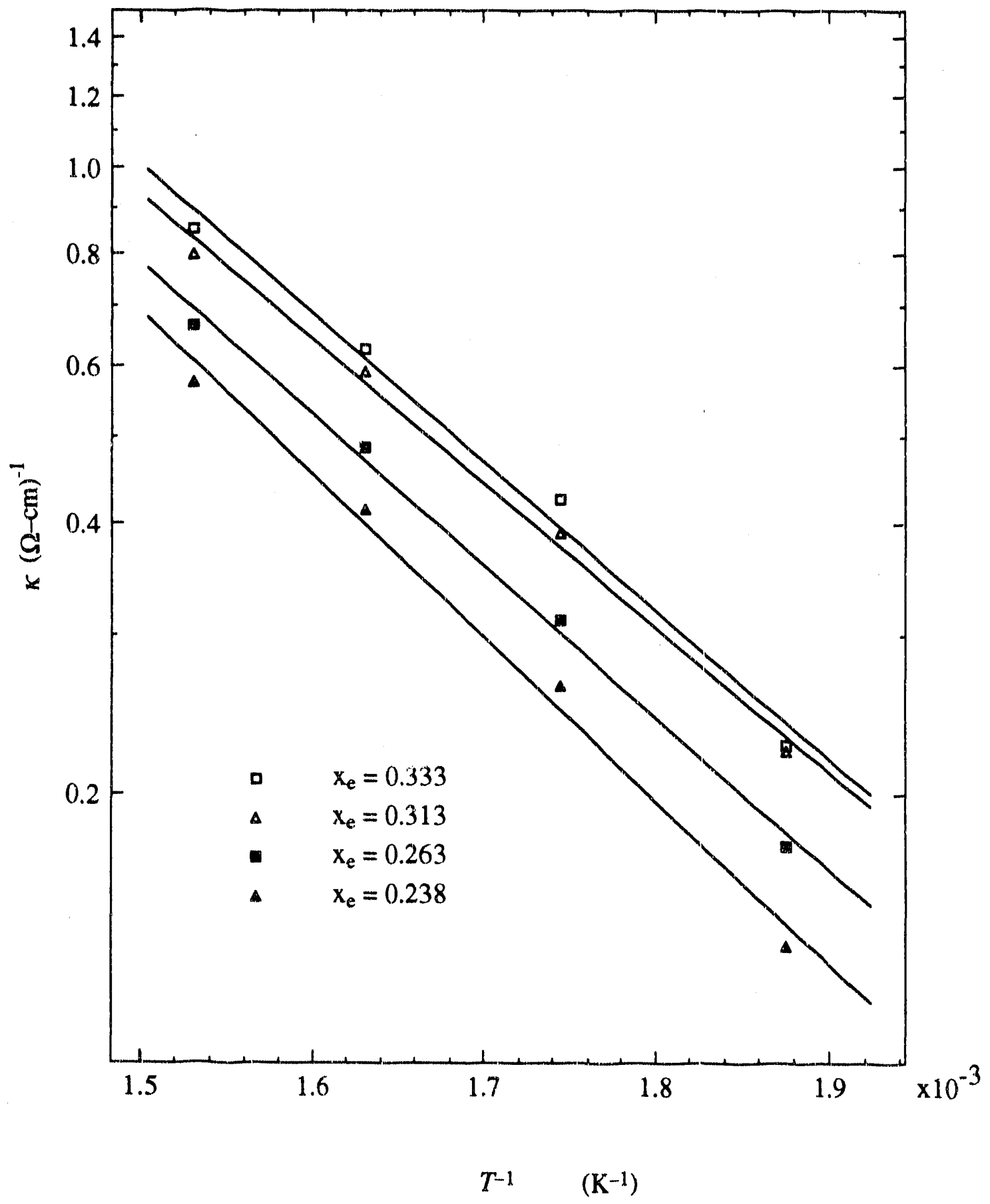

Figure 2-7. Sodium polysulfide conductivity versus temperature. Data from Cleaver and Davies. ${ }^{9}$ 


$$
\kappa=A \exp \left[-\frac{E_{\mathrm{A}}}{R T}\right]
$$

$A$ is a function of melt composition. The values of activation energy in the Arrhenius equation for different compositions are between 31 and $34 \mathrm{~kJ} / \mathrm{mol}$

In Table 2-3, the activation energy values determined from Thompson's restricted-diffusion experiment and Cleaver and Davies's conductivity data are compared to the results of Tischer and Ludwig, ${ }^{20}$ Divisek et al..$^{21}$ and the viscosity data. ${ }^{22}$ The activation energy from Divisek $e$ al . is based on diffusion-coefficient data. The fact that the activation energy of viscosity data from reference 22 is greater than that of conductivity data agrees with the previous discussion. Since the resistance of diffusion is governed by both large anions and small cations, the activation energy of diffusion should be greater than that of conductivity and smaller than that of viscosity. Due to possible expe: mental errors, it is accepTable that diffusion and viscosity have nearly the same temperature dependence.

Table 2-3. Values of the Activation Energy for Sodium Polysulfides.

Source $\quad E_{\mathrm{A}, \mathrm{kJ} / \mathrm{mol}} \quad$ Composition

Thompson ${ }^{24}$

Tischer and Ludwig ${ }^{20}$

Divisek et al. ${ }^{21}$

Viscosity 22

Conductivity?
49.5

57.3

48.1

$-46.9$

32.2
$\mathrm{Na}_{2} \mathrm{~S}_{3}-\mathrm{Na}_{2} \mathrm{~S}_{5}$

$\mathrm{Na}_{2} \mathrm{~S}_{5}$

$\mathrm{Na}_{2} \mathrm{~S}_{4}$

$\mathrm{Na}_{2} \mathrm{~S}_{3}-\mathrm{Na}_{2} \mathrm{~S}_{5}$

$\mathrm{Na}_{2} \mathrm{~S}_{3}-\mathrm{Na}_{2} \mathrm{~S}_{5}$

\subsection{Transport Parameters}

The three equations for the transport properties, equations (2-13), (2-14), and (2-18), can be inverted into expressions explicit in $\mathcal{D}_{i j}$ 's, ${ }^{23}$ 


$$
\begin{aligned}
& \mathcal{D}_{0-}=\frac{z_{+}}{z_{+}-z_{-}} \frac{\mathcal{D}}{t_{+}^{\circ}}, \\
& \mathcal{D}_{\mathrm{O}_{+}}=\frac{-z_{-}}{z_{+}-z_{-}} \frac{\mathcal{D}}{1-t_{+}^{0}}, \\
& \frac{\mathcal{L}_{-}}{\mathcal{D}_{+}}=-\frac{z_{+} z_{\mathrm{T}_{\mathrm{T}}} F^{2}}{R T K}-\frac{z_{+}-z_{-}}{z_{+} V_{+}} \frac{c_{\mathrm{o}} t_{+}^{\circ} t_{-}^{\circ}}{c \mathcal{D}} .
\end{aligned}
$$

In order to obtain transport parameters from transport-property data presented in section 2.3 , we need to express the concentration ratio $c_{\mathrm{o}} / c$ and the total concentration $c_{\mathrm{T}}$ in equation $(2-37)$ in terms of melt composition $x_{e}$. In addition, the concentration ratio $c_{\mathrm{T}} / c_{\mathrm{o}}$ in equation $(2-22)$ has to be related to $\mathrm{x}_{\mathrm{e}}$ as weil for the determination of $\mathcal{D}$.

\section{Concentration and Mensity}

The concentration of the electrolyte and the solvent can be expressed in terms of melt composition $\mathrm{X}_{\mathrm{e}}$ as

$$
c=\frac{\rho}{M_{\mathrm{av}}} \mathrm{x}_{\mathrm{e}}
$$

and

$$
c_{\mathrm{o}}=\frac{\rho}{\mathrm{M}_{\mathrm{av}}}\left(1-\mathrm{x}_{\mathrm{e}}\right) \text {, }
$$

where the average molecular weight is

$$
M_{\mathrm{av}}=\mathrm{x}_{\mathrm{e}} \mathrm{M}_{\mathrm{e}}+\left(1-\mathrm{x}_{\mathrm{e}}\right) \mathrm{M}_{\mathrm{e}}
$$

The concentration ratio $c_{\mathrm{o}} / c$ is simply

$$
\frac{c_{\mathrm{o}}}{c}=\frac{\mathrm{x}_{\mathrm{e}}}{\left(1-\mathrm{x}_{\mathrm{e}}\right)}
$$

and the total concentration is

$$
c_{\mathrm{T}}=v c+c_{\mathrm{o}}=\frac{\rho}{\mathrm{M}_{\mathrm{av}}}\left[1+(v-1) \mathrm{x}_{\mathrm{e}}\right]
$$

Moreover, the concentration ratio $c_{\mathrm{T}} / c_{0}$ in equation $(2-22)$ is 


$$
\frac{c_{T}}{c_{0}}=\frac{1+(V-1) x_{e}}{1-x_{e}}
$$

Although the concentration ratio $c_{\mathrm{o}} / c$ is independent of density, calculation of $c_{\mathrm{T}}$ requires knowledge of density.

The densities of polysulfide melts have been measured by Cleaver and Davies ${ }^{22}$ experimentally. They correlated densities for several discrete melt compositions as linear functions of temperature.

$$
\rho=\mathbb{D}+\mathbf{E}(T-100) \text {. }
$$

D and $\mathbf{E}$ depend on melt composition. Figure 2-8 and Figure 2-9 plot densities versus temperature and melt composition. Thompson ${ }^{8}$ represented the data by a function of temperature only,

$$
\rho=2.255-6866 \times 10^{-4} \times T \mathrm{~g} / \mathrm{cm}^{3}
$$

with a maximum error of $0.018 \mathrm{~g} / \mathrm{cm}^{3}$ if the $\mathrm{Na}_{2} \mathrm{~S}_{3.7}$ data are neglected.

\section{Transport Parameters ${ }^{8}$}

After the concentration terms in equations (2-37) are determined versus melt composition $\mathbf{X}_{\mathbf{e}}$, the fundamental transport parameters, $\mathcal{D}_{i j}$ 's, versus $x_{e}$ can be calculated using values of transport properties, $\mathcal{D}, \boldsymbol{K}$, and $t_{+}^{\mathrm{o}}$ presented in section 2-3.

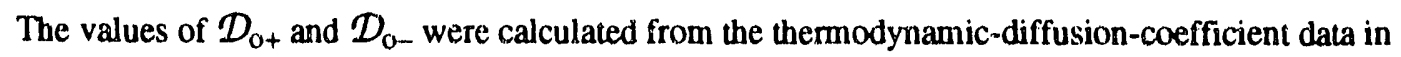
Figure 2-5 and the transference number data in Figure 2-1, using equation (2-35) and equation (2-36). The transference numbers in Figure 2-1 were interpolated linearly in temperature to obtain transference numbers for temperatures other than 300 and $360^{\circ} \mathrm{C}$. The results are shown in Figure 2-10 and appear reasonable.

In addition to the transference-number data and the thermodynamic-diffusion-coefficient data mentioned above, the density values calculated from equation (2-45) and the conductivity data of Cleaver and Davies were also applied in equation (2-37) for the calculation of $\mathcal{D}_{+}$values. The results are listed in Table 2-2. For the temperatures of 300 and $325^{\circ} \mathrm{C}$ the negative values of $\mathcal{D}_{+-}$are not physically reasonable. 


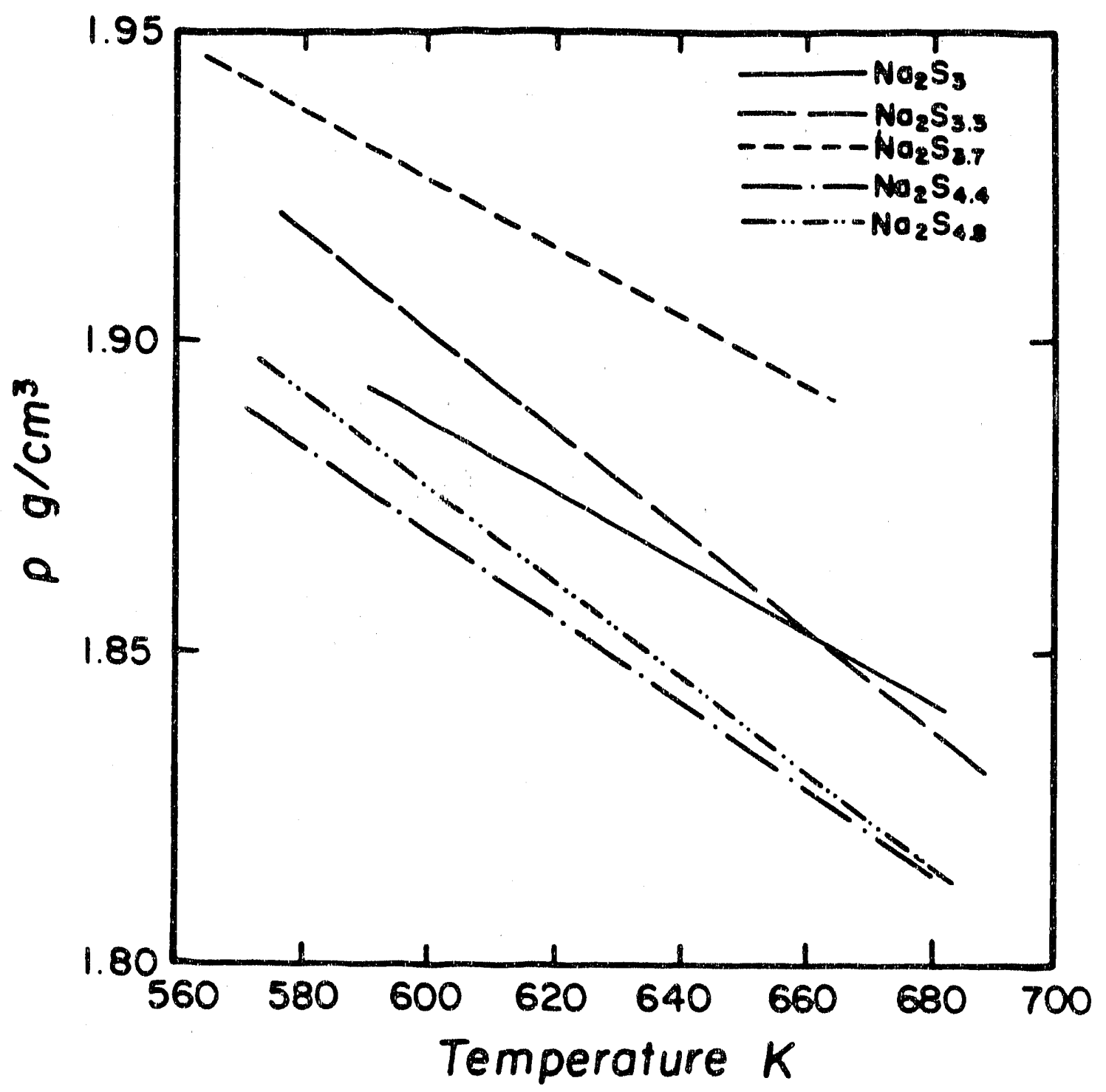

XBI 925-1161

Figure 2-8. Sodiurn polysulfide density versus temperature for various melt compositions. ${ }^{12}$ Data obtained from Cleaver and Davies. ${ }^{22}$ 


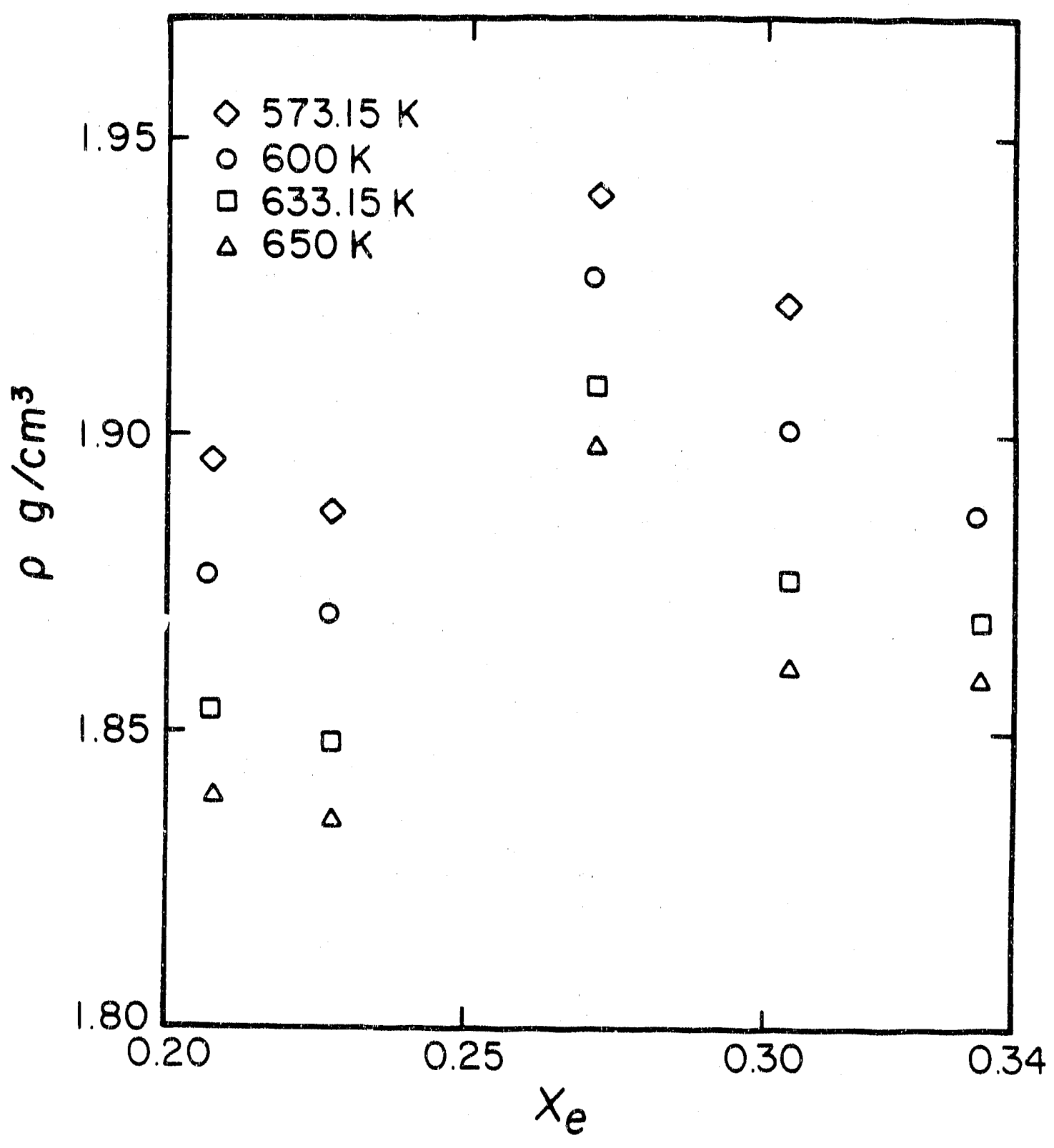

$x 81.841-365$

Figure 2-9. Sodium polysulfide density versus melt composition for several temperatures. ${ }^{12}$ Data obtained from Cleaver and Davies. ${ }^{22}$ 


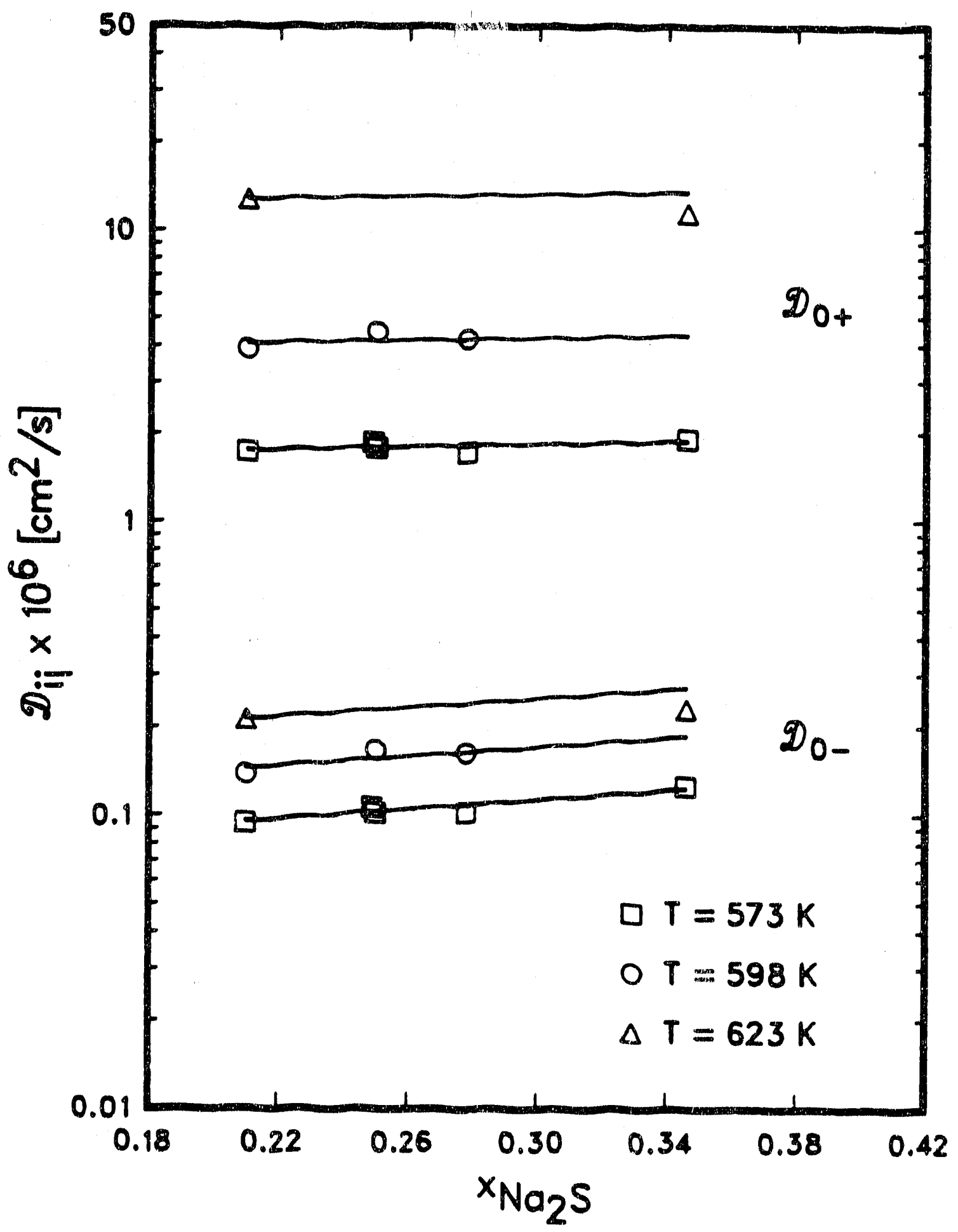

XBL 859-3965

Figure 2-10. Calculated transport parameters $\mathcal{D}_{\mathrm{O}^{+}}$and $\mathcal{D}_{0-}$ versus melt composition. Solid lines calculated using the diffusion-coefficient correlation given in equation (2-29). ${ }^{8}$ 
The negative values of $D_{+}$suggest that some transport property data may not be accurate. Since the values of $\mathcal{D}_{0+}$ and $\mathcal{D}_{0 \text { - }}$ are reasonable, it can be assumed that the transference number data are accurate enough. Furthermore, in equation (2-37), the values of density for the temperature range of $573 \mathrm{~K}$ to $623 \mathrm{~K}$ were almost constant. For the temperature of $623 \mathrm{~K}$, the $\mathcal{D}_{+}$values are positive, so the density data should not have resulted in the negative values of $\mathcal{D}_{+-}$. Consequently, it is concluded that the conductivity data may be the ones which give negative $\mathcal{D}_{+}$'s.

Table 2-2. Values of $\mathcal{D}_{+}$

\begin{tabular}{|c|c|c|c|}
\hline $\begin{array}{c}\text { Temperature } \\
\text { (K) }\end{array}$ & Melt & $\mathrm{x}_{\mathrm{e}}$ & $\begin{array}{c}\mathcal{D}_{+} \times 10^{6} \\
\mathrm{~cm}^{2} / \mathrm{s}\end{array}$ \\
\hline \multirow[t]{5}{*}{573} & $\mathrm{Na}_{2} \mathrm{~S}_{2.89}$ & 0.346 & -2.57 \\
\hline & $\mathrm{Na}_{2} \mathrm{~S}_{3.59}$ & 0.278 & -1.37 \\
\hline & $\mathrm{Na}_{2} \mathrm{~S}_{4}$ & 0.25 & -1.26 \\
\hline & $\mathrm{Na}_{2} \mathrm{~S}_{4,02}$ & 0.249 & -1.38 \\
\hline & $\mathrm{Na}_{2} \mathrm{~S}_{4.76}$ & 0.21 & -0.965 \\
\hline \multirow[t]{3}{*}{598} & $\mathrm{Na}_{2} \mathrm{~S}_{3.59}$ & 0.278 & -16.7 \\
\hline & $\mathrm{Na}_{2} \mathrm{~S}_{4}$ & 0.25 & -2.26 \\
\hline & $\mathrm{Na}_{2} \mathrm{~S}_{4.76}$ & 0.21 & -5.26 \\
\hline \multirow[t]{2}{*}{623} & $\mathrm{Na}_{2} \mathrm{~S}_{2.89}$ & 0.346 & 5.98 \\
\hline & $\mathrm{Na}_{2} \mathrm{~S}_{4,76}$ & 0.21 & 3.69 \\
\hline
\end{tabular}




\section{Chapter 3. The Measurement of Flectrolytic Conductivity}

\subsection{Introduction}

To determine electrolytic conductivity, experimentally we measure the resistance between two electrodes of fixed shape and size in a ceil filled with the electrolyte. This resistance naturally depends on the geometry of the cell as well as the dimensions and separation of the electrodes. Normally a cell constant, $a$, is defined hy 25

$$
\kappa=a / R .
$$

$R$ is the measured resistance with a solution of specific conductivity, $K$, in the cell.

Regardless of the electrode effects and treating the cell as consisting of a number of regions in each of which the current density is uniform, the cell constant is given by

$$
a=\sum \frac{L}{A}
$$

where $L$ is the length of each region and $A$ is its cross-sectional area normal to the current. However, usually the current density is not uniform throughout the cell. Therefore, the calibration of the cell by means of a solution of known specific conductivity is the unavoidable procedure to obtain the cell constant.

In fach, electrode effects often cause errors in the measurements. Due to these effects, the cell constant for the same cell may change from one kind of electrolyte to another. In other words, the cell constant does therefore not only depend on the size and shape of the cell and electrodes but also on the kind of electrolyte in the sell. Since the object of the measurements is to determine the pure resistance of the electrolyte between electrodes, the electrode effects must be minimized or eliminated.

Feates, I wes, and Pryor ${ }^{25}$ eliminated the electrode effects by the double cell design, where they measured the difference in the resistances of the two cells with identical electrodes but different lengths of solution between them. In general, the electrode effects can be minimized by the use of audio-frequency 
alternating current and the platinization of electrodes. In section 3.2, the dependence of the electrode effects on frequency will be discussed in detail.

High cell constants give high electrolyte resistances, which make the electrode effects become negligible. For instance, based on equation (3-2), capillary cells have high cell constants, so they bave been used in the conductivity measurement of highly conductive aqueous solutions. However for some highly viscous and conductive electrolyte solutions, such as sodium polysulfide melts, filling capillary cells with melts completely is experimentally difficult since bubbles are often trapped in melts. Therefore instead of using cells with a narrow and long geometry like a capillary, one can use microelectrodes in wide and short cells to obtain high cell constants. In section 3.4 , the primary resistance for disk electrodes in axisymmetric cylindrical cells will be presented first in order to introduce the usefulness of microelectrodes in the conductivity measurement of electrolytes.

\subsection{Electrode Effects}

The understanding of the effects associated with the electrode process themselves are necessary in order to minimize or eliminate them from the resistance measurements

\section{Double-Layer Capacity ${ }^{26,27}$}

At the interface of a charged solid and a solution, the electrical forces and/or the covalent (or specific) forces between the solid and some species in the solution can form a double layer with a diffuse part in the solution. The structure of the electrical double layer consists of four parts: (a) Charge $q$ in the metal phase, very close to the surface. (b) The surface of the metal, assumed to be an impenetrable barrier. (c) On the solution side of the metal surface, a layer of absorbed species which could be charged ions, $q_{1}$, or oriented dipoles. (d) Outside of the adsorbed layer, a layer of diffuse charge $q_{2}$ which is like the bulk of the electrolytic solution except that it is not electrically neutral. The magnitude of the potential drop actoss the interface depends on the nature and composition of the two phases. The whole interfacial region is electrically neutral:

$$
q+q_{1}+q_{2}=0
$$


The double-layer capacity (per unit area) $C$ is the derivative of the double-layer charge $q$ with respect to potential at constant composition:

$$
C=\left(\frac{\partial q}{\partial U}\right)_{\mu, T}
$$

At relatively high concentrations, the capacity of the double layer is in effect largely governed by the adsorption layer, the diffuse portion of the former exerting only a minor effect. Generally speaking, cations with a structure resembling that of an inert gas are not specifically adsorbed. Their hydration envelopes remain intact, and their interaction with the charged metallic surface is purely electrostatic. On the other hand, most anions are specifically adsorbed with the loss of most or all of their hydration envelopes.

When one can vary the charge on the metal side of the surface and also the potential without an electrode reaction occurring, such an electrode system is called an ideally polarizable electrode. The double-layer capacity of an ideally polarizable electrode can be measured directly with an alternating current. Because the double layer is thin, this capacity is fairly large, often amounting to several microfarads per sq. cm of electrode surface, and it responds quickly to the alternating current as well. Therefore, except when the adsorption of long-chain organic compounds is involved, this capacity is expected to be independent of frequency until a frequency of about $1 \mathrm{MHz}$.

\section{Charge-Transfer Resistance ${ }^{27}$}

The driving force required to make the electrode reactions proceed at appreciable rates is the surface overpotential. The simplest type of dependence of the current density on the surface overpciential and the composition adjacent to the electronde surface is given by the Butler-Volmer equation :

$$
i=i_{0}\left[\exp \left(\frac{\alpha_{a} F}{R T} \eta_{\mathrm{s}}\right)-\exp \left(-\frac{\alpha_{c} F}{R T} \eta_{\mathrm{s}}\right)\right]
$$

The exchange current $i_{0}$ depends on the composition of the solution adjacent to the electrode, as well as the temperature and the nature of the electrode surface. $\alpha_{a}$ and $\alpha_{c}$ are apparent transfer coefficients and usually have values between 0.2 and 2 . 
For large values of $i_{0}$, a given current density can be obtained with small surface overpotentials. At low surface overpotentials, equation (3-5) can be approximated by a linear expression :

$$
i=i_{0} \frac{\left(\alpha_{a}+\alpha_{c}\right) F}{R T} \eta_{\mathrm{s}}
$$

The value of $\eta_{\mathrm{s}} / i$ may be defined as the charge-transfer resistance. The greater $i_{0}$ is, the smaller the charge-Iransfer resistance is.

At high surface overpotentials, one of the terms in equation (3-5) can be neglected, and the relationship between the current density and the surface overpotential becomes

$$
i=i_{0} \exp \left(\frac{\alpha_{0} F}{R T} \eta_{\mathrm{s}}\right)
$$

where the charge-transfer resistance, $\eta_{\mathrm{s}} / i$, depends on the surface overpotential. Although many simple reactions follow equation (3-5), many reactions show quite different behavior. For instance, the passivation phenomenon of anodic dissolution processes is that, for sufficiently large overpotentials, a thin protective anodic oxide film forms on the electrode, and the current density drops to a very low value.

When the potential of the electrode is varied, the current that flows is partly due to charging the double-layer capacity and partly due to a faradaic reaction. The current density for an electrode of constant area will be given by

$$
i=f\left(\eta_{\mathrm{s}}, c_{i}\right)+C \frac{d \eta_{\mathrm{s}}}{d \mathrm{t}}
$$

$f$ is a function describing the kinetics of the electrode reaction, for instance equation (3-5).

\section{Concentration Overpotential ${ }^{28,29}$}

The presence of concentration variations near the electrodes in an electrochemical cell leads to concentration overpotentials. The concentration overpotential was defined as the potential difference between a reference electrode adjacent to the surface, just outside of the diffusion layer, and another reference electrode in the bulk of the solution, minus the potential difference which would exist between these reference electrodes if the current distribution were unchanged but there were no concentration 
variations between the electrode surface and the bulk solution. The potential $V_{r}$ of a movable reference electrode, relative to a fixed reference electrode, varies with position as

$$
\nabla V_{r}=-\sum_{i} \frac{s_{i}}{n \mathrm{~F}} \nabla \mu_{i}
$$

$s_{i}$ is the stoichiometric coefficient of species $i$ and $n$ is the number of electrons involved in the electrode reaction.

$$
\sum_{i} z_{i} s_{i}=-n
$$

Let us select an ionic species $n$ as a reference species and rewrite equation (3-9) as

$$
\nabla V_{r}=\frac{1}{z_{i} F} \nabla \mu_{n}-\sum_{i} \frac{s_{i}}{n F}\left(\nabla \mu_{i}-\frac{z_{i}}{z_{n}} \nabla \mu_{n}\right)
$$

Transport process in electrolytic solutions can be expressed as

$$
\frac{1}{z_{n}} \nabla \mu_{n}=-\frac{F}{\kappa} i-\sum_{i} \frac{t_{i}^{0}}{z_{n}}\left(\nabla \mu_{i}-\frac{z_{i}}{z_{n}} \mu_{n}\right)
$$

and at uniform temperature,

$$
\nabla \mu_{i}=R T \nabla \ln c_{i}+z_{i} F \nabla \Phi+R T \nabla\left(\ln f_{i}-\frac{z_{i}}{z_{n}} \ln f_{n}\right)
$$

where $\Phi$ is the quasi-electrostatic potential. ${ }^{30}$ By substituting equation (3-12) into the first term on the right of equation (3-11) and applying equation (3-13) at the same time, we will have

$$
\nabla V_{r}=-\frac{i}{\kappa}-\frac{R T}{n F} \sum_{i} s_{i} \nabla \ln c_{i} f_{i, n}-\frac{R T}{F} \sum_{i} \frac{t^{\rho}}{z_{j}} \nabla \ln c_{i} f_{i, n} .
$$

Then the concentration overpotential as defined above will be

$$
\eta_{\mathrm{c}}=\int_{0}^{\infty} i_{y}\left(\frac{1}{x}-\frac{1}{\kappa_{\infty}}\right) d y+\frac{R T}{n F} \sum_{i} s_{i} \ln \frac{\left(c_{i} f_{i n}\right)_{\infty}}{\left(c_{i} f_{i n n)}\right)}+\frac{R T}{F} \int_{0}^{\infty} \sum_{j} \frac{t_{j}^{0}}{z_{j}} \frac{\partial \ln c_{i} f_{i n}}{\partial y} d y .
$$


For dilute solutions, the Nerst-Einstein relation can be used to express the last term with diffusion coefficients instead of transference numbers, and the activity coefficients can be assumed to be unity. With an excess supporting electrolyte, conductivity variations are negligible. Therefore, for dilute solutions with an excess supporting electrolyte, the above equation becomes

$$
\eta_{\mathrm{c}}=\frac{R T}{n F} \sum_{i} s_{i} \ln \frac{c_{i \infty}}{c_{i 0}}+\frac{F}{\kappa_{\infty}} \sum_{j} z_{i} D_{i}\left(c_{j \infty}-c_{j 0}\right)
$$

The last term can be neglected since it is on the order of the reactant concentration divided by the supporting-electrolyte concentration. If only one depleting component is present in the overall electrode reaction, a good approximation of the concentration overpotential is

$$
\eta_{\mathrm{c}}=\frac{R T}{n F} \mathrm{~s}_{i} \ln \frac{c_{j 0}}{c_{j \infty}}
$$

E. Warburg and F. Kruger calculated the concentration distribution when applying a sinusoidal alternating current. Fick's laws and Faraday's law were used in the derivation of the concentration as a function of time and distance from the electrode. On the basis of Fick's second law, the material balance equation is

$$
\frac{\partial c_{j}}{\partial t}=D_{j} \frac{\partial^{2} c_{j}}{\partial y^{2}}
$$

$y$ is the distance from the surface. In this case, the movement of the species due to migration and convection is neglected, and the diffusion coefficient is assumed to be independent of concentration.

In addition to the initial condition, $c_{j}(0, y)=c_{\infty}$, and the boundary condition at infinity, $c_{j}(t, \infty)$ $=c_{\infty}$, the boundary condition based on Fick's first law and Faraday's law is

$$
\left[\frac{\partial c_{j}}{\partial y}\right]_{y=0}=-\frac{i s_{j}}{n F D_{j}}
$$

where

$$
i=I \sin \omega t
$$


Expect at very low frequencies, the equation of the concentration can be expressed simply as

$$
c_{j}(y, \mathrm{t})=c_{j \infty}+\frac{l \cdot s_{j}}{n F \sqrt{D_{j} \omega}} \exp \left[-\sqrt{\frac{\omega}{2 D_{j}}} \cdot y\right] \times \sin \left[\omega \mathrm{t}-\sqrt{\frac{\omega}{2 D_{j}}} \cdot y-\frac{\pi}{4}\right] .
$$

The concentration wave is damped going fmm the electrode surface into the electrolyte.

Let us apply this concentration equation in equation (3-17) to obtain the concentration overpotential for dilute solutions with an excess electrolyte.

$$
\eta_{\mathrm{c}}=\frac{l \cdot R T \cdot \mathrm{s}_{j}^{2}}{n^{2} \cdot F^{2} \cdot c_{j 0} \cdot \sqrt{D \omega}} \cdot \sin \left(\omega \mathrm{t}-\frac{\pi}{4}\right)
$$

Then, the concentration overpotential lags the current by a phase angle of $\pi / 4=45^{\circ}$. The direction of the phase corresponds to that in an equivalent RC (resistive capacitive) circuit.

When migration and convection are considered, the derivation for th diffusion impedance will be more complicated. For instance, the material balance for a dilute binary electrolytic is given by

$$
\frac{\partial c}{\partial t}+\mathbf{v} \cdot \nabla c=\nabla \cdot(D \nabla c)-\frac{i \cdot \nabla t_{+}}{z_{+} v_{+} F},
$$

where $c$ is the electrolyte concentration and

$$
\begin{gathered}
t_{+}=\frac{z_{+} u_{+}}{z_{+} u_{+}-z_{-} u_{-}}, \\
D=\frac{z_{+} u_{+} D_{--}-z_{-} u D_{+}}{z_{+} u_{+}-z_{-} u_{-}} .
\end{gathered}
$$

When we assume constant properties and no convection and consider only the normal component of the electrolyte flux, equation (3-24) becomes as simple as equation (3-18). If only the cation reacts at the electrode, the current density is related to the concentration gradient by ${ }^{31}$

$$
\frac{i_{y}}{z_{+} v_{+} F}=-\frac{D}{1-t_{+}} \frac{\partial c}{\partial y} \quad \text { at } y=0 \text {. }
$$


For a metal deposition reaction, the concentration overpotential is

$$
\eta_{c}=\frac{\left(z_{+}-z_{-}\right) R T}{z_{+} z_{-} F}\left[\ln \frac{c_{\infty}}{c_{0}}-t_{+}^{\mathrm{o}}\left(1-\frac{c_{0}}{c_{\infty}}\right)\right] .
$$

For a concentrated binary electrolytic solution, the procedure to obtain the diffusion impedance is even more complicated. The convection effect may not be negligible, since it is not only the solvent velocity which contributes to the average velocity. From the Stefan-Maxwell equations, Tribollet and Newman ${ }^{32}$ developed a model describing the distribution of concentration of each species and the electrochemical impedance as well. Pollard and Comte ${ }^{33}$ developed a mathematical model that specifically describes the response obtained from ac impedance experiments using a thin-layer cell with the electrolyte sandwiched between planar electrodes. Equations in this model are derived for binary and ternary electrolytes that contain one or more neutral species as well as for fused salts, where all the species are charged Composition profiles in this systern were obtained under the circumstance that the magnitude of the ac perturbation is sufficiently small. The concentration overpotential was determined by substitution of concentration-profile equations into equation (3-15).

\subsection{Electrochemical Impedance ${ }^{34,35}$}

The impedance of an electrochemical system is defined as the ratio of the total alternating potential to the total alternating current, $Z=V / i$. The electrode effects contribute to the frequency dependence of the electrochemical impedance. Equivalent circuits are often used to interpret experimental impedance data, whereas it is pointed out by Grahame that an independent analysis of the problem must be carried out to know whether or not a given equivalent circuit is in fact equivalent to the interface (the electrode-electrolyte interface) under consideration. A mathematical modeling approach should prove to be a more fruitful procedure for characterizing the electrochemical impedance than the use of equivalent circuits. The mathematical impedance models for a rotating disk electrode have been developed by Hauser. ${ }^{35}$ Nevertheless, the objective in this section is to explain how to minimize the electrode effects by adjusting the frequency of the alternating cursent. Hence, for simplicity, only equivalent-circuit models will be introduced at this time. 
The theory of electrode processes mentioned in section 3.2 leads to a schematic representation of the conductance cell shown in Figure 3-1.

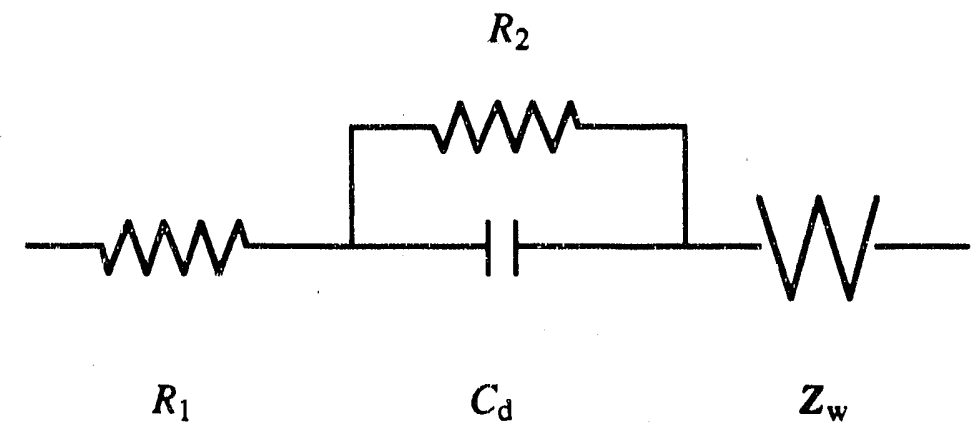

Figure 3-1. Network electrically equivalent to conductance cell.

$R_{1}$ represents the ohmic resistance of the electrolyte and is independent of frequency up well past audio frequencies. $C_{\mathrm{d}}$ represents the capacity of the double layer, which is in series with $R_{1}$ and the diffusion impedance $Z_{w}$. The charge transfer resistance $R_{2}$ is in parallel with the double-layer capacity.

If the electrolyte is a dilute solution with an excess supporting electrolyte and only one depleting component is present in the overall electrode reaction, the diffusion impedance (also called the Warburg impedance) can be obtained using equation (3-22).

where

$$
\begin{gathered}
Z_{\mathrm{w}}=\eta_{\mathrm{c}} / i=\sigma(1-\mathrm{j}) / \sqrt{\omega}, \\
\sigma=\frac{R T}{n^{2} F^{2}} \cdot \frac{1}{\sqrt{2 \omega}} \cdot \frac{\mathrm{s}_{j}^{2}}{c_{j \infty} \cdot \sqrt{D_{j}}} .
\end{gathered}
$$

As shown in this equation, the higher the frequency is, the smaller the Warburg impedance is. On the other hand, for binary concentrated solutions, the steady diffusion impedance determined by Pollard and Comte ${ }^{33}$ is

$$
z_{\mathrm{W}}=z_{\mathrm{w}}(0) \frac{\tanh (\sqrt{\mathrm{j} \Omega})}{\sqrt{\mathrm{j} \Omega}}
$$

$\Omega$ is $\omega L^{2} / 4 D$ and 


$$
Z_{\mathrm{w}}(0)=-\frac{2 \mu R T}{A F_{c^{0}}} \sum_{\sharp \neq 0} v_{i} \gamma_{i}\left[1+\left(\frac{d \ln f_{i n}}{d \ln c}\right)_{c^{0}}\right]
$$

where

$$
\mu=-\frac{c_{0}^{0} \bar{V}_{0} L \gamma_{2}}{2 D F}
$$

and $\gamma_{i}$ is defined by

$$
v_{i} \gamma_{i}=\frac{t_{i}^{0}}{z_{i}}+\frac{s_{i}}{n}-\frac{s_{0} c_{i}^{0}}{c_{0}^{0} n}
$$

The superscript 0 denotes the initial state and $\bar{V}_{\mathrm{o}}$ is the partial molar volume of the neutral solvent. $L$ and $A$ are respectively the thickness and cross-sectional area of the electrolyte sandwiched between two planar electrodes.

The measured total impedance, $\boldsymbol{Z}$, of the conductance cell can be expressed as

$$
\begin{aligned}
& Z=Z_{R e}+j Z_{I m}, \\
& Z_{\mathrm{Re}}=R_{1}+\frac{R_{2}}{1+\omega^{2} C_{\mathrm{d}}{ }^{2} R_{2}{ }^{2}}+\operatorname{Re}\left\{Z_{\mathrm{w}}\right\}, \\
& Z_{\mathrm{Im}}=-\frac{\omega C_{\mathrm{d}} R_{2}^{2}}{1+\omega^{2} C_{\mathrm{d}}{ }^{2} R_{2}^{2}}+\operatorname{Im}\left\{Z_{\mathrm{w}}\right\} \text {. }
\end{aligned}
$$

Since sodium polysulfide melts in the microscopic model are binary concentrated solutions, let us apply equation (3-30) in equation (3-35) and (3-36). Then a typical plot of $\boldsymbol{Z}_{\mathrm{Im}} v s$. $\boldsymbol{Z}_{\mathrm{Re}}$ for concentrated solutions is shown in Figure 3-2. The variation of total impedance in this complex plane consists of three regions. Regions of mass transfer and kinetic control are found at low and high frequencies, respectively. At high frequencies, the diffusion impedance can be neglected. Based on equation (3-35) and (3-36) without $Z_{\mathrm{w}}$ terms, $\boldsymbol{Z}_{\mathrm{Re}}$ and $\boldsymbol{Z}_{\mathrm{Im}}$ can be related as

$$
\left(Z_{R e}-R_{1}-R_{2} / 2\right)^{2}+Z_{\mathrm{Im}^{2}}=\left(R_{2} / 2\right)^{2} .
$$




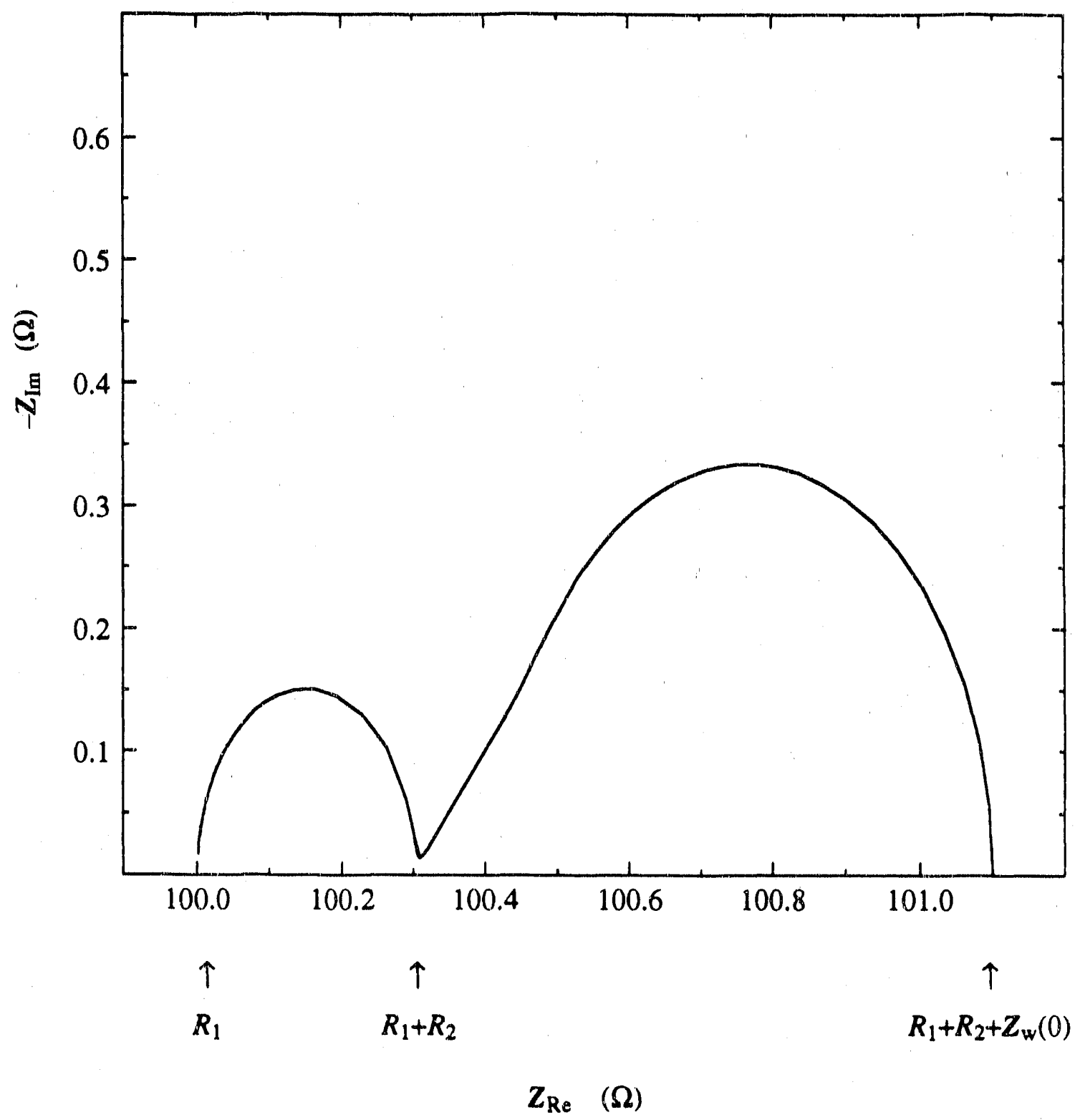

Figure 3-2. Impedance-plane plot for an electrochemical system, where $R_{1}=100 \Omega, R_{2}=0.3 \Omega, L^{2} / D$ $=8 \mathrm{~s}$, and $Z_{\mathrm{w}}(0)=0.8 \Omega$. The frequency ranges of the small and large loops are $[32 \mathrm{kHz}, 350 \mathrm{~Hz}]$ and $[350 \mathrm{~Hz}, 0 \mathrm{~Hz}]$ respectively. 
Therefore., the plot in the region of kinetic control is a semicircle. The center of the plot is at $Z_{R e}=R_{1}+$ $R_{2} / 2$ and $Z_{\operatorname{Im}}=0$, and the radius is $R_{2} / 2$. In the region of mass-transfer control, the plot at higher frequencies has unit slope because

$$
Z_{w}(\omega \rightarrow \infty)=Z_{w}(0) \sqrt{\frac{2 D}{\omega L^{2}}}(1-j)
$$

much like the Warburg impedance. At low frequencies, the plot curves down to a zero-frequency limit, where $Z_{\mathrm{Re}}=R_{1}+R_{2}+Z_{\mathrm{w}}(0)$ and $Z_{\mathrm{Im}}=0 . Z_{\mathrm{w}}(0)$ is the zero-frequency limit of the mass-transfer impedance.

Tae impedance-plane plots for actual chemical systems may show two limiting cases. If the chemical reaction on the electrode is rather sluggish, $R_{2}$ is large. The impedance complex plot is mainly a semicircle, and the linear mass transport-control region appears only at very low frequencies. At the other extreme, $R_{2}$ is very small, then the linear region covers a wide range of frequencies, and the semicircular region could almost disappear in the plot.

\subsection{The Primary Resistance of Axisymmetric Cylindrical Cells with Disk Electrodes}

Newman ${ }^{36}$ computed the primary current distribution for a disk electrode surrounded by an infinite insulating plane with the counterelectrode being the entire hemisphere at infinity. Its primary resistance is $1 / 4 r_{d} K$, where $r_{d}$ is the radius of the disk electrode. A carefully designed disk and cell can approach conditions which allow calculations for infinite cells to be applied to finite laboratory-sized cells without correction. Pierini and Newman ${ }^{37}$ have analyzed the primary resistance of a cylindrical cell with disk electrodes. Values of the resistance are given for a large number of cell configurations, and the resistance calculations permit the simpler resistance formulas for infinite cells to be applied to the design of finite cells.

The disk and cell treated by Pierini and Newman are shown in Figure 3-3. A working electrode of radius $r_{\mathrm{d}}$ is located at the center of the upper plane of the ceil. The remaining area, that between the edge of the disk and the cell wall and the vertical cell walls of height $h$, is considered to be an insulater. The 


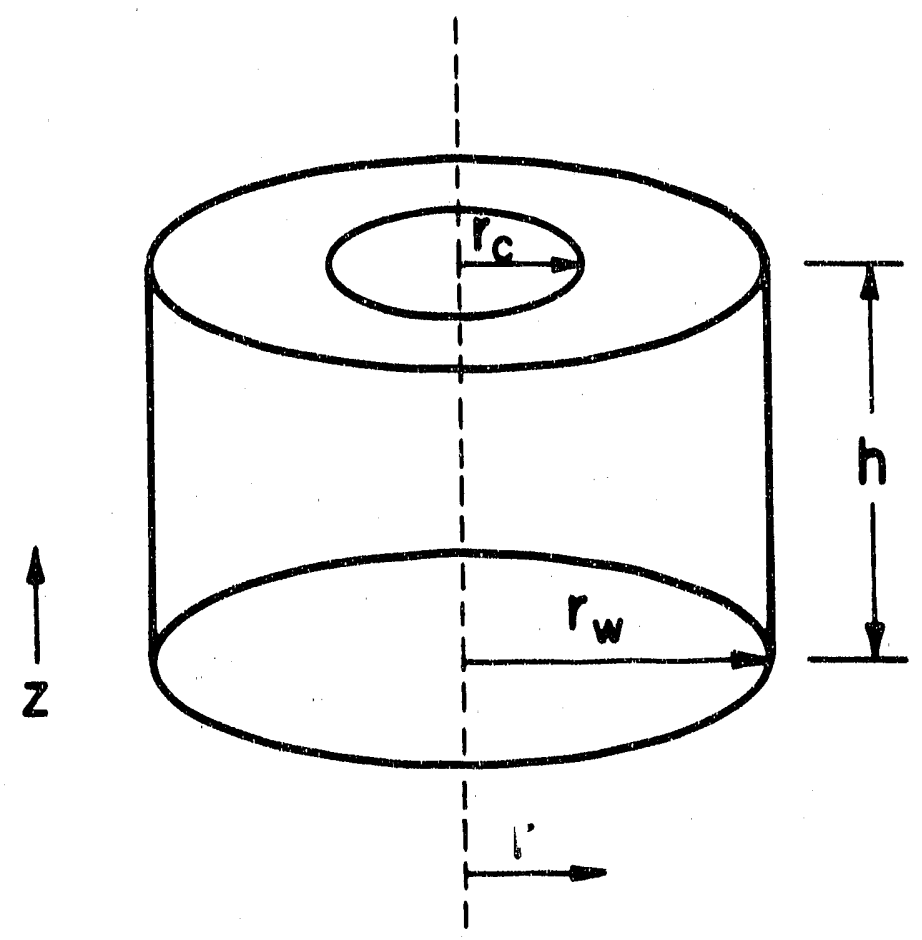

\section{XBL729-4058}

Figure 3-3. Axisymmetric cylindrical cell with disk electrodes. ${ }^{37}$ 
entire bottom plane of the cell is a counterelectrode of radius $r_{\mathrm{c}}$. The basic governing equation to be solved for the primary distribution is Laplace's equation

$$
\nabla^{2} \Phi=0
$$

Since this equation is linear, any solution may be added to any other solution, and the resulting field will satisfy Laplace's equation. Using a separation-of-variables technique to solve equation (3-39) in rotational elliptic coordinates, Newman ${ }^{36}$ derived functions

$$
\Phi_{\mathrm{n}, 0}=P_{2 \mathrm{n}}(\eta) M_{2 \mathrm{n}}(\xi)
$$

where $\eta$ and $\xi$ are related to the coordinate system of Figure $3-4$ by

$$
\begin{gathered}
z=h-r_{\mathrm{d}} \xi \eta \\
r=r_{\mathrm{d}}\left[\left(1+\xi^{2}\right)\left(1-\eta^{2}\right)\right]^{1 / 2} .
\end{gathered}
$$

$P_{2 \mathrm{n}}(\eta)$ are Legendre polynomials, and $M_{2 \mathrm{n}}(\xi)$ are functions which satisfy

$$
\left(1+\xi^{2}\right) \frac{d^{2} M^{2}}{d^{2} \xi^{2}}+2 \xi \frac{d M}{d \xi}-2 n(2 n+1)=0,
$$

with boundary conditions

$$
M=1 \quad \text { at } \quad \xi=0
$$

and

$$
M \rightarrow 0 \quad \text { as } \quad \xi \rightarrow \infty
$$

The functions $\Phi_{\mathrm{n}, 0}$ are well behaved at the centerline and give a zero current density on the insulating plane surrounding the disk electrode. They may be added to meet the boundary conditions on the upper disk and surrounding plane but not those on the insulating cylinder and the counterelectrode. These conditions will be met by defining a sequence of corrections which can be added to the functions of equation $(3-40)$ in the following manner. 


$$
\Phi_{\mathrm{n}}=\sum_{j=0}^{k} \Phi_{\mathrm{n} j}
$$

$k$ indicates the number of corrections in the sequence. The correctior. iunctions indexed by $j$ in equation (346) are required to be solutions to Laplace's equation written in cylindrical coordinates

$$
\frac{1}{r} \frac{\partial}{\partial r}\left(\frac{\partial \Phi}{\partial r}\right)+\frac{\partial^{2} \Phi}{\partial z^{2}}=0
$$

Three types of correction functions bave been developed to satisfy the boundary conditions on the insulating cylinder and the counterelectrode. In brief, the firsi correction function, $\Phi_{\mathrm{n}, 1}$, is chosen to eliminate the current near the bottom comer of the cell where the insulating cylinder is normal to the counterelectrode. Some of the current from the side wall is deflected onto the botton of the cell, without disturbing the current distribution on the top surface of the cell. The remaining normal current through the cell walls is canceled by the second correction function, $\Phi_{\mathrm{n}, 2}$, which has zero potential at the bottom of the cell and zero current density at the top. In other words, the boundary condition of zero curtent density along the cylindrical cell walls is satisfied by the use of the first two correction functions. The third correction function, $\Phi_{\mathrm{n}, 3}$, which must have a zero current density along the sides and top of the cell, was developed carefully so that the potential will be zero on the counterelectrode. So far, all boundary conditions are satisfied except for a uniform potential across the top disk. The final solution is achieved by summing up all the generated correction functions as

$$
\Phi_{\text {total }}=\sum_{l=0}^{m} c_{i} \Phi_{l}(r, z)
$$

where $\Phi /$ 's are evaluated from equation $(3-45)$ with $k=3$. The coefficients $c_{1}$ are found by requiring $\Phi_{\text {toeal }}$ be constant between zero and $r_{\mathrm{d}}$ along the upper disk.

Since the potential distribution has been solved, the total current to the disk is

$$
I_{\text {total }}=-2 \pi \kappa \int_{0}^{r_{d}}\left[\frac{\partial \Phi}{\partial z}\right]_{z \infty} r d r
$$


The primary resistance is

$$
R=\Phi_{\text {total }}(z=h) / I_{\text {total }}
$$

Resistances for a large number of cell configurations were computed and plotted in Figure 3-4 and 3-5, where $R$ is made dimensionless with the resistance of a disk electrode with radius $r_{\mathrm{d}}$ in an infinite cell, $1 / 4 \kappa r_{\mathrm{d}}$. In Figure 3-5, the disk dimensions were held constant and the height of the cylinder was varied. When $r_{\mathrm{d}} / r_{\mathrm{d}}$ is equal to unity, the current distribution is uniform, and the dimensionless resistance can be computed as

$$
4 \times r_{\mathrm{d}} R=\frac{4 h}{r_{\mathrm{d}} \pi}
$$

Equation (3-51) can be arranged as

$$
\kappa R=\frac{h}{r_{\mathrm{d}}^{2} \pi}
$$

One can see that the right term is equal to the cell constant defined by equation (3-2). As the ratio $r_{d} / r_{d}$ increases, the cell appears more like the infinite cell where the dimensionless resistance is equal to unity.

In Figure 3-5, the dimensionless resistance is plotted with cells of constant height and varying disk radius. The shorter cylinders require a much smaller upper disk electrode to approach the infinite-cell resistance.

Therefore, when the values of $h / r_{\mathrm{d}}$ and $r_{\mathrm{c}} / r_{\mathrm{d}}$ are chosen so that the dimensionless resistance in Figure 3-4 or Figure 3-5 is close to unity, the finite cell approaches the infinite cell. For the infinite cell, the cell constant is

$$
\kappa R=\frac{1}{4 r_{\mathrm{d}}}
$$

The decrease of the upper electrode radius can increase the cell constant. Since bigh cell constants are preferred in conductivity measurements of sodium polysulfide melts, very small disk electrodes, called microelectrodes, were used in the experiment. The size of the microelectrode, $r_{d}$, should be chosen 


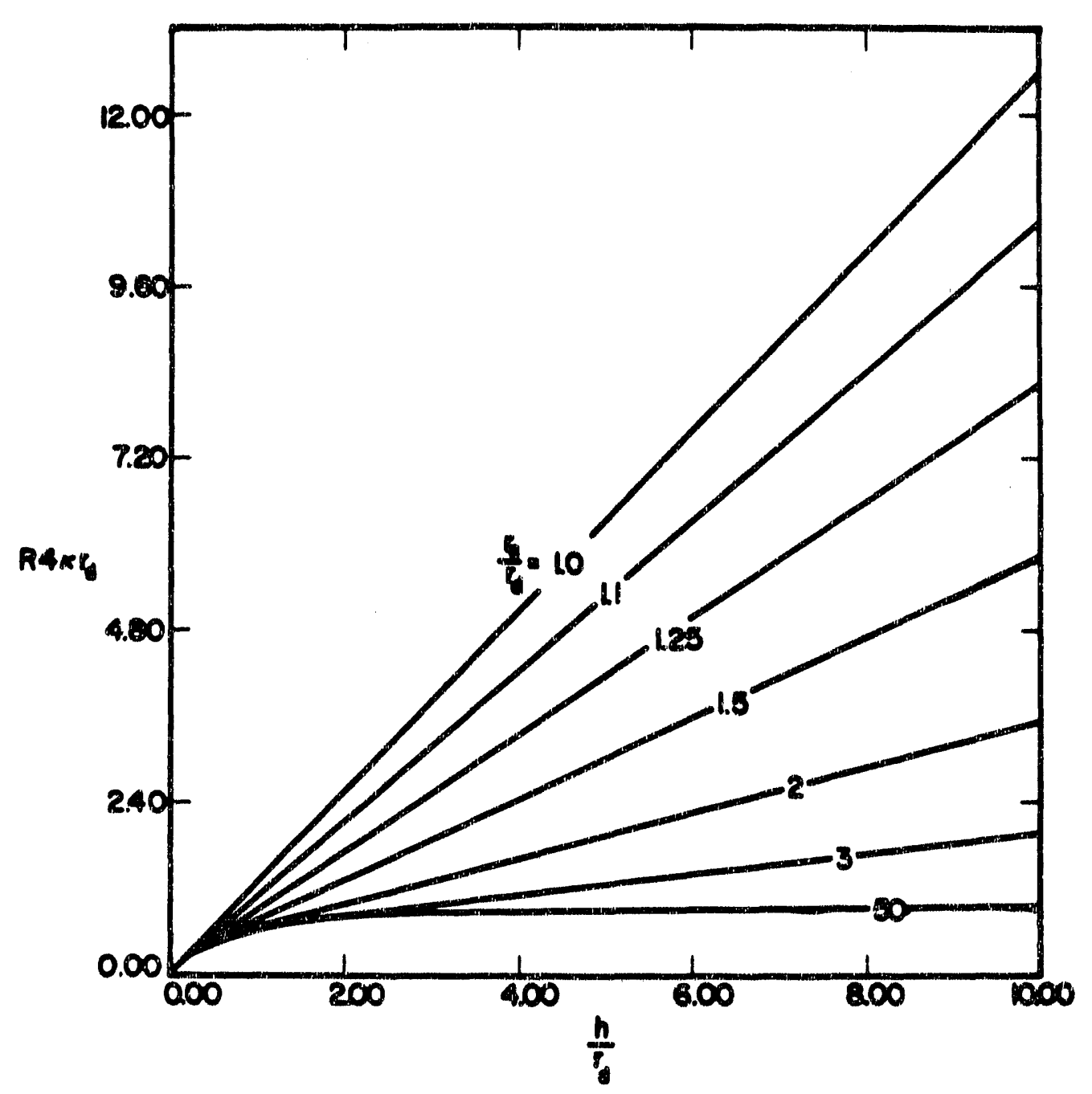

XBL $7812-13751$

Figure 3-4. Resistance of the axisymmetric cell with diameter beld constant. ${ }^{37}$ 


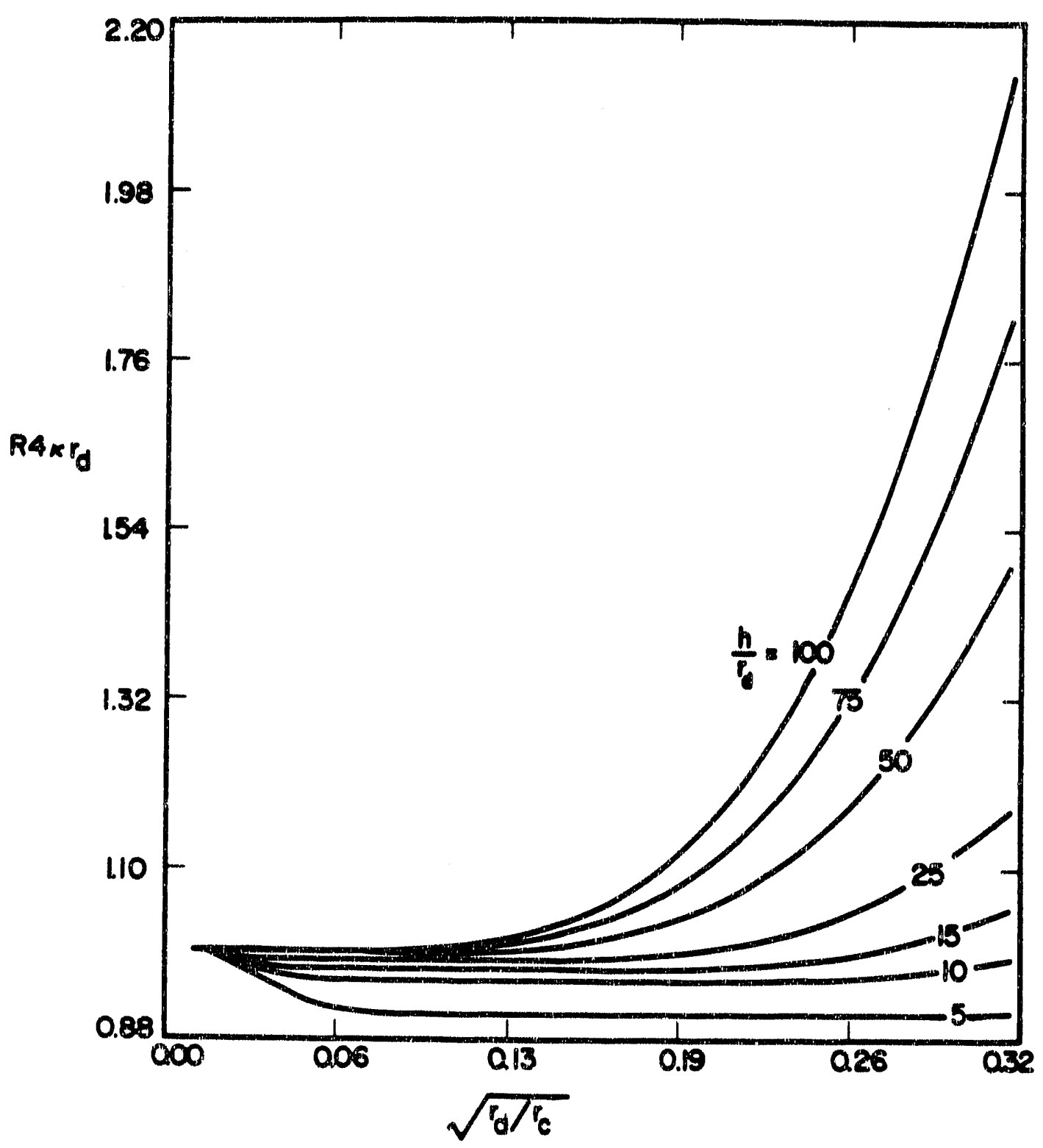

XBL $7812-13750$

Figure 3-5. Resistance of the axisymmetric cell with height held constant. ${ }^{37}$ 
properly so that its fabrication is feasible and the size of the cell which approaches the infinite cell is reasonable. 


\section{Chapter 4. Experimental Determination of Electrical Conductivity}

\subsection{Introduction:}

The requirernents for precise measurement of electrolytic conductivity may be summed up as (1) avoidance of electrode effects at the electrodes, (2) accuracy in the electrical measurements themselves. and (3) accurate temperature control and measurement. ${ }^{13}$

The measurement equipment of electrical resistance, the temperature controller and the temperature measurement devices used in the conductivity experiments will be introduced in section 4.2 . During the experiments, the temperature of the conductance cell was controlled to steady state by the temperature controller and was measured by the temperature measurement equipnent. Based on the conductivity data of Cleaver and Davies, the majority of sodium polysulfide melts have a temperature coefficient of conductivity close to 2 per cent per degree at $300{ }^{\circ} \mathrm{C}$. For instance, if an accuracy of 0.5 per cent is sought, the temperature should therefore be controlled to $\pm 0.25^{\circ} \mathrm{C}$. For accurate temperature control, the conductance cell was enclosed by a brass block with a large heat capacity so that temperature fluctuation of the cell around the steady state was minimized. The temperature measurement equipment and the electrical measurement equipment were calibrated for accurate temperature and electrical measurements. The accuracy of calibrated equipment will be discussed in the experimental procedure section.

Electrode effects are usually minimized by the use of audio frequency alternating current for the measurements. In general, the measured resistance approaches the true ohmic resistance of the electrolyte as the frequency of the alternating current increases. However, at radio frequencies, the Falkenhagen effect, associated with the relaxation of the ionic atmospheres, becomes appreciable, and the true ohmic resistance of the electrolyte becomes dependent of frequency. On the other band, the electrical measurements of the alternating current bridge used in the conductivity experiments of sodium polysulfide melts have better accuracy at lower frequencies. Therefore, as regards the first and the third requirements for precise measurement stated in the first paragraph, the frequency of the alternating current was chosen carefully so 
that the combined measurement errors from both the electrode effects and the electrical measurements were the minimum.

Furthermore, the design of conductance cells for the electrical conductivity measurements of sodium polysulfide melts affects for the accuracy of the conductivity measurements. For highly conductive electrolyte, high cell constants are often used to minimize the significance of the electrode effects. Chpillary cells are often used in the conductivity experiments. However, they were not used in the conductivity experiments of sodium polysulfides because gas bubbles were often trapped in capillary. The diffusion cell designed by Thompson were first modified and then applied in the conductivity experiments. However, the modified cell design was not capable to prevent the leakage of sulfur vapor from cells, and the cell constant of the modified cell could be too small for accurate electrical merasurement. The final conductance cell design was based on the calculation results shown in section 3-5. The high cell constant, no gas bubbles, and no sulfur vapor leakage are the features of this final cell.

\subsection{Experimental Equipment}

The central part of the equipment is the conductance cell. Due to the hydroscopic property of sodium polysulfides, all of the experiments regarding chemical handling were perforned within an inertatmosphere glove box. A combination of electronic equipment measured temperature and electrical resistance of conductance cells and recorded the measurements periodically and automatically.

\section{Cell Design 1}

First, the diffusion cell and the method of filling the diffusion cell designed by Thompson were basically applied in the experiments of electrical-conductivity measurement, since good diffusion coefficient data were obtained using these experimental designs. However void spaces inside the cell caused uncertainty in the cell constant. Thus a few modifications were made on the diffusion-cell design.

Figure 4-1 shows a schematic of the modified apparatus inside a brass block. In brief, the cell was simply a $1 \mathrm{~cm}$ tall quartz disk, with a $3.76 \mathrm{~mm}$ hole bored through the center, sandwiched between a 5.6 $\mathrm{mm}$ thick molybdenum electrode on bottom and an alumina insulator on top. The insulator consists of two 


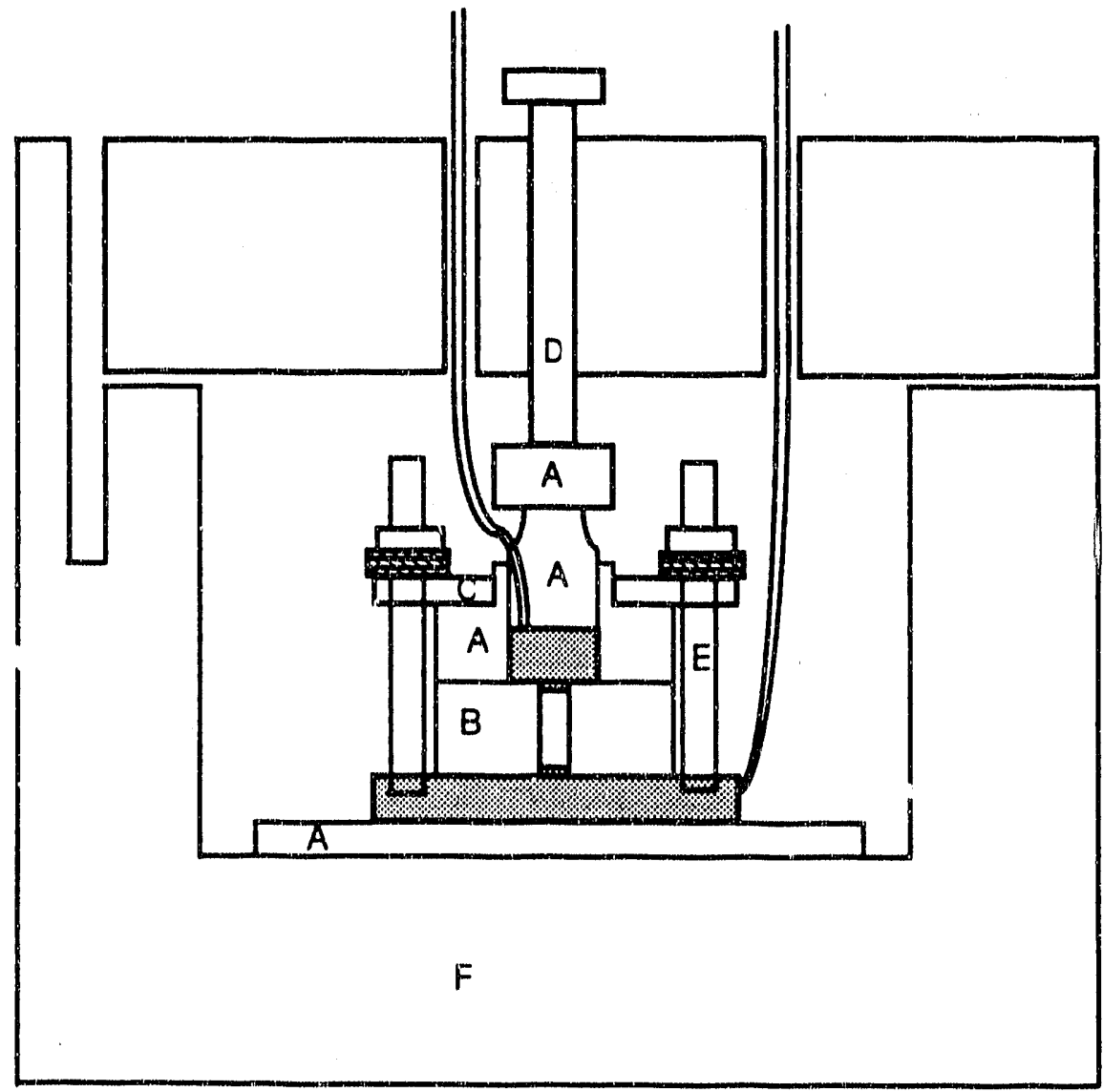

$12 \mathrm{~cm}-1$

A: Alumina insulator

B: Quartz disk

C: Stainless steel plate

D: Fully threaded staintless steel screw

E: Threaded molybdenum rod

F: Brass block

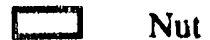

Metal spring

Figure 4-1. Sketch of the disk cell, including the brass block enclosing the cell. 
sections with $2.54 \mathrm{~cm}$ od and $1.27 \mathrm{~cm}$ od and a $9.53 \mathrm{~mm}$ hole was bored through its center. A $5.1 \mathrm{~mm}$ thick molybdenum electrode fits into the hole and sits upon the quartz disk. A molybdenum electrode was chosen since its sulfide coating is electronically conducting and provides some corrosion resistance. Quartz was chosen as the body of the cell since it is electrically insulating and inert in molten sodium polysulfides in the temperature range $573 \mathrm{~K}$ to $633 \mathrm{~K}$.

A $3.18 \mathrm{~mm}$ thick stainless steel disk with a $1.27 \mathrm{~cm}$ hole bored through its center was seated on the lower section of the top insulator. Four threaded molybdenum rods passed through four holes on the stainless steel plate and were screwed into the bottom electrode. The nuts on the rods were screwed downward to push the plate down and squeeze the quartz disk, the top insulator, and the bottom electrode together. The metal springs purchased from Nor-Cal Supply Co. were used between the nuts and the plate to compensate for the thermal expansion difference between parts so that the strength of squeezing was maintained during heating processes. To insure tight seals between the quartz cell and molybdenum electrodes, the touching quartz and molybdenum surfaces were highly polished, and pure aluminum gaskets were placed between them. The bottom electrode was machined to extend approximately $0.76 \mathrm{~mm}$ into the cell hole in order to hold the quartz disk and the aluminum gasket in place. The cell was placed in a brass block for uniform temperature distribution across the cell and was electrically insulated on top and bottom from the brass block by two alumina insulators. To eliminate lead resistance from the measured resistance, the four-lead method was used. Each electrode was attached to a Nextel 312 ceramic fiber insulated thermocouple wire purchased from OMEGA. Each thermocouple wire had two sub-wires inside, and each sub-wire had its own ceramic fiber sleeving.

The hole of the disk cell was filled with a prepared polysulfide slug at room temperature. Because the slug did not fit the hole perfectly, void spaces existed in the hole. The bolt capped with an insulator as shown in the diagram was used to push the top insulator and electrode downward after the slug melted and the gas in void spaces ascended to the top of the melt. The top electrode extended into the hole by $0.76 \mathrm{~mm}$ to chase gas out of the bole, so the hole was filled completely by melt. During the heating process, the bolt was further tightened to account for the thermal expansion of the apparatus and insure tight seals between the quartz disk and electrodes. 
Since no melt leaked from the bottom of the quartz disk, the metal springs on the molybdenum rods were mechanically strong enough to insure tight seals between the quartz disk and two electrodes. However, sulfur vapor leakage from the hole could not be prevented no matter how strongly the top electrode was squeezed downward by the bolt. The melts in the cell apparently diminished after the experiments. A new cell design was needed.

\section{Cell, Design II}

A glass cell was designed to prevent the leakage of sulfur vapor. A diagram of the glass cell used in this experiment is shown in Figure 4-2, and its photographs are shown in Figure 4-3.

The horizontal cylindrical chamber on the bottom is the conductance cell, which resembles to the design shown in Figure 3-3. The length of the cell and the diameters of two disks were determined using Figure 3-5 so that the conductance cell approaches the infinite cell. The conductance cell was basically walled by a $1.27 \mathrm{~cm}$ long, $2.24 \mathrm{~cm}$ id medium-wall glass tube and two $3.18 \mathrm{~mm}$ thick glass disks sealed at the two ends of the tuhe. The microelectrode located at the center of one glass disk was the cross section of $0.127 \mathrm{~mm}$ platinum wire. The platinum wise passed through a small glass rod extending out of the cell at the center of the disk. The inside disk surface, with the platinum cross section, was polished by silicon carbide until the platinum microdisks were seen round and flat under the microscope. Two microscopic photographs of a platinum microelectrode are shown in Figure 4-4. The other glass disk was covered by a $0.076 \mathrm{~mm}$ thick round platinum foil with a diameter of $2.24 \mathrm{~cm}$. This round foil served as a counterelectrode and is spot-welded to a $0.127 \mathrm{~mm}$ platinum wire passing through a small glass rod on the back of the disk. The top cylindrical chamber is a reservoir of polysulfides melts and communicates with the conductance ceil through a $7 \mathrm{~mm}$ o.d. regular-wall glass tube between them. The $9 \mathrm{~mm}$ o.d. regular-wall glass tube, on the top of the reservoir chamber, was to be connected to the vacuum line in the glove box after the chemical-mixture powder was placed inside the glass cell.

The bottom chamber, as a conductance cell, was operated inside a brass block to reduce temperature variation across the cell, but the top chamber was not enclosed by the block. At the temperature of over 573 $\mathrm{K}$, all of the chemicals in the reservoir chamber descended into the bottom chamber. 


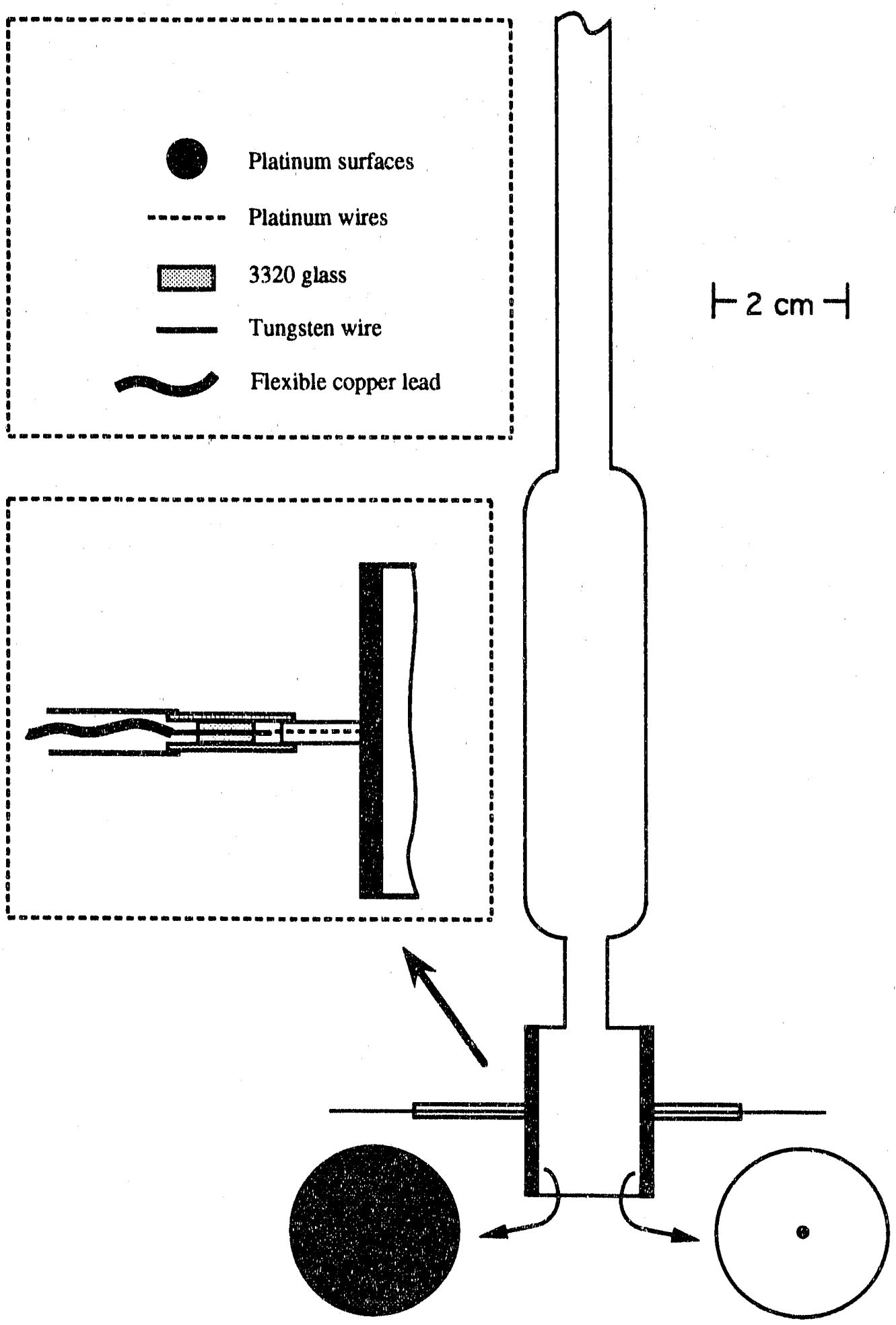

Figure 4-2. Sketch of the glass cell. 


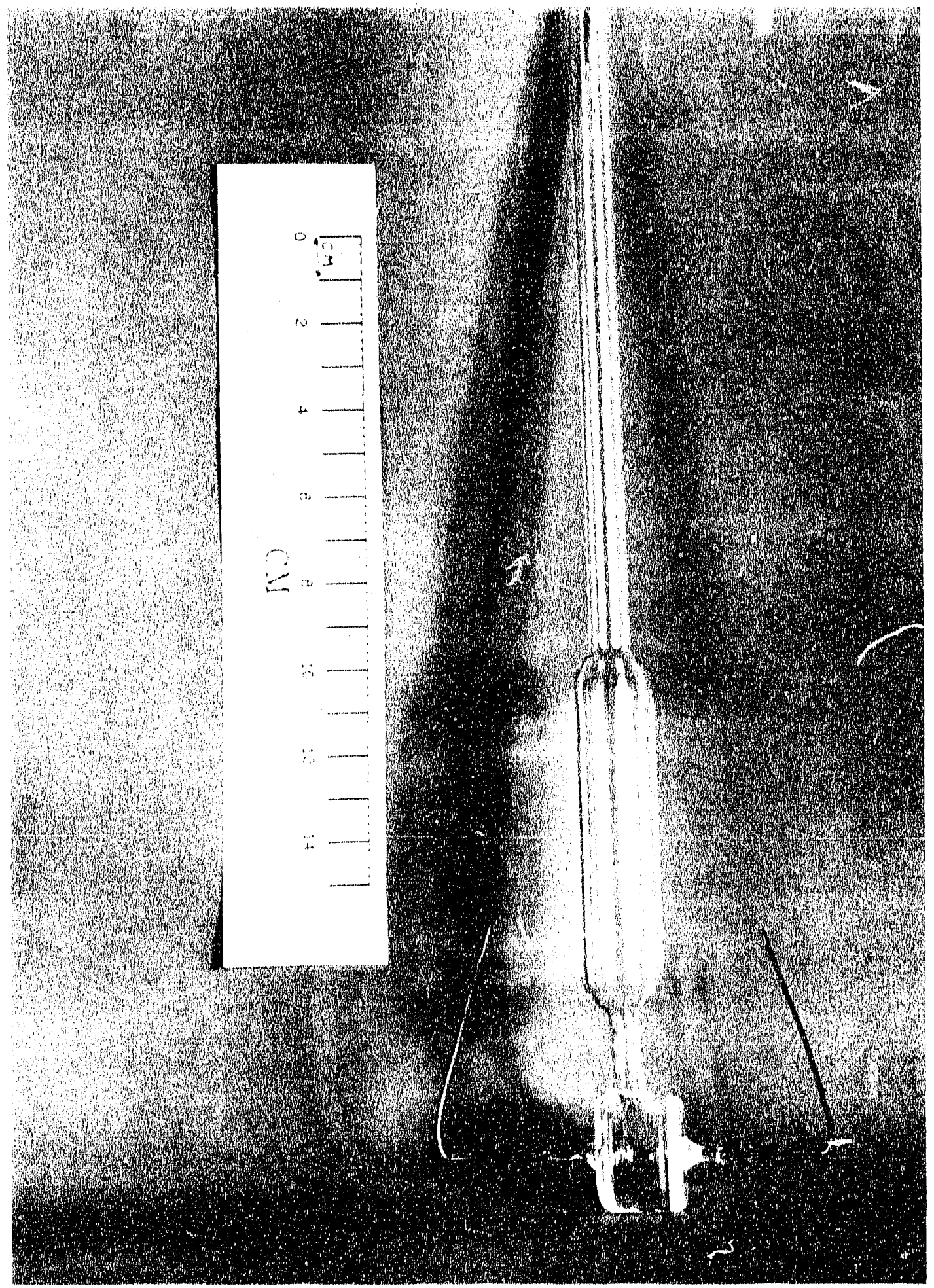

(a)

Figure 4.3. Photographs of the glass cell. (a) shows the entire glass cell. (b) and (c) are the views from the two disk--sides of the bottom chamber. 


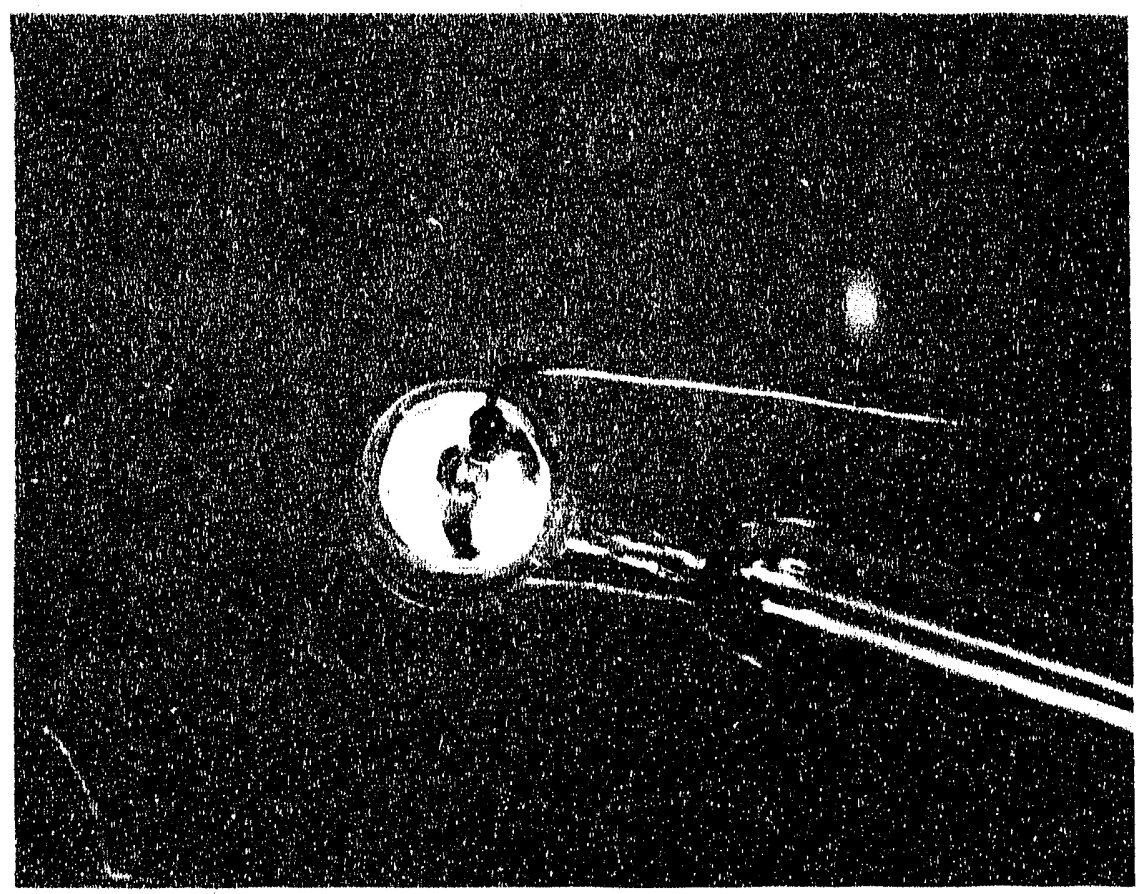

(b)

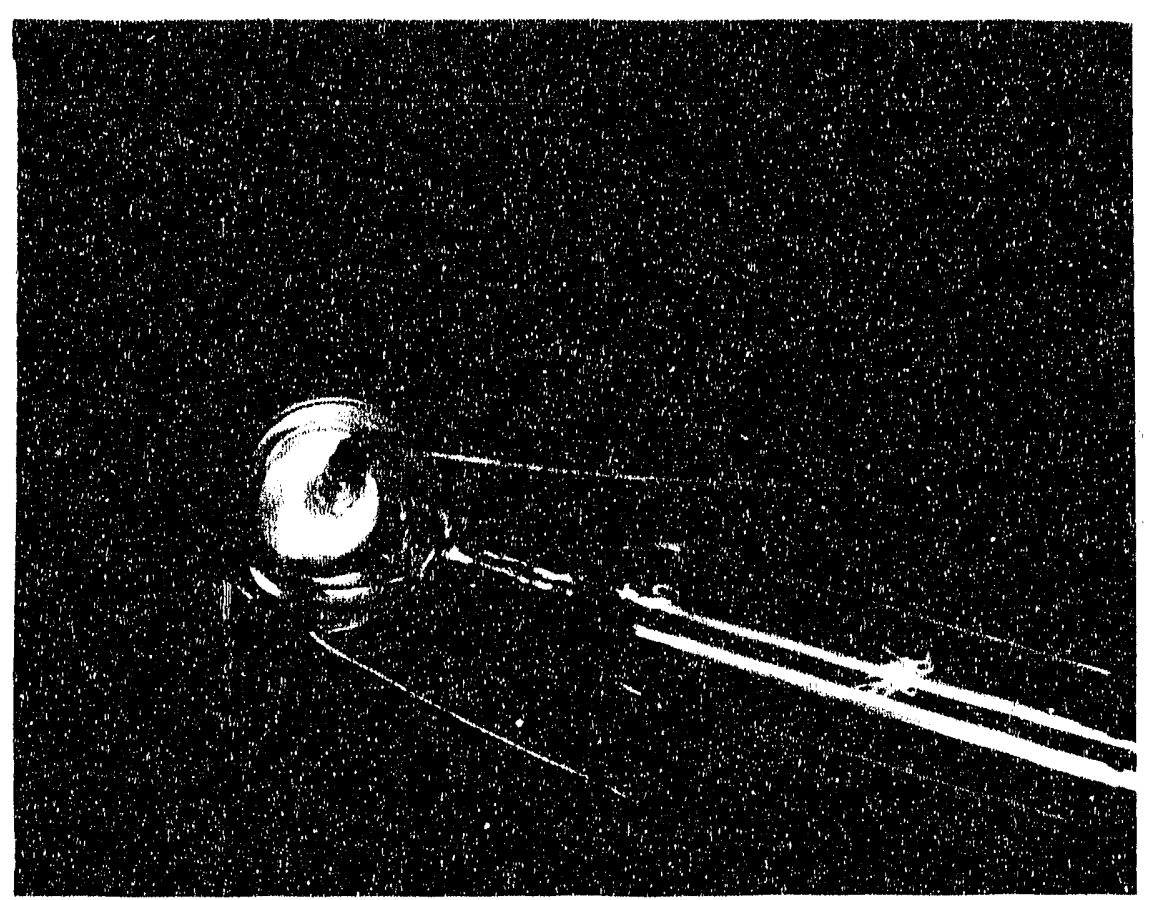

(c) 


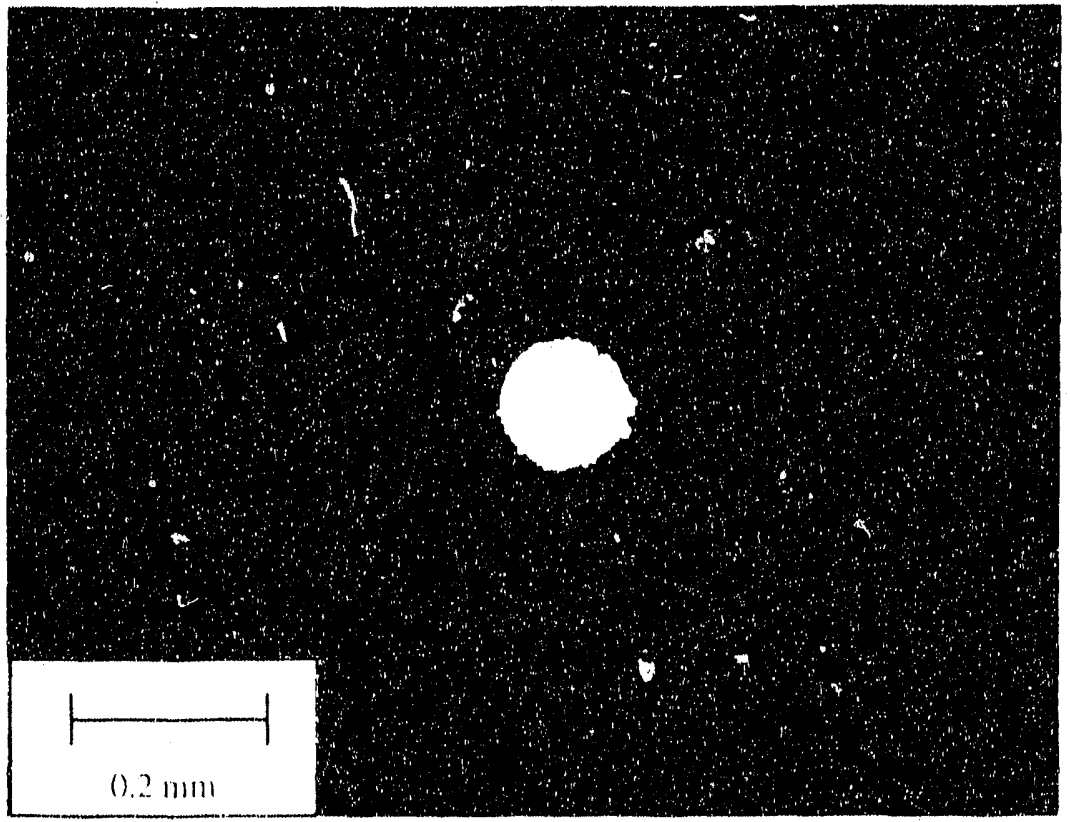

(a)

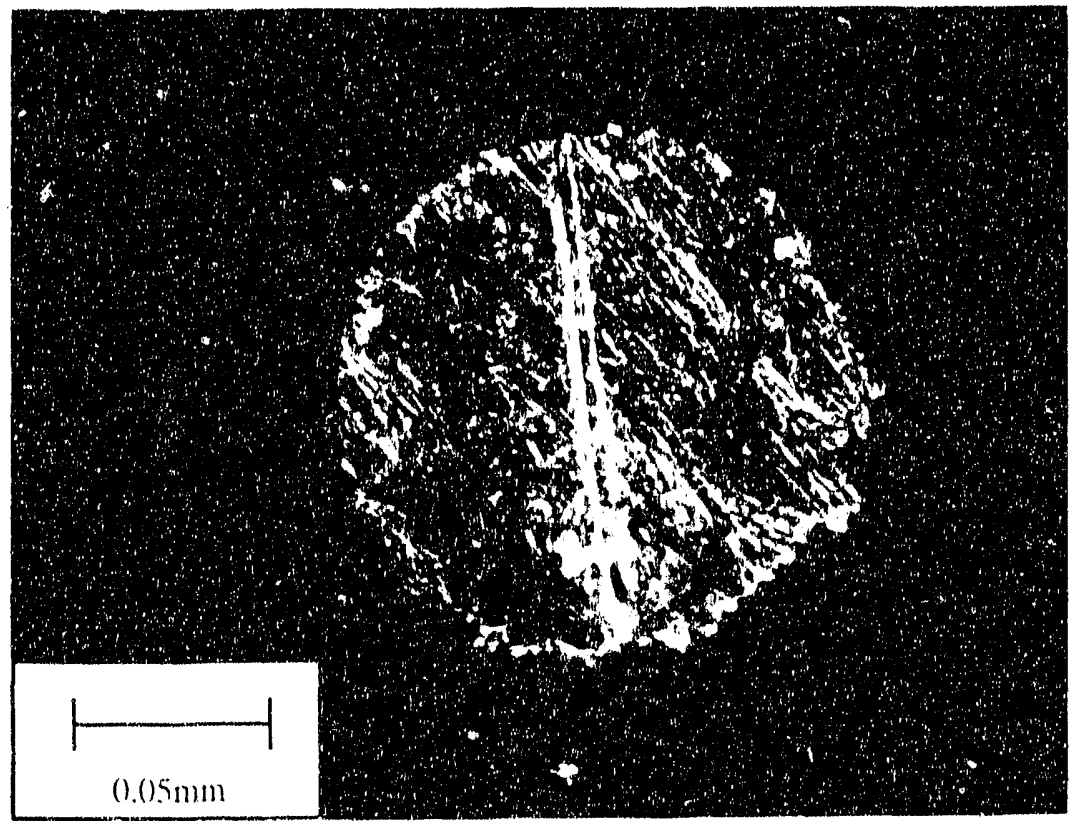

(b)

Figure 4-4. Microscopic photographs of a platinum microelectrode. (a) $1(x) \times$ magnification (b) $400 \times$ magnification. 
0.127 mun platinum wires are very fragile, so they were connected to the external equipment in a special way. As shown in Figure 4-2, the platinum wire was spot welded to a $0.89 \mathrm{~mm}$ tungsten wire within a 3320 glass tube attached behind the glass rod. The tungsten wire passed through a 3320 glisss slug sealed inside the 3320 glass tube and was connected to a flexible copper lead. Consequently the platinum ware was completely isolated from any external stress. 3320 glass was used because the thermal expansion coefficient of it is close to that of the tungsten wire. Each flexible lead was twisted with a thermocouple wire, which went out of the furnace well and was electrically connected to the VideoBridge.

\section{Glove Box and Furnace Well}

The glove box used for this experiment is a Dri-Lab model DL 002-D-P He- Atmosphere box manufactured by Vacuum Atmosphere Company (VAC). A photograph of the glove box and its surrounding equipment is shown in Figure 4-5. The glove box contains four w'ork stations, a single vacuum/transfer chamber, and two fumace wells installed in the bottom of the glove box. To prevent the leakage of air into the glove box, the pressure in the box was kept at a positive pressure of $250 \mathrm{~N} / \mathrm{m}^{2}$ using VAC Pedatrol and Safe-Trol pressure control systems. The purifying equipment includes a VAC MO 40-2 Dri-train for oxygen and water removal and a VAC Ni-20 Ni train for nitrogen removal. The He-atmosphere inside the box was continuously circulated through VAC MO 40-2 Dri-train by an electric blower; therefore the oxygen and water levels inside the box were kept low. Monitoring of the oxygen level was performed continuously by a trace oxygen analyzer model FA31110SA manufactured by Delta F Co. The oxygen level was normally below $0.5 \mathrm{ppm}$. The water content was measured periodically by a System 580 Hygrometer manufactured by Panametrics Inc. The water concentration was kept lower than $1 \mathrm{ppm}$.

The furnace wells were mainly surrounded by Applied Test Systems Inc. \#2961 Split Test furnaces. Figure 4-6 shows the dimensions of the furnace, the furnace well, and the equipment inside the well used in the experiments. The bottom one third of the furnace wells were placed in the center of the furnace where the temperature profiles were the flattest. The upper one third of the fumace wells, not surrourded by the furnaces, were water cooled to help maintain the glove box at a comfortable temperature, 


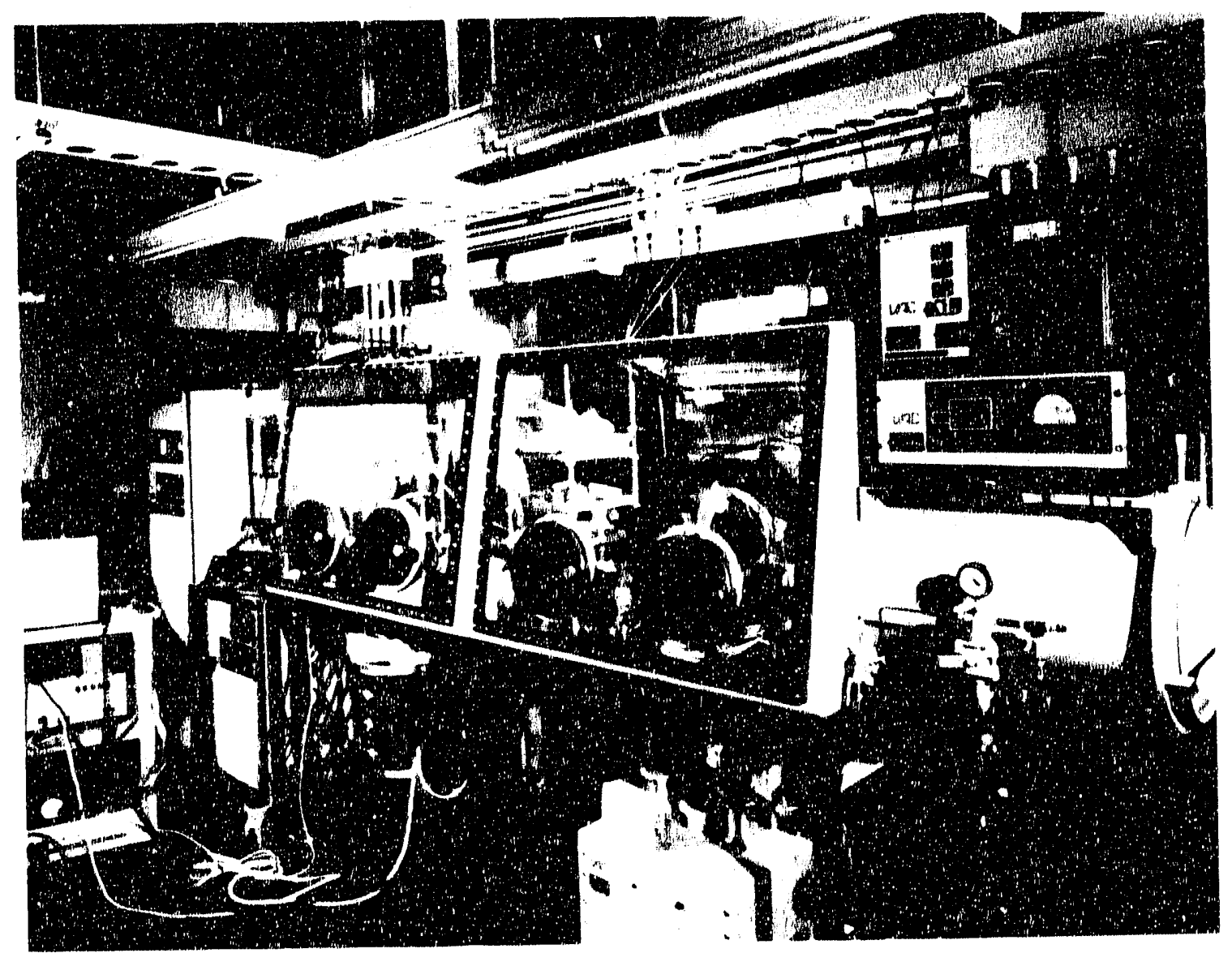

Figure 4-5. Photograph of the glove box and purifying equipment. 


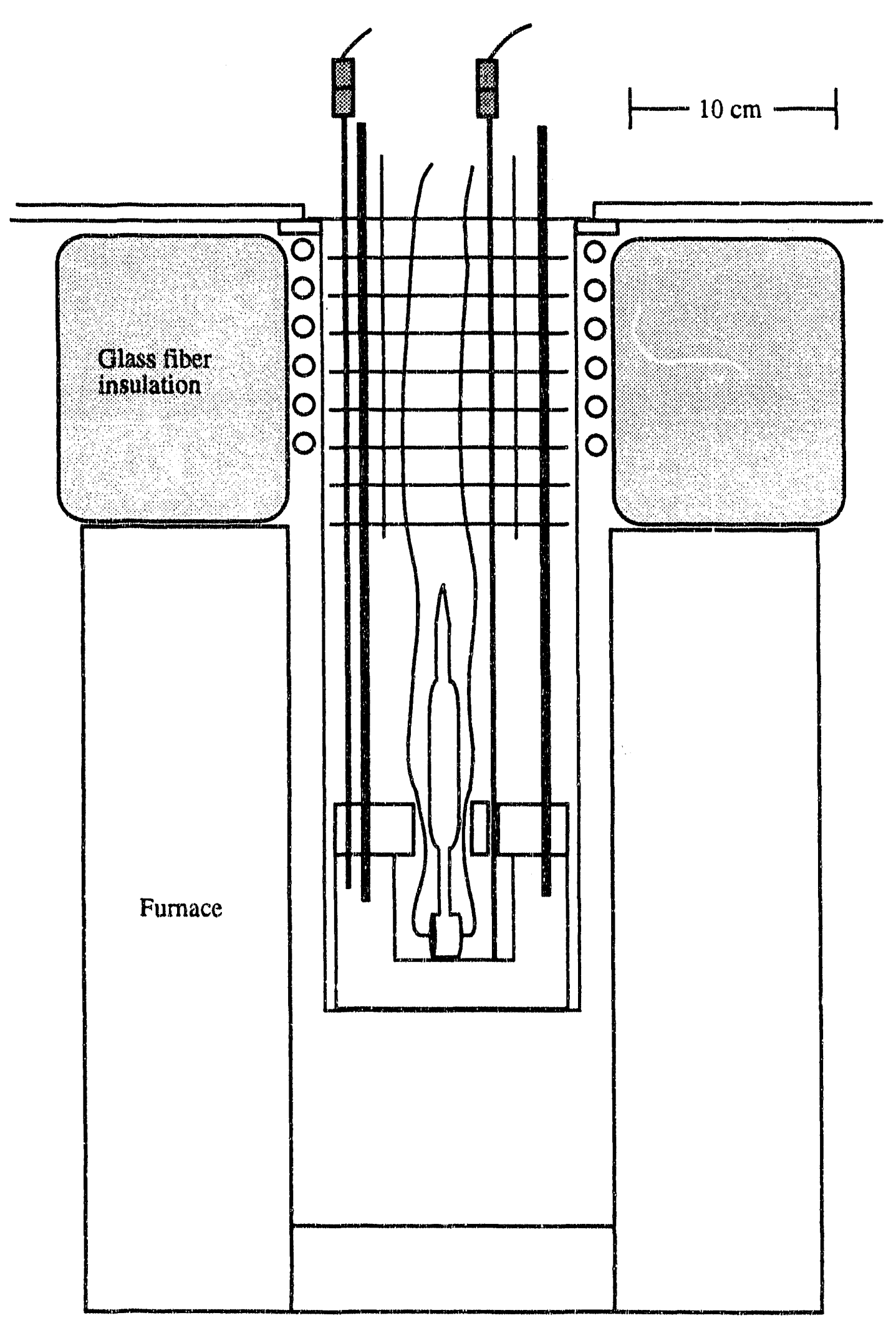

60 
protect the gaskets between the furnace wells and the glove box, and condense the sulfur vapor accidentally leaking from the cell. To block the upward heat convection from the gap between the furnace and the well, glass fiber insulation, normally used for construction, was used to cover the top of the gap. The brass block enclosing the conductance cell was lowered into the furnace well by using two stainless steal rods screwed on the top of the block. Aluminum heat shields were suspended from the top of the well to reduce the free convection of heat. For cell design $I$, an extension bar is necessary for a ratchet wrench outside of the furnace well to tighten the bolt on the block inside of the well. Holes were cut through the shields for thermocouple probes, wires, rods, and the extension bar to pass through. The temperature of the furnaces was controlled by model number 61010 Panel Packer controllers manufactured by Research Incorporated.

\section{Electronic Equipment}

The controlling center of the experiments is a personal computer manufactured by IBM. PC communicated with peripheral equipment using a few interfaces. The experiments were directed by a controlling program written in BASIC language. The controlling program was designed to change the temperature set point of the furnace controller and record the temperature and resistance measurements transmitted from the measurement devices periodically during the experiments. The electronic components and the interconnecung wires Le shown schematically in Figure 4-7, which will be explained in details in the following paragraphs.

The impedance across the conductance cell was measured by Model 2100 VideoBridge manufactured by Electro Scientific Industries, Inc. in 1981 . This unit is basically composed of a frequency selectable, digital sinewave generator, a test-level regulator, precision range resistors, a phase-sensitive voltmeter, and a charge balancing analog-to-digital converter. The level regulator's sinewave output is imposed across both the device under rest and a selected precision, standard range resistor. The resulting voltage-drops are measured in both phase and amplitude by the phase-sensitive voltmeter. These voltages are serially processed by the A/D converter with resistance and reactance, computed by the $\mathrm{Z} 80 \mathrm{CPU}$ in this unit. 'The accuracy of measurement depends on the test level, the test frequency, and the impedance magnitude of the device under test. In general, the measurements obtained using bigher currents (or potentials) and lower frequencies have betuer accuracy. 


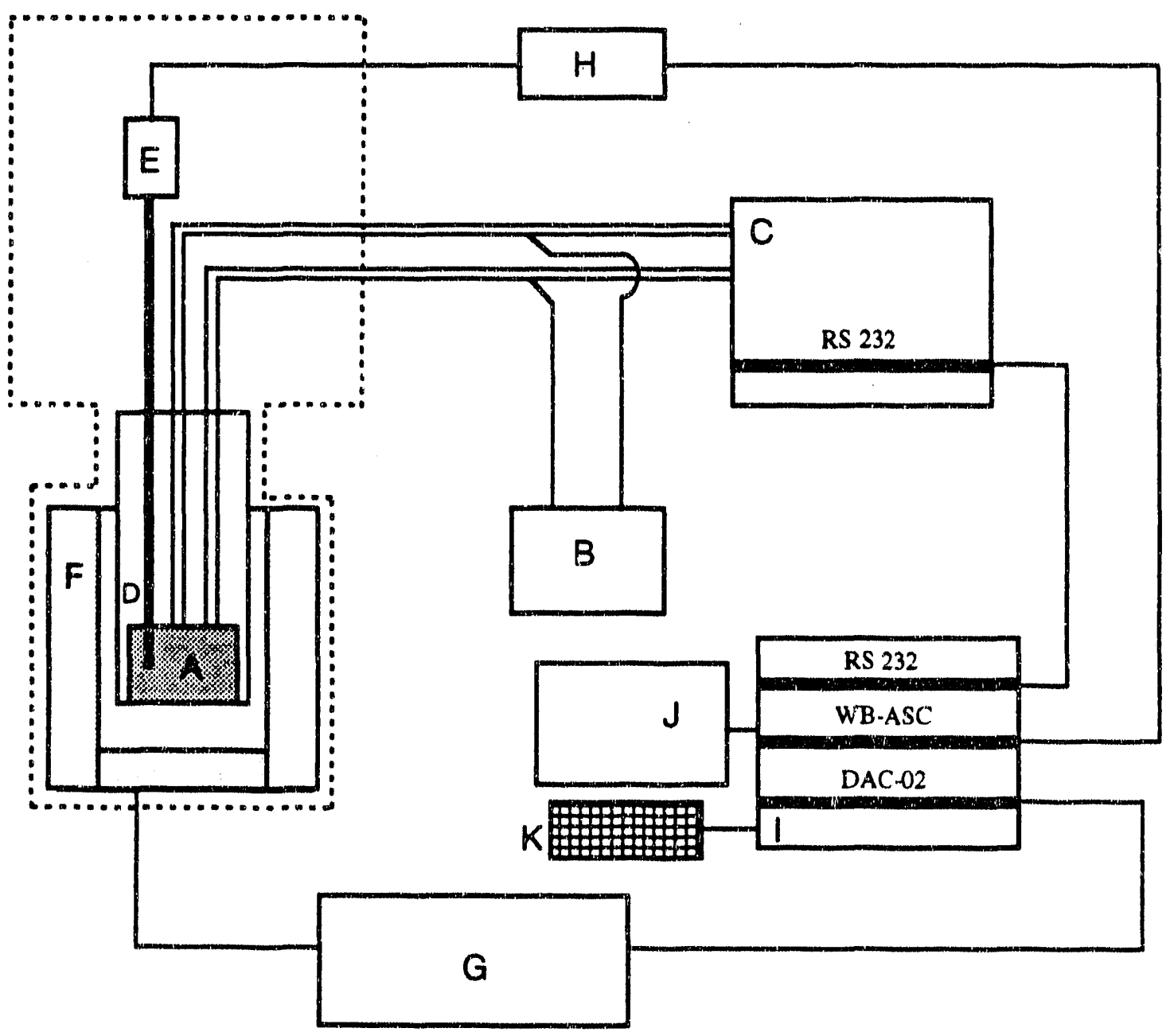
A: Brass block
B: Multimeter, Keithly 173A
C: VideoBridge, ESI 2100
D: Furnace well
E: E type thermocouple, OMAGA
F: Spill Test Furnace, Applied Test System inc. $\$ 2961$
G: Panel Packer Controller, Research Incorporated 61010
$H$ : T11 terminal panel, OMAGA
I: IBM PC
$\mathrm{J}$ : Monitor
K: Keyboard

Dashed line represents the glove box boundary.

Figure 4-7. Schematic diagram of the electronic equipment. Dashed line represented the glove box boundary. 
The RS 232 interface installed in the VideoBridge was to interface it to the PC. Since this interface purchased in 1990 was not compatible with the old software in the VideoBridge made in 1981, the VideoBridge was upgraded to the latest specifications before the installation of the new RS 232 interface. This interface was connected to another RS 232 in the IBM PC. Through this connection, the controlling program in the PC was able to command the VideoBridge to make measurements and send the measurement results back to the PC for storage.

To measure the resistance of the conductance cell at different temperatures between $573 \mathrm{~K}$ and 633 $\mathrm{K}$, the temperature inside the furnace had to be adjusted a few times during the experiment of one cell. The temperature controller of the furnace, Model number 61010 Panel Packer Controller, controlled the temperature of only one of the heating coils embedded in the refractory bricks of the furnace. The power supplies of the other two beating coil can be adjusted individually from 0 to $100 \%$ based on the power supply to the controlled heating coil. Due to the air gap existing between the furnace well and the furnace and the low thermal conductivity of the refractory bricks, it takes a few hours for the temperature inside the furnace well to respond completely to the temperature changes of the heating coils and stabilize. Therefore, in order to trace the experiments continuously for hours or days, the experiments needed to be operated automatically. The controlling program controlled the temperature set point of the temperature controller by the use of the DAC-02 interface in the PC. The DAC- 02 Interface is manufactured by MetraByte corporation. The wire connections between the DAC-02 and the temperature controller were arranged so that the VDC signal output by the DAC-02 interface was the remote set point signal for the temperature controller. The VDC signal ranging from 0 to $5 \mathrm{~V}$ is proportional to the temperature set point ranging from $273 \mathrm{~K}$ 10 $1273 \mathrm{~K}$.

For the temperature range of $573 \mathrm{~K}$ to $633 \mathrm{~K}$, E type thermocouples are the mcst stable among all types of thermocouples. Additionally, they have the highest EMF change per degree so their limits of error are the smallest. Therefore two quick-disconnect $\mathrm{E}$ type thermocouple probes were used to measure the temperatures of the brass block and inside the block, where the conductance cell was located.

The E type thermocouples were connected to the T11 terminal panel, which has built-in-cold. junction compensation for thermocouples. The cable of the TI1 terminal panel plugged into the edge of the 
WB-ASC interface card at the back of the computer. The WB-ASC interlace card, manufactured by OMEGA Engineering, Inc., transformed EMF's from thermocouples to temperatures and then transmitted temperatures to the controlling program for storage.

The controlling program called the WB-ASC interface for temperature measurements and the RS 232 interface for resistance measurements simultaneously and periodically. These measurements were saved versus time in temperature-data files and resistance-data files, respectively.

To check whether a concentration or temperature gradient exists across the conductance cell during operation, the open-circuit potential of the conductance cell was measured with a Keithly $173 \mathrm{~A}$ multimeter during some of the intermissions of the resistance measurements.

\subsection{Experimental Procedure}

\section{Chemical}

Sodium polysulfides were prepared from sulfur and sooium sulfide. A lot of anhydrous sodium sulfide and two lots of sulfur were purchased from Alfa Products Division of Johnson Matuhey Catalog Co. Anhydrous sodium sulfide was supplied as flakes and could contain 1 to 3 wt \% water based on the analysis information of the manufacturer. Two lots of sulfur were sublimed sulfur powder and grade $6 \mathrm{~N}$ sulfur pieces. On the other hand, anhydrous sodium sulfide of grade $4 \mathrm{~N}$ was purchased from the Noah Chemical Div. of Noah Industrial Corp. The chemical was supplied as 100 mesh powder.

The $0.1 \mathrm{~N}$ potassium chloride reference solution used tc calibrate conductance cells was purchased from Anderson Laboratories Inc. The solution contained 7.4365 gram of potassium chloride per cubic centimeter of water at $20^{\circ} \mathrm{C}$.

\section{Preparation of Sodium Polysulfides}

Sodium polysulfides were prepared from anhydrous sodium sulfide and sulfur by the procedure suggested by Fosen and Tegman ${ }^{38}$. Stochiometric amounts of :odium sulfide and sulfur were weighted on a Scientech multifunctional electronic balance to within $0.001 \mathrm{~g}$ and ground together carefully using a mortar and pestle. 
The mixture was subjected to a series of heat treatments in an evacuated sealed pyrex tube to form a polysulfide slug for the disk cell. In detail, the pyrex reaction tube had two sections. The upper section of $9 \mathrm{~mm}$ o.d. was to fit onto the vacuum line installed on the glove box, and the lower section of $3.73 \mathrm{~mm}$ id was to shape polysulfides as a cylinder fitting into the cell hole on the quartz disk. Using the Nic-chrome heating coil in the glove box, the tube was sealed under 0.3 bar vacuum after the mixture was placed in the tubes using a pyrex funnel. The funnel prevented sulfur from sticking on the pyrex wall since the sulfur would react with pyrex at high temperature and cause it to crack instead of soften and seal. Due to the high sulfur vapor pressure in the tube and the risk. of explosion, the mixture was first reacted at 200 to $230{ }^{\circ} \mathrm{C}$ for 12 hours. To ensure a complete conversion, the temperature was then increased to $380^{\circ} \mathrm{C}$ for 24 bours so that a homogeneous melt was obtained. Finally, the melt was cooled down slowly to form a crystalline polysulfide product on the bottom of the tube. The tube had to be cracked carefully so that the cylindrical product could be removed from it without being smashed. However, polysulfide products were often broken into a few slugs with different lengths. Slugs as long as the cell hole on the disk were selected to fill the cell bole.

For the glass-cell design with a microelectrode, the mixture of sodium sulfide and sulfur was filled into the glass cell directly. Its quantity, about 8 to 9 grams, was determined on the basis of the volume of the conductance cell and the density data of sodium polysulfide melts. ${ }^{22}$ Similarly, the $9 \mathrm{~mm}$ o.d. tube on the top of the glass cell was connected to the vacuum line and sealed under 0.3 atm vacuum using the Niccrome heating coil. Figure 4-8 shows a photograph of the sealed glass cell filled with the chemical mixture. The conductance cell was enclosed by the brass block and then the apparatus shown in the furnace well of Figure 4-5 was assembled and lowered into the well. The mixture was first reacted at 200 to $230^{\circ} \mathrm{C}$ for 12 bours and then $380^{\circ} \mathrm{C}$ for 24 hour. At this step, the homogeneous melt in the conductance cell was ready for the conductivity measurements. Therefore, the conductivity measurements followed the heat treatment of $380^{\circ} \mathrm{C}$ immediately without the cooling procedure used in the preparation of polysulfide slugs. Due to the difficuity of cleaning the polysulfides inside the cells after the conductivity experiments, cells were not reused, and each experiment started with a new glass cell. 


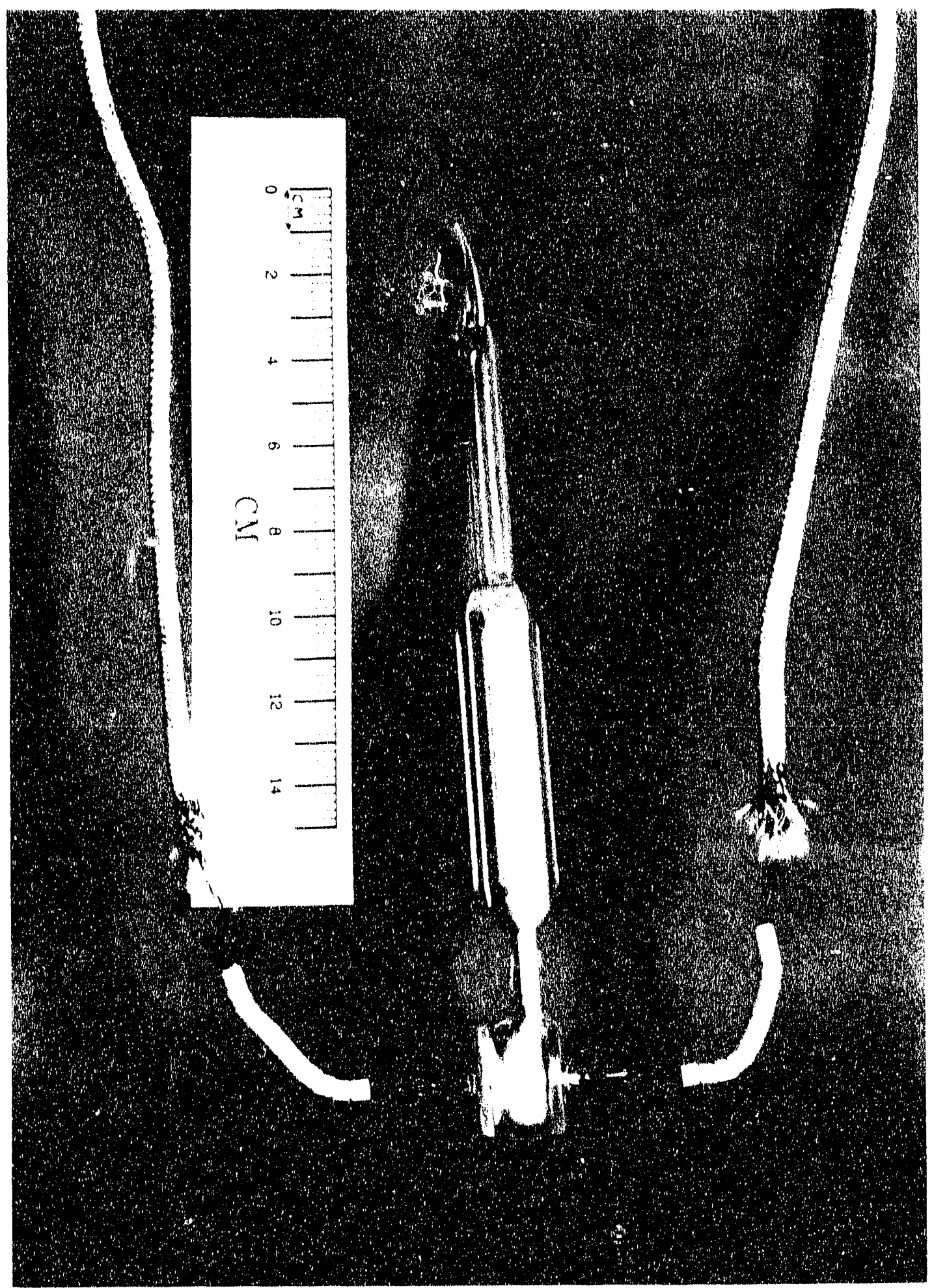

Figure 4-8. Photograph of the sealed glass cell before the heat treatments. 
Unfortunately, the mixtures of grade $6 \mathrm{~N}$ sulfur and grade $4 \mathrm{~N}$ sodium sulfide were not reacted completely even though the temperature of the second heat treatment was increased from 380 to $450^{\circ} \mathrm{C}$ and the treatment period increased from 24 hours to 3 days. Moreover, no homogeneous sodium polysulfides were obtained from the mixtures of the sublimed sulfur and grade $4 \mathrm{~N}$ sodium sulfide or the mixtures of grade $6 \mathrm{~N}$ sulfur and the anhydrous sodium sulfide from Alfa. Therefore, the sodium polysulfides used in the conductivity measurements were made from the sublimed sulfur and the anhydrous sodium sulfide.

\section{Calibration of Electronic Equipment}

Model 2100 VideoBridge was calibrated by Electro Scientific industries, Inc. The dependence of the resistance-measurement accuracy on test level and frequency was well presented in the manual.

E type thermocouple probes were calibrated by OMEGA at some temperature points between 300 and $360^{\circ} \mathrm{C}$. The calibration report showed the information of actual temperature versus indicated temperature. The average deviation of indicated temperature from actual temperature was about $+1.2{ }^{\circ} \mathrm{C}$. The uncertainty of the actual temperatures was $\pm 0.4^{\circ} \mathrm{C}$.

The perfomance of the WB-ASC interface was tested using a calibrated precision voltage source, DIAL-A-SOURCE model \# DAS-H6L series \# 380 manufactured by General Resistance Inc. The voltage source substituted E type thermocouples as an accurate EMF source. Using the E type thermocouple reference table, the EMF's input by the voltage source were transformed to actual temperatures. On the other hand, the WB-ASC interface transformed EMF's to indicated temperatures. The average deviation of the indicated temperatures from the actual temperatures was $+1.5^{\circ} \mathrm{C}$. Since the calibration uncertainty of the precision voltage source was $\pm 0.002 \mathrm{mV}$, the uncertainty of the actual temperatures was $\pm 0.04{ }^{\circ} \mathrm{C}$.

Using the calibration information of the thermocouple probes and the interface, the temperature measurements stored by the controlling program were corrected by $-2.7^{\circ} \mathrm{C}$ to the accuracy of $\pm 0.44{ }^{\circ} \mathrm{C}$.

Finally, another set of equipment, used to measure the temperatures of potassium chloride standard solutions in conductance cells, was calibrated around room temperature. It was composed of a Keithly thermometer, model 870 , and a $\mathrm{K}$ type thernocouple probe plugged in the thermometer. The calibration uncertainty is $-0.1^{\circ} \mathrm{C}$. 
Measurement of Electrical Conductivity us. Temperature

For the glass cells with a microelectrode, the measurement followed the $380{ }^{\circ} \mathrm{C}$ heat treatment of the cells. However, before the mixtures of sulfur and sodium sulfide were filled into cells, the cell constant of each cell needed to be calibrated using $0.1 \mathrm{~N}$ potassium chloride solution. The temperature of the solution was measured by the calibrated Keithly thermometer and $\mathrm{K}$ type thermocouple probe. The VideoBridge measured the resistances across the cells with a test levei of $100 \mathrm{mV}$ and a frequency of 20 kHz.

Once the heat treatment of $380^{\circ} \mathrm{C}$ was finished, the controlling program began to direct the peripheral equipment to change the temperature of the furnace periodically and measure resistance and temperature continuously. The test levels between 100 and $70 \mathrm{mV}$ and a frequency of $1000 \mathrm{~Hz}$ were selected on the VideoBridge. As shown in Figure 4-6, two E type thermocouple probes were used to measure the temperatures of and inside the brass block. The temperature set point of the furnace controller was changed by 15 or $20^{\circ} \mathrm{C}$ each time. The temperatures of and inside the block would stabilize and become equal to each other after 5 or 6 hours, and then the controlling program would change the temperature set point of the controller again. For the resistance measurements, the stable temperatures of the block were controlled between 300 and $360^{\circ} \mathrm{C}$. To test the repeatability of the resistance measurements at stable temperatures, the temperature of the block was changed and stabilized back and forth between 300 and $360^{\circ} \mathrm{C}$ for a few times. The temperature inside the block and the resistances across conductance cells were measured once a minute, and the measurements were stored versus time in two separate data files.

For the disk-cell design, after the polysulfide slug was put into the cell, the apparatus shown in Figure 4-1 was assembled and lowered into the furnace well with heat shields above it. The furnace was then turned on to heat the apparatus inside the furnace to the temperature of $300^{\circ} \mathrm{C}$. During the heating process, once the temperature inside the block was a few degrees higher than the melting point of the polysulfide in the cell, the bolt on the block was screwed down to push the top electrode onto the quartz disk. Then, the same controlling program, used for the glass cells with a microelectrode, began to direct the progress of the experiment. The same test levels and frequency were selected on the VideoBridge. The temperature of the block was changed periodically in the same way, and the temperature-versus-time data and resistance-versus- 
time data were saved in separate files as well. The bolt on the block was adjusted during heating or cooling processes to account for thermal expansion.

\section{Analysis of Sodium Polysulfides}

Sodium polysulfides prepared in the experiments were analyzed by Galbraith Laboratories, Inc. and UC Berkeley microanalytical laboratory. Sodium concentrations were detected using atomic adsorption, and the relative accuracy of analyses was $1 \%$. Sulfur concentrations were detected using $X$-ray fluorescence (UC Berkeley microanalytical laboratory) or Leco combustion (Galbraith laboratories, Inc.). The accuracies of Xray flıorescence and Leco combustion were $0.4 \%$ and $0.8 \%$, respectively. 


\section{Chapter 5 Experimental Results and Discussion}

\subsection{Introduction}

Reproducible conductivity data of sodium polysulfide melts were obtained from the glass-cell experiments. However, the results from the disk-cell experiments were disappointing. The disk-cell design will be investigated in the following section to explain the unsuccessful results.

The choice of the amplitude or the frequency of the alternating current affects the accuracy of the conductivity results, because of the diffusion impedance and the specifications of the VideoBridge. Determination of the alternating current's amplitude and frequency as well as the accuracy of the conductivity results will be discussed in section 5.3 .

Using glass cells with a microelectrode, the electrical conductivities of sodium polysulfides, $\mathrm{Na}_{2} \mathrm{~S}_{4}$ and $\mathrm{Na}_{2} \mathrm{~S}_{5}$, were measured as a function of temperature. The results will be compared to the conductivity data of Cleaver and Davies. The Arrhenius equation will be used to summarize the temperature dependence of the experimental results and values of the activation energy in the equation will be derived. However the free-volume model for transpon in fused salts was applied to the sodium polysulfides by Cleaver and

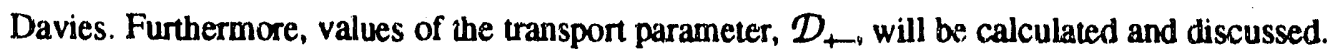

\subsection{The Experimentsl Results of Disk Cells}

The experimental results showed that the electrical resistance of the conductance cell increased gradually even though the temperature remained constant. It was first assumed that the growth of sulfide films on the molybdenum electrode surfaces caused the increase of the electrical resistance.

The electrical properties of molybdenite, $\mathrm{MoS}_{2}$, were measured by Mansfield and Salam. ${ }^{39}$ The results shows that the conductivities of different $\mathrm{MoS}_{2}$ specimens at $573 \mathrm{~K}$ are between 0.01 and 4.5 ( $\Omega$ $\mathrm{cm})^{-1}$. The thickness of the sulfide film estimated by Mitof ${ }^{2}$ is approximately $0.32 \mu \mathrm{m}$ after molybdenum's having been corroded by polysulfide melts for one month. Based on the above information, the calculated electrical resistance of the molybdenite layer on the molybdenum electrode was as small as $0.003 \Omega$, while 
the electrical resistance of the polysulfide inelts in the cell was at least $10 \Omega$. Therefore, the electrical resistance of the sulfide films on the electrode surfaces was negligible.

Post experiment examination revealed that the quantity of sodium polysulfide in the disk cell diminished. Since the vapor pressure of sodium pentasulfide, $\mathrm{Na}_{2} \mathrm{~S}_{5}$, at $350^{\circ} \mathrm{C}$ is as high as $0.832 \mathrm{~atm}$, the loss of the polysulfide in the cell was possibly due to the leakage of the sulfur vapor from the cell. The decrease of the melt quantity changed the cell constant and could even cause a bad contact between the melt and the top electrode. Moreover, the melt composition could change as well. In other words, the sealings between two electrodes and the disk were not tight enough to prevent escape of sulfur vapor. Therefore, the electrical resistance across the disk cell was unstable, and no reproducible conductivity data were obtained.

\subsection{Determination of the Alternating Current's Amplitude and Trequency}

According to the specifications of the VideoBridge used in the experiments, the measurements obtained using higher test levels (potentials or currents) and lower test frequencies have better accuracy. Also the accuracy depends to the resistance magnitude of the device under test. However the test levels and frequencies used in the experiments can not be determined solely from these specifications.

The test potential of the VideoBridge was maintained under $100 \mathrm{mV}$ in the conductivity experiments of polysulfide melts, since a second phase may form near one or both of the electrodes at greater potentials. ${ }^{41}$ On the other hand, when $0.1 \mathrm{~N}$ potassium chloride solution was filled into glass cells for determination of cell constants, the test potential was limited under $1 \mathrm{~V}$ to avoid any gas evolution on electrode surfaces. Gas bubbles can disturb current distribution and change the cell constant.

High frequencies are necessary to minimize the diffusion impedance. For the conductance cells filled with potassium chloride solution, the diffusion impedance was estimated using equation (3-29). The diffusion coefficients of potassium and chloride ions are both about $2 \times 10^{-5} \mathrm{~cm}^{2} / \mathrm{s}^{42}$ If the frequency is 20 $\mathrm{kHz}$, the calculated diffusion impedance is $0.012 \Omega$, which is negligible compared to the total electrical resistance of 2 to $3 \mathrm{k} \Omega$.

The order of the diffusion impedance in the conductivity experiments of polysulfide melts was estimated using equations (3-31)-(3-33) and (3-38) for concentrated solutions at high frequencies, although 
these equation are derived not for the cylindrical cell with a microelectrode but for the planar cell. Provided that the thermodynamic factor $1+\left(\frac{d \ln f_{i n}}{d \ln c}\right)_{c^{0}}$ and $c 0 \bar{V}_{0}$ are unity, $L / A$ is the cell constant of the glass cell with a microelectrode, the diffusion coefficient is $2 \times 10^{-6} \mathrm{~cm}^{2} / \mathrm{s}^{8} \mathrm{~L}$ is $1.27 \mathrm{~cm}$, and the frequency is 1000 $\mathrm{Hz}$, the calculated diffusion impedances for sodium polysulfides $\mathrm{Na}_{2} \mathrm{~S}_{4}$ and $\mathrm{Na}_{2} \mathrm{~S}_{5}$ are 0.027 and $0.032 \Omega$ respectively. Furthermore, The experimental results show that the measured electrical resistences were itwependent ui frequency if frequencies were greater than $1000 \mathrm{~Hz}$. Therefore, the diffusion impedance in the experiments of polysulfide melts was negligible.

Normally, the test level of $100 \mathrm{mV}$ and a frequency of $20 \mathrm{kHz}$ were applied to the glass cells filled with potassium chloride solutions to determine their cell constants. Cell constants were calculated from electrical-resistance measurements and the conductivity data of $0.1 \mathrm{~N}$ potassium chloride solution shown in reference 40. Based on the specifications of the VideoBridge, the accuracy of the electrical-resistance measurements is $\pm 1 \%$. Since the error of the conductivity data of potassium chloride solution, compared to $1 \%$, is negligible, the accuracy of the cell constants is $\pm 1 \%$. On the other hand, the experiments of polysulfide melts used 70 to $100 \mathrm{mV}$ and $1000 \mathrm{~Hz}$ alternating currents, and then the accuracy of the electrical resistances is $\pm 0.25 \%$. Since the conductivity results were calculated from cell constants and electrical resistances, the accuracy of the conductivity results is $\pm 1.03 \% .46$

\subsection{Results}

The sodium polysulfides used in the conductivity experiments were made from sublimed sulfur and anhydrous sodium sulfide. Although $6 \mathrm{~N}$ sulfur and $4 \mathrm{~N}$ sodium sulfide were purchased as well, unfortunately these highly purifiet chemicals were unable to react completely to form homogeneous sodium polysulfides by the procedure presented in chapter 4 . Furthermore, the sodium and sulfur analyses of the sodium polysulfides prepared from sublimed sulfur and anthydrous sodium s"1. Tde gave reasonable results. Therefore, the sodium polysulfides used in the conductivity experiments were made from sublimed sulfur and anhydrous sodium sulfide. 


\section{Experimental Electrical Conductivities}

The experimental electrical conductivities of sodium polysulfides $\mathrm{Na}_{2} \mathrm{~S}_{4}$ and $\mathrm{Na}_{2} \mathrm{~S}_{5}$ are listed on Table 5-1. The results shows no dependence on time and cell number. Variations of up to $2 \%$ were observed between cell runs and days. The accuracy of the temperature measurements was $\pm 0.44^{\circ} \mathrm{C}$ and that of the conductivity results was $\pm 1.03 \%$. Since sodium polysulfide melts between 300 and $360{ }^{\circ} \mathrm{C}$ have a temperature coefficient of conductivity about 2 per cent per degree $C$, the $\pm 0.44{ }^{\circ} \mathrm{C}$ temperature error caused an additional $\pm 0.4 \%$ conductivity error. The total conductivity error was about $\pm 1.11 \%, 46$

\section{Temperature Dependence of Electrical Conductivities}

The conductivities listed in Table 5-1 are plotted as a function of temperature in Figure 5-1 and 5. 2 and appear to have an Anthenius temperature dependence.

$$
\kappa=\text { const } \exp [-E / R T]
$$

The linear-regression line in Figure 5-1 is

$$
\kappa=142.2 \exp \left[-31.9 \times 10^{3} / R T\right]
$$

and that in Figure 5.2 is

$$
\kappa=146.9 \exp \left[-34 \times 10^{3} / R T\right]
$$

Therefore, the values of the activation energies are $31.9 \mathrm{~kJ} / \mathrm{mol}$ for $\mathrm{Na}_{2} \mathrm{~S}_{5}$ and $34.0 \mathrm{~kJ} / \mathrm{mol}$ for $\mathrm{Na}_{2} \mathrm{~S}_{4}$.

\section{Transport Parameters}

Three transpon parameters, $\mathcal{D}_{+-,} \mathcal{D}_{+0}$, and $\mathcal{D}_{-0}$, were calculated using equations (3-35) to (3. 37). The calculation procedure was presented in detail in Chapter 2 . The values of $\mathfrak{D}_{+o}$, and $\mathfrak{D}_{-0}$ calculated by Thompson ${ }^{8}$ have been shown in Figure 2-10. The values of $\mathcal{D}_{+-}$, listed in Table 5-2, were obtained by applying the conductivity results in equation (2-37),

$$
\frac{1}{D_{+}}=-\frac{z_{+} z_{C} F^{2}}{R T K}-\frac{z_{+}-z}{z_{+} V_{+}} \frac{c_{0} t_{+}^{0} t_{-}^{\circ}}{c \mathcal{D}} \text {. }
$$


Table 5-1 Experimental electrical conductivity of sodium polysulfides

\begin{tabular}{|c|c|c|c|c|}
\hline composition & cell \# & $\begin{array}{l}\text { time } \\
\text { (day) }\end{array}$ & $\begin{array}{c}\text { temperature } \\
\left({ }^{\circ} \mathrm{C}\right)\end{array}$ & $\begin{array}{l}\text { conductivity } \\
(\Omega-\mathrm{cm})^{-1}\end{array}$ \\
\hline $\mathrm{Na}_{2} \mathrm{~S}_{5}$ & 1 & $\begin{array}{l}1 \\
\\
2 \\
3\end{array}$ & $\begin{array}{l}358.26 \\
338.80 \\
317.80 \\
299.05 \\
355.80 \\
337.10 \\
318.42 \\
337.73 \\
317.73 \\
298.06 \\
\end{array}$ & $\begin{array}{l}0.3284 \\
0.2756 \\
0.2203 \\
0.1725 \\
0.3273 \\
0.2729 \\
0.2213 \\
0.2728 \\
0.2200 \\
0.1709 \\
\end{array}$ \\
\hline $\mathrm{Na}_{2} \mathrm{~S}_{5}$ & 2 & 1 & $\begin{array}{l}359.15 \\
339.48 \\
317.60 \\
359.37 \\
337.56 \\
317.11 \\
\end{array}$ & $\begin{array}{l}0.3264 \\
0.2724 \\
0.2143 \\
0.3205 \\
0.2637 \\
0.2101 \\
\end{array}$ \\
\hline $\mathrm{Na}_{2} \mathrm{~S}_{4}$ & 3 & $\begin{array}{l}1 \\
2\end{array}$ & $\begin{array}{l}359.70 \\
321.94 \\
303.70 \\
\\
351.00 \\
330.77 \\
\end{array}$ & $\begin{array}{l}0.2287 \\
0.15751 \\
0.12045 \\
0.2132 \\
0.1735 \\
\end{array}$ \\
\hline $\mathrm{Na}_{2} \mathrm{~S}_{4}$ & 4 & 1 & $\begin{array}{l}357.51 \\
337.20 \\
316.76 \\
358.80 \\
337.80 \\
317.61 \\
297.49\end{array}$ & $\begin{array}{l}0.2195 \\
0.1797 \\
0.1440 \\
0.2197 \\
0.1800 \\
0.1436 \\
0.1099\end{array}$ \\
\hline
\end{tabular}




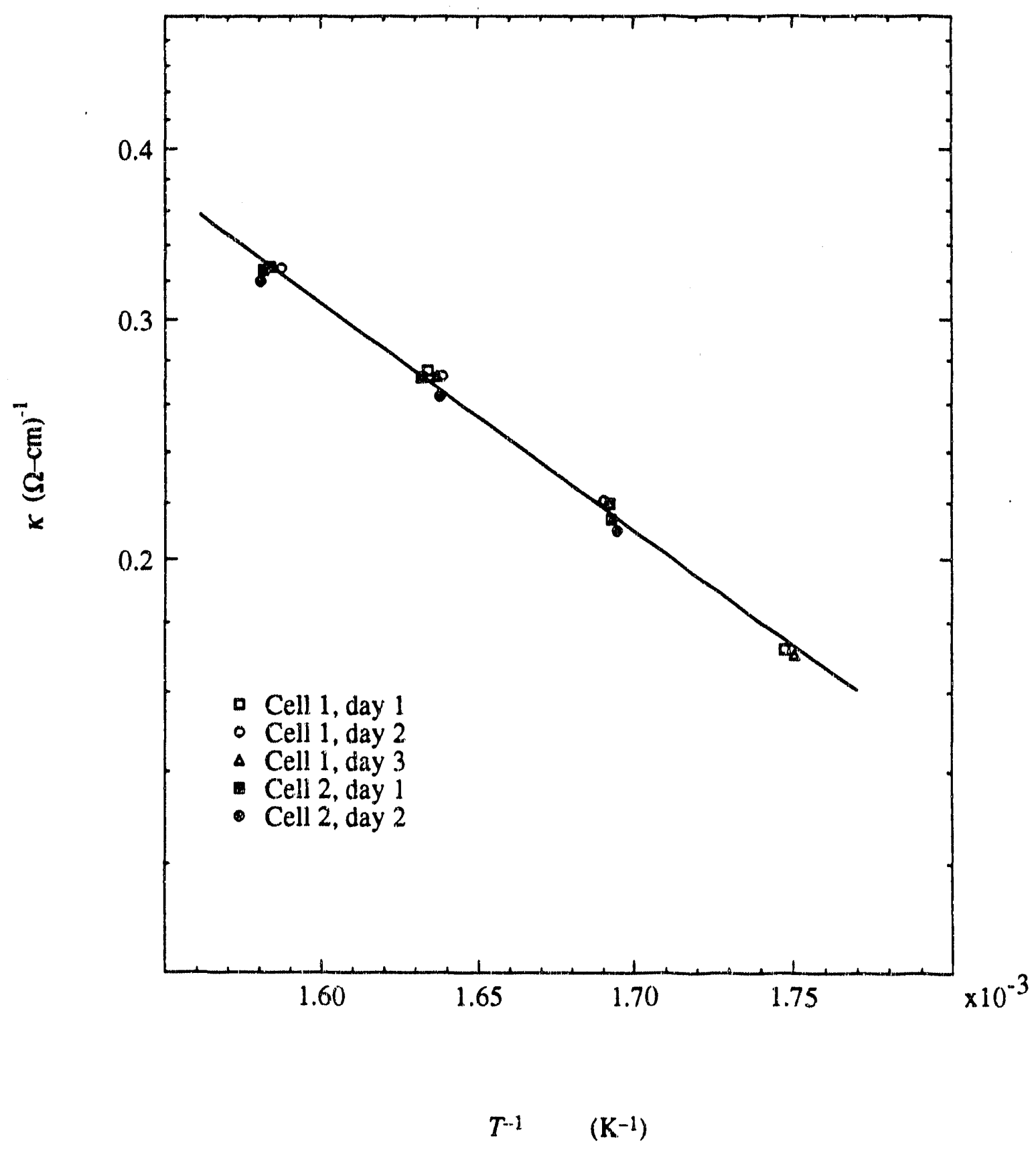

Figure 5-1. The experimental conductivities of sodium polysulfide $\mathrm{Na}_{2} \mathrm{~S}_{5}$, plotted as a function of temperature. 


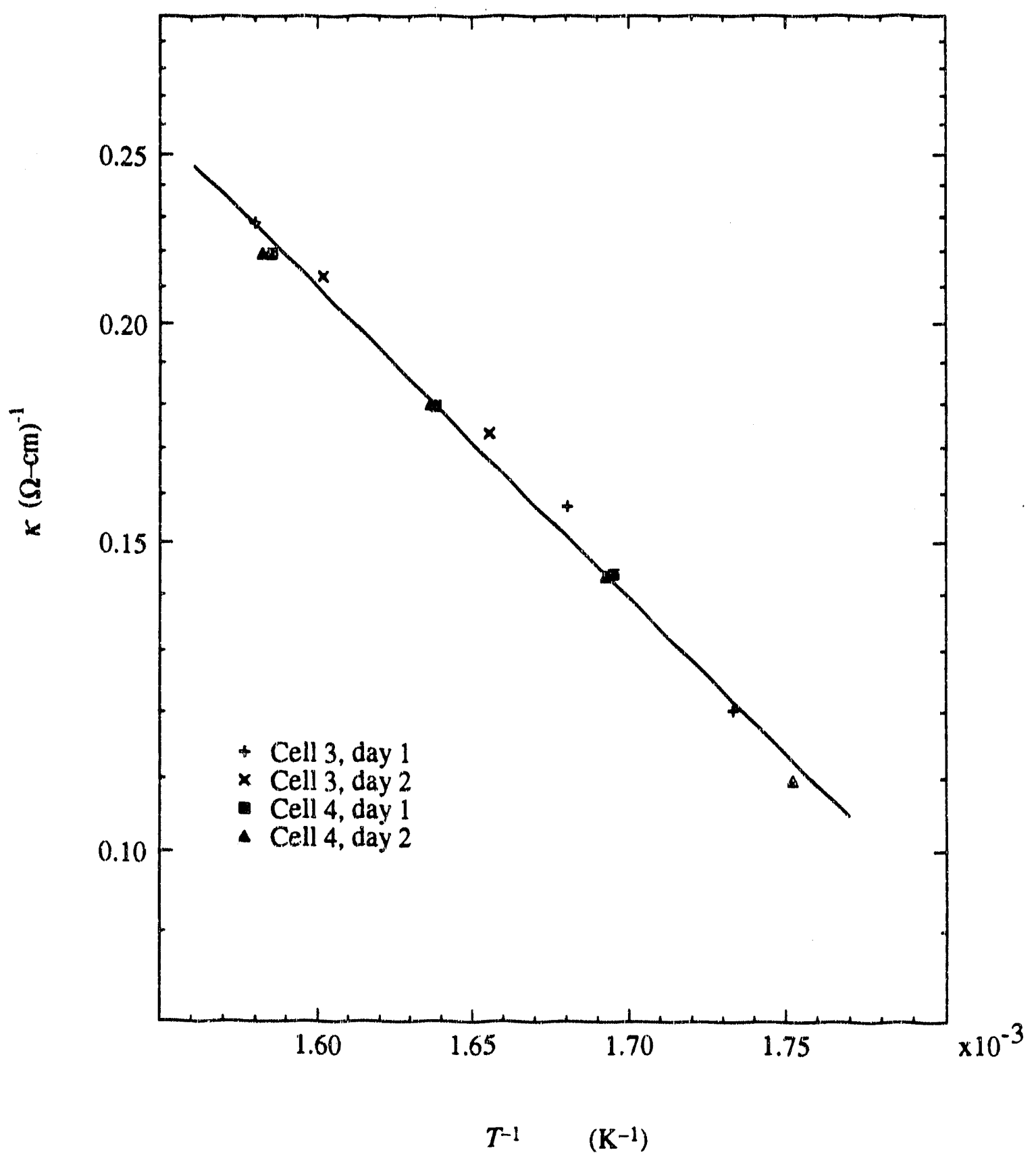

Figure 5-2. The experimental conductivities of sodium polysulfide $\mathrm{Na}_{2} \mathrm{~S}_{4}$, plotted as a function of temperature. 
where the values of thernodynamic-diffusion-coefficient, $\mathcal{D}$, and transference number, $t_{-}^{\circ}$, were obtained from the correlation lines in Figure 2-5 and Figure 2-1.

$\begin{array}{lccc}\text { rsdive (j-2. Values of } \mathcal{D}_{+} & & \\ \text {Melt } & \mathrm{x}_{\mathrm{e}} & \text { Temperature } & \mathcal{D}_{4} \times 10^{6} \\ & & (\mathrm{~K}) & \left(\mathrm{cm}^{2} / \mathrm{s}\right) \\ & & & \\ & 0.25 & 573.15 & -15.65 \\ \mathrm{Na}_{2} \mathrm{~S}_{4} & & 598.15 & 3.026 \\ & & 623.15 & 2.144 \\ \mathrm{Na}_{2} \mathrm{~S}_{5} & 573.15 & 0.8514 \\ & 0.20 & 598.15 & 0.9519 \\ & 623.15 & 1.100\end{array}$

\subsection{Discussion}

The results are compared to the conductivity data of Cleaver and Davies in Figure 5-3. The Cleaver and Davies's data ${ }^{9}$ are greater than the experimental results. As shown in Table 5-1, the conductivity values of $\mathrm{Na}_{2} \mathrm{~S}_{5}$ are higher than the values of $\mathrm{Na}_{2} \mathrm{~S}_{4}$, but Cleaver and Davies's data have an opposite composition dependence. The four linear-regression lines in Figure 5-3 are almost parallel to each other, so values of the Arrhenius activation energy derived from these four groups of data are about the same.

By comparing linear-regression lines and conductivity data pioted in Figure 5-1 and 5-2 carefully, one can see that curves $x$ ay fit data better than lines. Although a linear relationship is expected between In $\kappa$ and $1 / T$ for pure ste schiometric, ionic conductors, Kortitm ${ }^{19}$ pointed out that equation (2-31) does not apply to some salts, such $\mathrm{LaCl}_{3}, \mathrm{PbCl}_{2}, \mathrm{ZnCl}_{2}$, etc., owing possibly to the fact that these salts possess a 


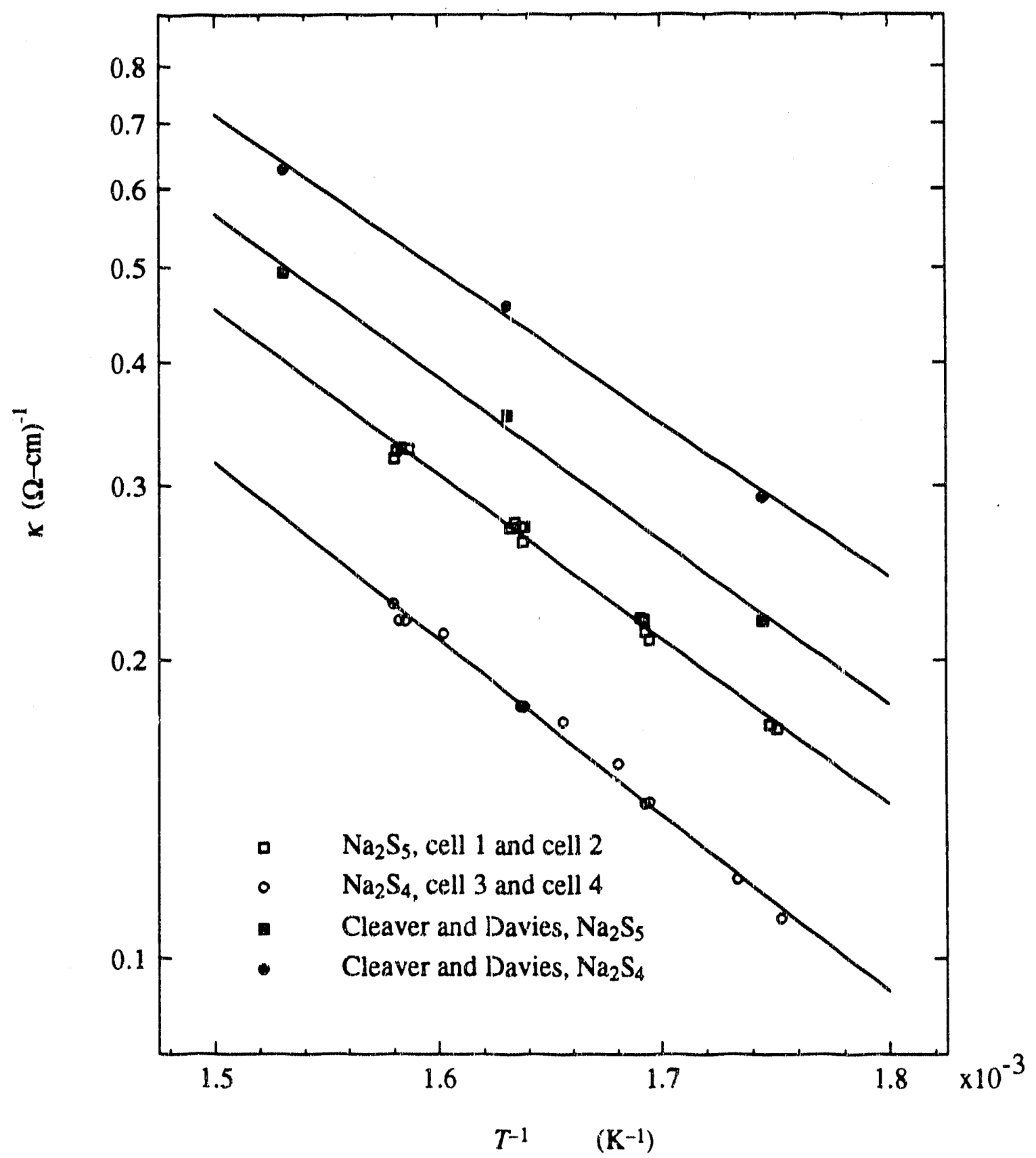

Figure 5-3. Comparison of the experimental conductivity data to the data of Cleaver and Davies. ${ }^{9}$ Data are plotted as a function of temperature. 
strongly covalent character. Both the number of ions present, and their transport numbers could therefore change with temperature, due to alternations in their structures, thus affecting the quantities $A$ and $E_{\mathrm{A}}$ in equation (2-31). According to Figure 2-1, the transference number of sodium polysulfide melts changes with temperature. Therefore, the possible covalent character of sodium polysulfides, $\mathrm{Na}_{2} \mathrm{~S}_{4}$ and $\mathrm{Na}_{2} \mathrm{~S}_{5}$ may explain the possible nonlinear fittings. However, the experimental conductivity data, shown in Figure 5-1 and 5-2, do not cover a wide range of temperature. Consequently, a comprebensive temperature dependence of the conductivity of sodium polysulfide melts can not be concluded at this time.

In reference 9, Cleaver and Davies used equation (2-30) to fit their data by curves.

$$
\kappa=\boldsymbol{H} \exp \left[-\frac{\mathbf{E}_{\mathrm{k}}}{R\left(T-T_{\mathrm{o}}\right)}\right] .
$$

This equation was first used by Angell ${ }^{43}$ based upon the concepts of the free-volume theory for transport in liquids, because the continuous variations of Arrhenius activation energy with temperature have been observed particularly with low melting salts and salt mixtures. The free volume model assumes that an abrupt structural change of liquids happens at $T_{0}$ and causes an abrupt change of heat capacity. Newman ${ }^{44}$ pointed out that, if an abrupt structural change does occur in liquids, the Arrhenius activation energy should then change abruptly too, instead of continuously. In other words, values of the Arrhenius activation energy, below and above $T_{0}$, should be two different constants, which shift from one to the other at $T_{0}$.

On the other hand, Table 5-2 shows most of the calculated $D_{+}$values are positive, compared to the negative $\mathcal{D}_{+-}$values shown in Table 2 -2. The $\mathcal{D}_{+--}$values become positive because the smaller experimental values of $\kappa$, instead of Cleaver and Davies's conductivity data, were substituted into equation (2-37). The $\mathcal{D}_{+-}$of $\mathrm{Na}_{2} \mathrm{~S}_{4}$ at $573.15 \mathrm{~K}$ is a negative value. If the conductivity of $\mathrm{Na}_{2} \mathrm{~S}_{4}$ at $573.15 \mathrm{~K}$ were $5 \%$ less, a positive value of $\mathcal{D}_{+-}$about $3.1 \times 10^{6} \mathrm{~cm}^{2} / \mathrm{s}$ could be obtained. Similarly if the diffusion coefficient were $5 \%$ more, the calculated $\mathcal{D}_{+-}$could be $3.7 \times 10^{6} \mathrm{~cm}^{2} / \mathrm{s}$. The accuracy of the conductivity results was $\pm 1.11 \%$ and variations between cell runs and days were up to $2 \%$. The errors of the transference number and the density data are unknown. Thompson ${ }^{45}$ mentioned that the variations of diffusion coefficients between cell runs were up to $5 \%$. Probably the negative value of $\mathcal{D}_{\leftarrow}$ is due to the combination of these experimental errors. Therefore, the calculated $\mathcal{D}_{+-}$values of sodium polysulfide melts strongly 
depend on the accuracy of the experimental data of conductivity, diffusion coefficient, transference number, and density for sodium polysulfide melts.

\subsection{Conclusions}

Axisymmetric cylindrical cells with a microelectrode were successfully used to determine the electrical conductivity of the sodium polysulfides $\mathrm{Na}_{2} \mathrm{~S}_{4}$ add $\mathrm{Na}_{2} \mathrm{~S}_{5}$ between $300^{\circ} \mathrm{C}$ and $360{ }^{\circ} \mathrm{C}$. Owing to their high cell constants, variations between cell runs and days were only up $2 \%$. Both sulfides were made from sublimed sulfur and anhydrous sodium sulfide. The fact that $\xi \quad \mathrm{N}$ sulfur and grade $4 \mathrm{~N}$ sodium sulfide could not be reacted by the heat trearments is disappointing. Provided that the conductivity errors caused by the impurities in the melts were negligible, the accuracy of the conductivity results was $1.11 \%$, which was composed of the measurement errors of the electrical equipment.

The experimental results show that the electrical conductivity of sodium pentasulfide is higher than that of sodium tetrasulfide. The Arrhenius-type temperature dependence of the conductivity data was observed, and the values of the Arrhenius activation energy were about $33 \mathrm{~kJ} / \mathrm{mole}$, which is close to the average activation-energy value derived from the conductivity data of Cleaver and Davies. ${ }^{9}$ However, the values of the conductivity from the experiments were only about one half to three forths of hhose from Cleaver and Davies.

Values of the transport parameter $\mathcal{D}_{+-}$were recalculated with the use of the experimental conductivity data. Positive results were obtained for most temperatures. $D_{+}$for $\mathrm{Na}_{2} S_{4}$ at $573 \mathrm{~K}$ has a negative value in Table 5-2, but it could be changed to a positive values if one of three transport properties or density were $5 \%$ more or less. Therefore, very accurate experimental data of conductivity, diffusion coefficient, transference number, and density for sodium polysulfide melts are necessary for the calculation of $\mathcal{D}_{+}$. 


\section{References}

1. J.L. Sudworth and A. R. Tilley, "The Sodium-Sulfur Battery with $\beta$-alumina Electrolyte," R.P. Tischer, ed.. The Sulfur Electrode, Academic Press, pp. 235-322 (1983).

2. S. P. Mitoff, Development of Sodium Sulfur Batteries for Utility Application, Interim Report subrnitted to EPRI EM-683, Palo Alto, CA, Project 128-4 (1978).

3. Charles A. Levine, "Sodium-Sulfur Cells with Glass Electrolyte," R. P. Tischer, ed., The Sulfur Electrode, Academic Press, pp. 327-338 (1983).

4. N. K. Gupta and R. P. Tischer, "Thermodynamic and Physical Properties of Molten Sodium Polysulfides from Open-Circuit Voltage Measurements," J. Electrochem. Soc., 119, 1033-1037 (1972).

5. E. J. Cairns and R. K. Steunenberg, "High-Temperature Batteries," C. A. Rouse, ed., Progress in High Temperature Physics and Chemistry, 5, Pergamon, New York, p. 63 (1973).

6. Ragnar Tegman, "Thermodynamic Studies of High Temperature Equilibria," C'hemica Scripta, 9, $158-166(1976)$.

7. Tim Risch, The Transpon Properies of Sodium Polysulfide Melts and a Theoretical Comparison of Flow-Through and Flow-By Porous Electrodes at the Limiting Current, M. S. Thesis, University of California at Berkeley (December, 1983).

8. S. D. Thompson, Mass Transport in Sodium Polysulfide Melts, M. S. Thesis, University of California at Berkeley (September, 1985).

9. B. Cleaver, A. J. Davies, and M. D. Hames, "Properties of Fused Polysulfides - I. The Electrical Conductivity of Fused Sodium and Potassium Polysulfides," Electrochim. Acta, 18, 719-726 (1973).

10. John Newman, Douglas Bennion, and Charles Tobias, "Mass Transfer in Concentrated Binary Electrolytes," Berichte der Bunsengesellschaft fur Physikalische Chemie, 66, 608-612 (1965).

11. Jobn Newman, Electrochemical Systems, Prentice-Hall, Englewood Cliffs, N. J., pp. 239-249 (1973). 
12. Tim Risch, op. cit., pp. 43-53.

13. R. A. Robinson and R. H. Stokes, Electrolyte Solutions, Butterworths, London, 2nd edition, pp. 87. $102(1965)$.

14. T. Risch and J. Newman, "Transference Number Calculations for Sodium Polysulfides," J. Electrochem. Soc., 135, 1715-1718 (1988).

15. B. Cleaver, and A. J. Davies, "Properties of Fused Polysulfides-III. EMF Measurements on the Sodium-Sulfur Cell, and Sulfur Activities and Constitution in Fused Sodium polysulfides," Electrochim. Acta, 18, 733-739 (1973).

16. S. D. Thompson, op. cis., pp. 27-36.

17. H. S. Harned and D. M. French, "A Conductance Method for the Determination of the Diffusion Coefficients of Electrolytes." Annals New York Acad. Sci., 46, 267 (1945).

18. John Newman and Thomas W. Chapman, "Restricted Diffusion in Binary Solutions," AIChE J., 19, 343-348 (1973).

19. G. Kortum, Treatise on Electrochemistry, Elsevier Publishing Company, pp. 267-270 (1965).

20. R. P. Tischer and F. A. Ludwig, "The Sulfur Electrode in Nonaqueous Media," Heinz Gerischer and Charles Tobias, eds., Advances in Elecirochemistry and Electrochemical Engineering, 10, John Wilej' and Sons, Inc., N.Y., $391-482$ (1977).

21. J. Divi sek, F. G. Bodewig, J. Mergel, and H. Lippert, "Mass Transport Phenomena in the Molten S'iffur-Sodium Polysulfide System," J. Electrochem. Soc., 127, $357-363$ (1980).

22. B. Cleaver and A. J. Davies, "Properties of Fused Polysulfides - II. The Density, Surface Tension and Viscosity of Fused Sodium Polysulfides, "Elecirochim. Acıa, 18, 727-732 (1973).

23. John Newman, op cit., pp. 266-269.

24. S. D. Thompson and J. Newman, "Differential Diffusion Coefficients of Sodium Polysulfide Melts," J. Electrochem. Soc., 136, 3362-3369 (1989).

25. F. S. Feates, D. J. G. Ives, and J. H. Pryor, "Alternating Current Bridge for Measurement of Electrolytic Conductance," J. Electrochem. Soc., 103, 580-585 (1956).

26. G. Kortüm, op cil., pp. 389-394. 
27. John Newman, op. cil., pp. 140-189.

28. John Newman, op. cit., pp. 383-387.

29. Klaus J. Vetter, Electrochemical Kinetics: Theoretical and Experimental Aspects, Academic Press, N. Y., pp. 200-205 (1961).

30. William H. Smyrl and John Newman, "Potential of Cells with Liquid Junctions," Journal of Physical Chemistry, 72, 4660-4671 (1968).

31. John Newman, op. cit., pp. 236.

32. Bernard Tribollet and John Newman, "Impedance Model for a Concentrated Solution," J. Electrochem. Soc., 131, 2780-2785 (1984).

33. R. Pollard and T. Comte, "Determination of Transport Properties for Solid Electrolytes from the Impedance of Thin Layer Cells," J. Electrochem. Soc., 136, 3734-3748 (1989).

34. Allen J. Bard and Larry R. Faulkner, Electrochemical Methods, John Wiley \& Sons, Inc., pp. $347-$ 354 (1976).

35. A. K. Hauser, Steady-State and Impedance Analyses of Electrochemical Kinetics and Mass Transfer, Ph. D. Thesis, University of California at Berkeley (April, 1989).

36. John Newman。 "Resistance for Flow of Current to a Disk," J. Electrochem. Soc., 113, 501-529 (1966).

37. Peter Pierini and John Newman, "Potential Distribution for Disk Electrodes in Axisymmetric Cylindrical Cells," J. Electrochem. Soc., 126, 1348-1352 (1979).

38. E. Rosén and R. Tegman, "A Pteparative and X-Ray Powder Diffraction Study of the Polysulfides $\mathrm{Na}_{2} \mathrm{~S}_{2}, \mathrm{Na}_{2} \mathrm{~S}_{4}$ and $\mathrm{Na}_{2} \mathrm{~S}_{5}, "$ Acta Chem. Scand., 25, 3329-3336 (1971).

39. R. Mansfield and S. A. Salam, "Electrical Properties of Molybdenite," Proc. Phys. Soc. B, 66, pp. $377-385$ (1953).

40. G. Jones and B. C. Bradshaw, "The Measurement of the Conductance of Electrolytes. V. A Redetermiriation of the Conductance of Standard Potassium Solutions in Absolute Units," J. of Amer. Chem. Soc., 55, 1978-1880 (1933).

41. R. D. Armstrong, T. Dickinson, and M. Reid, "Rotating Disk Studies of the Vitroous Carbon- 
Sodium Polysulfide Interphase," Electrochim. Acta, 20, 709-714 (1975).

42. John Newman, op. cit., pp. 230.

43. C. A. Angell, "On the Importance of the Metastable Liquid State and Glass Transition Phenomenon to Transport and Structure Studies in Ionic Liquid. I. Transport Properties," Phys. Chem., 70, 2793 (1966).

44. John Newman, group seminar, May, 1992.

45. S. D. Thompson, op. cit., pp. 97.

46. D. A. Skoog and D. M. West, Analytical Chemistry: an Introduction, CBS College Publishing, pp. $56-58$ (1985). 

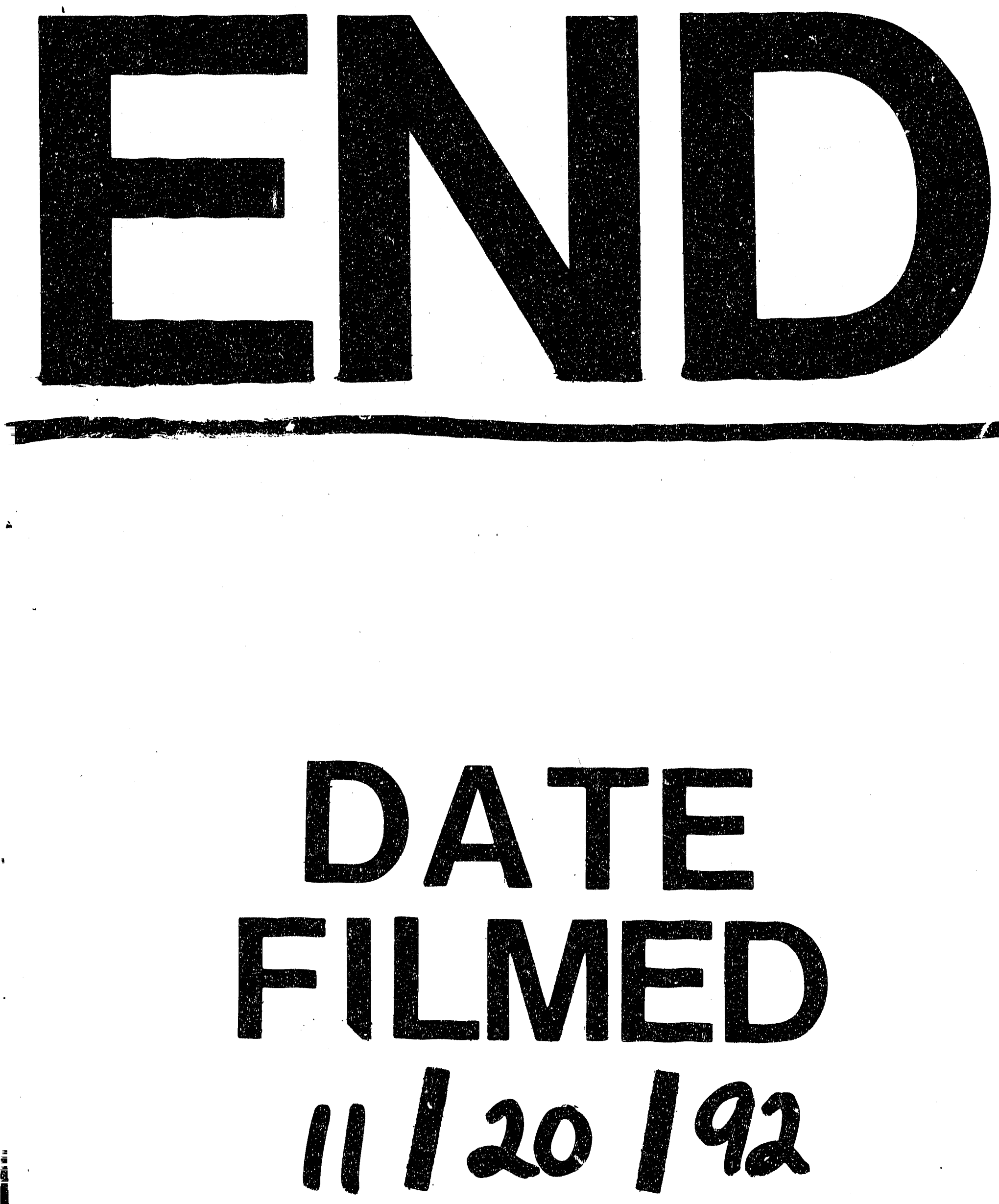